\title{
Can We Use Volatility to Diagnose Financial Bubbles? Lessons from 40 historical bubbles
}

\section{Journal Article}

Author(s):

Sornette, Didier; Cauwels, Peter; Smilyanov, Georgy

Publication date:

2018-03-13

Permanent link:

https://doi.org/10.3929/ethz-b-000229885

\section{Rights / license:}

Creative Commons Attribution 4.0 International

Originally published in:

Quantitative Finance and Economics 2(1), https://doi.org/10.3934/QFE.2018.1.1 


\title{
Research article
}

\section{Can we use volatility to diagnose financial bubbles? lessons from 40 historical bubbles}

\author{
Didier Sornette $^{1,2 *}$, Peter Cauwels ${ }^{1}$ and Georgi Smilyanov ${ }^{1}$ \\ ${ }^{1}$ ETH Zurich, Department of Management, Technology and Economics, 8092 Zurich, Switzerland \\ 2 also at the Swiss Finance Institute c/o University of Geneva, 40 blvd. Du Pont dArve, CH 1211 \\ Geneva 4, Switzerland
}

* Correspondence: Email: dsornette@ethz.ch; Tel: +41(0)446328917.

\begin{abstract}
We inspect the price volatility before, during, and after financial asset bubbles in order to uncover possible commonalities and check empirically whether volatility might be used as an indicator or an early warning signal of an unsustainable price increase and the associated crash. Some researchers and finance practitioners believe that historical and/or implied volatility increase before a crash, but we do not see this as a consistent behavior. We examine forty well-known bubbles and, using creative graphical representations to capture robustly the transient dynamics of the volatility, find that the dynamics of the volatility would not have been a useful predictor of the subsequent crashes. In approximately two-third of the studied bubbles, the crash follows a period of lower volatility, reminiscent of the idiom of a "lull before the storm". This paradoxical behavior, from the lenses of traditional asset pricing models, further questions the general relationship between risk and return.
\end{abstract}

Keywords: bubble; boom; bust; crash; prediction; volatility; risk-return

JEL classification numbers: G14

\section{Introduction}

Economic bubbles are generally defined as periods when financial assets are traded in high volume, and at prices significantly higher than the fundamental value (Galbraith, 2009; Kindleberger, 1978; Shiller, 2006; Sornette, 2017). In the last decade, there has been an increased interest in the study of bubbles and crashes (Bhattacharya and Yu, 2008 ; Brunnermeier and Oehmke, 2013; Xiong, 2013; Shiller, 2014; Scherbina and Schlusche, 2014). The first reason for this is that it is believed that the crisis of 2007-2008 was the climax of a long series of bubbles and crashes that swept through our financial and economic system since the 1980s. These were the consequence of financialization, deregulation and massive debt expansion (Sornette and Cauwels, 2014). The succession of bubbles and 
crashes that resulted from this include, amongst others, the worldwide stock market bubble followed by the great crash of October 1987, the savings and loans crisis of the 1980s, the burst in 1990-1991 of the Japanese stock market and real estate bubbles, the emerging markets bubbles and crashes in 1994 and 1997, the Long-Term Capital Management (LTCM) crisis of 1998, the Dotcom bubble bursting in 2000, the house price bubbles and resultant credit, stock market, commodities, oil and debt bubbles and subsequent crashes in 2007-2008. All of these developed jointly, feeding upon each other until 2008, when the financial system came close a total collapse (Sornette and Cauwels, 2014). The second reason for the renewed interest in bubbles rests with the concern that the unprecedented monetary actions of the major central banks (Federal Reserve, European Central Bank, Bank of Japan, Bank of England, Swiss National Bank ...) might create and fuel unintentionally * or as a collateral damage new bubbles in a number of asset classes which may develop, mature and crash in the years and decades to come.

Using forty historical bubbles, we investigate the behavior and dynamics of volatility during each bubble and its aftermath. Our main finding is that, contrary to previous claims, there is no systematic evidence of increasing volatility as a diagnostic or as an early warning signal that a bubble is present and/or developing. Sometimes volatility does tend to increase, often it decreases before the crash, and most of the time volatility barely changes as the bubble develops towards its end. However, what is systematic is the observation of a sharp increase of volatility during and after the crash, reflecting the increased risk perception during and after the crash period.

The article is organized as follows. Section 2 presents a brief review of the literature on bubble models and detection methods, which provides the background for our research question, which is formulated in section 3. The main results are also summarised in section 3. Section 4 exposes the method used to investigate the research question. Section 5 lists the forty bubbles that are investigated, with some properties. Section 6 presents each of the forty cases in detail. Section 7 concludes.

\section{Brief review of the literature on bubble models and detection methods}

Many mechanisms for bubbles have been studied in the literature (Stiglitz, 1990; Bhattacharya and Yu, 2008; Kaizoji and Sornette, 2010), including credit bubbles (Allen and Gale, 2000), psychological biases and over-optimism (Kindleberger, 1978; Shiller, 2006), agency problems (Allen and Gale, 2007), rational bubbles due to short-sale constraints (Allen et al., 1993) and its interplay with overconfidence (Scheinkman and Xiong, 2003), informational frictions between noise and rational traders (De Long et al., 1990) or among rational traders (Abreu and Brunnermeier, 2003), intrinsic financial instability due to the credit expansion cycle (Minsky, 1993) and the financial accelerator mechanisms (Corsi and Sornette, 2014), heterogeneous beliefs (Harrison and kreps, 1978; Scheinkman and Xiong, 2003; Abreub and Brunnermeier, 2003; Hong and Stein, 2003; Xiong, 2013) and mimetic contagion and convention (Orléan A, 1995; Johansen et al., 1999). Many of these mechanisms are procyclical, which means that, when in action, they tend to strengthen and further push the price upwards through positive feedback loops of reinforcement (Sornette, 2017; Hüsler et al., 2013; Leiss et al., 2015; Sornette and Cauwels, 2015b).

A wealth of approaches to detect bubbles have been proposed (Camerer, 1989; Bhattacharya and Yu, 2008; Kaizoji and Sornette, 2010; Evanoff et al., 2012, Anderson et al., 2013). One problem is that neither the academic nor the professional literature provides a clear consensus for an operational

\footnotetext{
${ }^{*}$ Or is it intentionally? For a discussion see (Sornette and Zhou, 2004b; Sornette and Cauwel, 2014)
} 
definition of financial bubbles and there is no widely accepted methodology for their ex-ante diagnosis, as the following brief review illustrates. As a consequence, most econometric methods fail to come up with realistic models of bubbles and crashes that can be of practical use.

Variance bound tests (Shiller, 1979; Shiller, 1981; LeRoy and Porter, 1981), originally designed to test the efficient market hypothesis and the present value model, led to the discovery of the so-called "excess volatility puzzle". Blanchard and Watson (Blanchard and Watson, 1982) proposed to use the variance bound test for bubble identification. The main problem is that the variance bound test is implementable for ex-post identification of market bubbles and needs aggregated data (i.e. indices) over a long period of time in order to avoid small sample bias. It is also implicitly defining a bubble as a time of excess volatility.

West's (1987) bubble test is based on the comparison of two models of how prices relate to dividends (West, 1987,West, 1988). A bubble is detected when the two models depart in their specification of how dividends predict prices. Again, the use of dividends requires long time series. And there are many reasons other than the presence of a bubble for the disagreement between two ways of modeling the dividend process and how it impacts the price (Flood et al., 1994).

Diba and Grossman (1988) assume that no bubble is present when the price is stationary in difference and prices and dividends are co-integrated (Diba and Grossman, 1988). When one or both conditions are rejected, a bubble is deemed present. This test is vulnerable to the difficulties of testing for co-integration. It is also unable to detect periodically collapsing bubbles, which are misinterpreted as absence of a bubble (Evans, 1991).

Froot and Obstfeld (1991) qualify a bubble when a nonlinear relationship between prices and dividends is found statistically significant, while assuming that the log-dividends follow a martingale (Froot and Obstfeld, 1991). The interpretation of nonlinearity of the price-dividend relationship is delicate. It could be due to managers' decisions or be misleading in the presence of switching regimes. Moreover, a nonlinear price-dividend relationship holds over very long periods of time (1871-1996) (Ma and Kanas, 2004), which either implies that the market has been consistently in a bubble over this extended time interval or that the nonlinear relationship between dividends and stock prices could actually be the 'true price process' without bubbles (Sornette, 2000; Gürkaynak, 2008).

Topol (1991) presented a mimetic fad model in which agents have limited rational behavior, aiming at rationalising the effect of the dynamics of prices during a bubble and in particular the contagion effect of price drops on a subsequent increase of volatility.

$\mathrm{Wu}$ (1997) estimates a bubble, if present, as a non directly observable component of the price using the recursive Kalman filter method on a model where price differences are regressed against a number of present and lagged dividend differences. The problem with this test is that a qualification of a statistically significant bubble component may simply diagnose a misspecification of the model itself and not the genuine presence of a bubble. The test is also vulnerable to the criticism on the assumed process (ARIMA) for the dividends (Phillips et al., 2011).

Regime switching tests have been designed to detect the existence of transient regimes of market growth characterized by strong returns, followed by "collapsing" phases of negative returns. In these tests, the probability of remaining in the bubble regime is assumed to be a decreasing monotonous function of the bubble price. In practice, most of the empirical implementations fail to reject the null hypothesis of no regime switching (and therefore of no bubble) (Van Norden, 1996; van Norden, 1998). One problem is that the price models fail to really distinguish between solid bullish regimes that can 
be justified by strong fundamentals and exuberant price explosion that would qualify a bubble. Thus, any price growth is deemed to be a bubble if it is followed by a regime where prices tend to decrease. This does not resonate well with the casual empirical evidence of relatively rare explosive bubbles followed by the crashes that are characterized by fast corrections. Another problem of the tests is that the detection of a bubble requires it to be followed by a change of regime to the "collapsed" state.

The "bond stock earning yields difference" model is a late stage indicator of a bubble, which holds that when long bond interest rates are too high relative to the trailing earnings over price ratio, then a crash usually occurs in the next four to twelve months (Lleo and Ziemba, 2012). The bond stock earnings yield difference may become high because stock prices have increased and/or because interest rates are suddenly raised by the central bank in an attempt to calm down an exuberant market, a move well-known to trigger crashes after a long market run-up.

A number of approaches have been developed to modify the conventional unit root tests and use them to construct early warning indicators for bubbles in financial markets. In these approaches, the problem of bubble detection is mapped to that of detecting a transition from a stationary process to a unit root process, or even to a "mildly explosive" process (Phillips et al., 2011; Phillips et al., 2013), and then back to a stationary process. Specifically, the conventional augmented Dickey-Fuller unit root test and some developments involving scanning different time windows with reduced variables associated with the mildly explosive process provides bubble indicators with predictive warning signals ahead of crashes (Taipalus, 2012). The augmented Dickey-Fuller unit root test with a recursive implementation of a right-side unit root test together with a mildly explosive process exhibits discriminatory power in detecting periodically collapsing bubbles, thereby overcoming a weakness in earlier applications of unit root tests for economic bubbles (Phillips et al., 2011).

Sornette and collaborators have proposed that bubbles can be identified as "super-exponential" price processes, punctuated by bursts of negative feedback spirals of crash expectations, which can be parametrised by so-called Log-Periodic Power Law Singularities (LPPLS) (Johansen et al., 1999; Sornette et al., 2017; Hüsler et al., 2013; Leiss et al., 2015; Sornette, 2015).This approach has been translated into an operational methodology to calibrate price time series and diagnose bubbles as they develop. ${ }^{\dagger}$.

In contrast to the "mildly explosive" processes of Phillips et al. (2011, 2013) and the super-exponential mechanism of Johansen (1999), Sornette (2017), Hüsler (2013), Leiss (2015) and Sornette and Cauwels (2015). which both focus on the drift process, Jarrow et al. (2006, 2010) developed a strict local martingale approach for very general processes. Then, in Jarrow et al. (2001a, b), the authors apply this approach to the specific model of a homogeneous diffusion. In this restrictive setting, the explosive volatility becomes necessary for a bubble to be qualified. In (Protter, 2013), both the general and the specific setting are presented. We can give a flavor of their explosive volatility model, which specifies the behavior of the volatility $\sigma\left(S_{t}\right)$ (i.e. the diffusive) part of the price process written as $d S_{t}=b\left(S_{t}\right) d t+\sigma\left(S_{t}\right) d W$, where $d W$ is the increment of a standard Wiener process and $b\left(S_{t}\right)$ is the drift. Their condition for a bubble is that the following integral be finite: $\int_{\epsilon}^{\infty}\left(x /[\sigma(x)]^{2}\right) d x<\infty$. Note that the standard Geometric Brownian Motion is such that $\sigma\left(S_{t}\right) \sim S_{t}$, so that the integral diverges logarithmically at its upper bound, confirming it is not a bubble according to

${ }^{\dagger}$ Many cases are reported in Chapter 9 of the book (Sornette, 2017) for tests performed up to 2002 and in the following articles (Jiang et al., 2010; Sornette et al., 2009; Sornette et al., 2010; Forró et al., 2015; Sornette et al., 2015; Zhang et al., 2016) and web resources (see the Financial Crisis Observatory website at www.er.ethz.ch/financial-crisis-observatory.html) 
this integral criterion. In order for the integral to be finite, $\sigma\left(S_{t}\right)$ must grow with $S_{t}$ faster than proportional, for instance as a power law $\sigma\left(S_{t}\right) \sim S_{t}^{\gamma}$, with $\gamma>1$, corresponding to so-called inverse Bessel processes (Protter, 2013). Then, in Jarrow et al.'s approach, the detection of a bubble boils down to estimating robustly that the volatility $\sigma\left(S_{t}\right)$ grows sufficiently faster than linearly with $S_{t}$ so as to make the integral finite. A practical implementation of this methodology is demonstrated by an analysis of the LinkedIn share price evolution around its IPO (Jarrow et al., 2011b). On thursday May 19, 2011, LinkedIn priced its initial public offering at $\$ 45$ a share, but the stock opened at $\$ 83$ and more than doubled in its public trading launch, peaking at $\$ 122.7$ in late morning before slipping back and remaining in a range from $\$ 95$ to $\$ 110$ over the following days. When analysing LinkedIn's price evolution around the IPO, one could see a very strong price acceleration before the peak, followed by a fast crash and then a more normal diffusion process. One can then wonder whether the bubble is indeed volatility-controlled as claimed in (Jarrow et al., 2011b) or the consequence of (the correction after) an explosive drift process, in which case the increased volatility is not the cause (or diagnostic) of the bubble and the subsequent crash but the consequence of the leverage effect (the fact that volatility rises when a stock's price drops) (Figlewski and Wang, 2000; Bouchaud et al., 2001). One should also note that the calibration and qualification of the explosive volatility performed in (Jarrow et al., 2011b) includes the explosive drift phase up to the peak at $\$ 122.70$, which could perhaps be mistaken for an explosive volatility. In other words, the emphasis on a particular dynamic of the drift or of the volatility as the diagnostic of a bubble may depend on the chosen time scale and on whether one focuses on transient (i.e. "explosive") dynamics. As a transient drift contributes to volatility at longer time scales, this might contribute to misunderstanding between these apparently fundamentally distinct approaches.

Recently, Vogel and Werner (2015) compared the historical and implied volatility time series of the S\&P500 from September 2004 to June 2014 and suggested that implied leads historical volatility and that a rise in the implied volatility foreshadows a bubble or crash condition. However, this conclusion is based on a very limited dataset, and may not be generalisable, as we discuss below.

\section{Research question and summary of main results}

The present investigation aims at clarifying the relationship between volatility and bubble expansion. The research questions of the present article can be articulated as follows:

Research questions: Does volatility, historical and/or implied, exhibit a tendency to increase during the maturation of a bubble? Is volatility surging towards the end of a bubble? Could volatility be used to diagnose bubbles and forecast their end?

One argument for a positive answer could be that, as investors become more aware of the development of a bubble and of the crash risk, this should translate into a growing implied and/or historical volatility as a result of the aggregate impact of the investors' decisions. Or the reasoning could be more technical, invoking that volatility increasing abnormally fast is the necessary embodiment of a strict local martingale process applied to an homogenous diffusion model (Protter, 2013). Alternatively, using analogies with bifurcations and phase transitions, there is a general (but not ubiquitous) mechanism that noise gets amplified and its variance increases according to specific laws on the approach of a change of regime, among other possible precursory signals (Sornette, 2004; 
Scheffer et al., 2012).

Volatility exhibits several different dynamics. First, mechanically, if there is a large positive or negative return, the volatility is instantaneously large by its definition of being a measure of the amplitude of returns. Second, volatility exhibits long-term memory (Beran, 1994) and multi-fractal properties (Calvet and Fisher, 2004; Filimonov and Sornette, 2011). Third, there is the so-called leverage effect (Figlewski and Wang, 2000; Bouchaud et al., 2001), such that a large negative return leads to a burst of increased volatility that progressively damps out. Finally, there could be a covariation of price and volatility, especially during the ascent of the price towards the end of bubbles, which is the very question investigated here.

Our main finding is that volatility is not a reliable indicator of the maturation towards the end of a bubble and of its impeding crash. In contradiction with some claims that historical volatility increases before a crash (Jarrow et al., 2006; Jarrow et al.,2010; Jarrow et al., 2011a, b; Protter, 2013), we report that volatility exhibits no consistent behavior. Sometimes it does increase, sometimes it decreases, and most of the time it barely changes as the bubble develops. This overall conclusion can be checked by examining each of the forty reported cases. A quite informative case study is provided by the Malaysian and the Philippine bubbles. Both had common underlying drivers (the great expectations of the "dragon economies"), developed over the same period (the year 1993), accelerated in the final phase together (December 1993) and burst at exactly the same moment (around January 5, 1994). Yet, in Malaysia, the volatility went down right before the crash, whereas in the Philippines, it went up. Thus, volatility is not a systematic and reliable diagnostic of bubbles, nor does it provide useful information on the impending crash.

\section{Method}

Our study of the relationship between volatility dynamics and bubble development distinguishes itself from previous research by the large size of the sample of bubbles. We examine forty financial time series that have been documented in previous publications to undergo a bubble regime ending in a crash. Different asset classes are covered, stock indexes, singles stocks, Exchange Traded Funds, commodity futures and currencies. The earliest case we analyse is the Dow Jones Industrial Average index, which ended in the crash of October 1929. The latest bubble we study is the one in Gold, crashing in September 2011. The present study makes no claim with respect to forecasting, but rather examines ex-post statistical characteristics of the financial volatility (mainly historical and sometimes implied when available).

These forty documented bubbles have been previously studied in one form or another by Sornette et al. in the last two decades. For each case, the context of the bubble is briefly explained, which can be financial, economical, systemic or (geo-)political. To study the volatilty, a uniform treatment on a consistent data set is performed. This includes the price and the historical (and implied, when available) volatility of the financial time series for each bubble, obtained from a standard Bloomberg terminal. The price is the last closing price for each day (Bloomberg's "PX_LAST") and the historical volatility is the twenty day price volatility (Bloomberg's "VOLATILITY_20D"), which is the annualized standard deviation of the relative price change for the twenty most recent closing prices, expressed as a percentage. When provided, we use the implied volatility (Bloomberg's "HIST_CALL_IMP_VOL"). This is calculated from a weighted average of the volatilities of the two 
call options closest to the at-the-money strike price. The contract used is the closest-pricing contract month that is expiring at least twenty business days out from today. This is provided only for a minority of the assets and time periods we are interested in. Sometimes Bloomberg does not provide values for all the variables of interest. In this case, we filter out the whole observation (e.g. remove a particular day if no price is available for it) and this is why in a few cases the presented curves appear jagged.

Our analysis mainly consists in obtaining and presenting graphical outputs. In a first graph, two plots are combined. The first plot shows the twenty-day historical volatility of the financial time series from one year before the peak and its subsequent crash up to one year after, together with the historical evolution of the price series. This allows one to compare visually the volatility levels and trends before (green) and after (red) the peak and following crash. The grey area helps the reader visualising the transition period from the bubble to the crash. Depending on the bubble case, it represents a onemonth period around or after the peak of the bubble or a one-month period during the crash. This apparent lack of consistency represents our best attempt to capture the period of the change of regime in highly heterogeneous bubble cases: in some instances, the peak of the price occur many months before the crash occurs and the price goes sideway until the crash. Our choice for the position of the grey area representing the change of regime has a degree of subjectivity, but we think it helps a better visualisation. In any case, it is not crucial for the strength of the evidence that we present.

The second plot presents box plots of six two-month periods before and six two-month periods after the peak. This shows the minimum and maximum values, the first quartile, the median and the third quartile of the volatility for each period. This set of statistics complements the time series of volatility by quantifying the possible time evolution of the median, quartiles and extreme excursions of the volatility before and after the crash. These box plots constitute direct evidence to test the research question raised above. If data for the implied volatility are available, the same graph with the two sub-plots will be given but this time using the implied instead of the historical volatility.

To allow for a fully dynamical interpretation, an arrow plot is added for each case showing the evolution of the monthly historical volatility as a function of the monthly price change. In this representation, arrows are shown, colored green before the crash and red after the crash. They are joined by the date, which is in the "MM.YY" format. An additional feature is that the arrows progressively thicken in the green pre-crash regime and thin out in the red post-crash period so that the eye can easily follow the course of time. This representation makes it possible to view and interpret the market evolution at each time as a dynamical system. In this way, one can identify the clusters of volatility and observe possible regime-changes over time. This representation is particularly powerful to visualize the general behavior of the volatility before and after the crash and to identify possible characteristic changes, or the absence of these, over time.

There is no generally accepted methodology that allows one to pinpoint exactly the start date of a crash. To overcome that problem, all the plots in this document are constructed relative to the peak in the price levels of the index before the crash. This approach can best be illustrated with a concrete example. The famous crash in 1929 happened in October. The peak in the price levels, however, was reached a month before, on September 3. Therefore, all the plots are centred relative to September 1, 1929. It is important to mention here that when we use the term "volatility", we will always mean "annualized volatility", omitting the term "annualized" for simplicity of writing.

To understand the credit conditions before and after the crash, a final plot is added. This shows the 
credit from banks to the private non-financial sector as the percentage of the GDP of that particular country, together with its two-yearly growth rate. The historical time series are plotted starting five years before and ending five years after the peak. The data are from the Bank for International Settlements (BIS, 2017). The purpose of this graph is to evaluate the credit conditions in the years before and after the bubble and to have an idea whether the bubble is a leveraged "credit boom" bubble or not (Jorda et al., 2015). In each plot, the exact values of the credit level and growth rate are labelled for the last observation before the peak and subsequent crash. When the data are not available, which is the case for some countries and some time periods, the credit conditions will not be evaluated. This will guarantee the consistency of the analysis.

\section{List of bubbles}

Table 1 lists some features of the forty bubble cases, including the corresponding asset name or country index, the year of its corresponding crash, the time $t_{c}$ at which the time series reached its maximum before the crash, and the reference(s) where the bubble and its subsequent crash were documented. The column containing the qualifiers "Fearful" or "Fearless", summarizes whether the volatility is found to typically grow together with the price ("Fearful') or not ("Fearless"). These terms were introduced by Sornette and Andersen (2004), who classified nine price time series exhibiting bubble behavior as either "Fearful" or "Fearless" according to the performance of a model assuming an accelerated growth of the volatility on the approach of the crash (Sornette and Andersen, 2002). Here, we borrow these two terms and attribute them to the forty bubble cases on the basis of the visual quantitative outputs defined above. Out of the forty bubbles, we find that 26 can be classified as "Fearless" and 14 as "Fearful".

When the data from the Bank for International Settlements (BIS, 2017) are available, the credit conditions before and after the crash will also be assessed. Bubbles will be identified as leveraged or non-leveraged depending on whether the credit level and growth rate are increasing significantly during the bubble build-up. For 29 bubbles, the data were available to do this type of analysis, 16 of these were identified as leveraged, 13 as non-leveraged.

\section{Study of the forty bubbles and their associated volatility dynamics}

\subsection{US stock market bubble ending in September 1929}

The bubble that developed in the late 1920s in the US peaked on September 3, 1929, when the Dow Jones Industrial Average index reached 381. It was followed by the crash of October 1929. This period has been analysed in great detail by Galbraith (Galbraith, 2009). It was the end of the roaring 1920s, a time of extraordinary growth and prosperity on Wall Street and Main Street that was fuelled by the reconstruction boom after the first world war. The Great Depression that followed, put 13 million Americans out of work (from a total population of 125 million at that time), two thousand investment firms went bankrupt. As a reaction to the crisis, the American banking industry went through extensive regulatory changes exemplified by the famous Glass-Steagall act of 1933 that led to the separation of retail -, commercial -, investment banking and insurance activities. Its progressive repeal from the 1980s till its official demise in 1999 via the Gramm-Leach-Bliley Act, also known as the Financial Services Modernization Act, has been argued to catalyse the conditions for the financial crisis of 2007- 
Table 1. List of the 40 bubbles studied here, with the corresponding asset name or country index, the year of its corresponding crash, the time $t_{c}$ at which the time series reached its maximum before the crash, and the reference(s) where the bubble and its subsequent crash were documented. A "Fearful" bubble (resp. "Fearless") summarises our finding that the bubble was accompanied by an increasing (resp. a constant or decreasing) volatility. The last column sum ups the credit conditions during each bubble.

\begin{tabular}{|c|c|c|c|c|c|c|}
\hline & Country & Index & Peak time before Crash & Reference & Fearless/Fearful & Leveraged? \\
\hline 1 & US & DJIA & September 1929 & Sornette, 2017; Galbraith, 2009 & Fearless & \\
\hline 2 & US & DJIA & March 1962 & Sornette, 2017; Malkiel, 2007; & Fearless & No \\
\hline 3 & US & S\&P 500 & October 1987 & Koning; Sornette, 2017; Carlson, 2006 & Fearless & Yes \\
\hline 4 & US & S\&P 500 & July 1998 & Sornette, 2017 & Fearless & No \\
\hline 5 & US & Nasdaq & March 2000 & $\begin{array}{l}\text { Sornette, 2017; Johansen and Sornette, 2000; Nagel and } \\
\text { Brunnermeier, } 2003\end{array}$ & Fearful & No \\
\hline 6 & US & S\&P 500 & October 2007 & Bear Markets; Martin, 2004 & Fearful & Yes \\
\hline 7 & US & IBM & July 1999 & Sornette, 2000; Johansen and Sornette, 2000; Sornette, 2017 & Fearless & \\
\hline 8 & US & Procter \& Gamble & January 2000 & Sornette, 2000; Johansen and Sornette, 2000; Sornette, 2017 & Fearless & \\
\hline 9 & UK & FTSE & October 1987 & Johansen and Sornette, 2010 & Fearless & No \\
\hline 10 & UK & FTSE & October 1997 & Johansen and Sornette, 2010 & Fearful & Yes \\
\hline 11 & UK & FTSE & July 1998 & Johansen and Sornette, 2010 & Fearless & No \\
\hline 12 & Germany & DAX & July 1998 & $\begin{array}{l}\text { Johansen et al., 1999; Johansen and Sornette, 2010; Craig et } \\
\text { al., 2003; Bohl et al., } 2007\end{array}$ & Fearless & No \\
\hline 13 & Japan & Nikkei & January 1990 & Sato, 1995; Barsky, 2009; Hamao et al., 2003; Werner, 2005 & Fearless & Yes \\
\hline 14 & Korea & KOSPI & November 1994 & $\begin{array}{l}\text { Johansen and Sornette, 2001; Kaufman et al., 1980-2001; } \\
\text { Ahmed et al., } 2010\end{array}$ & Fearless & Yes \\
\hline 15 & Hong Kong & HSI & October 1987 & Sornette, 2017; Yang and Bessler, 2008 & Fearless & Yes \\
\hline 16 & Hong Kong & HSI & January 1994 & $\begin{array}{l}\text { Sornette, 2017; Hong Kong Monetary Authority, 2011; } \\
\text { Flowerdew, } 1998\end{array}$ & Fearful & No \\
\hline 17 & China & SHCOMP & October 2007 & Shu-jie and Dan, 2008; Yao and Luo, 2009; Jiang et al., 2010 & Fearless & No \\
\hline 18 & China & SHCOMP & July 2009 & Jiang et al., 2010; Time Magazine, 2009 & Fearless & Yes \\
\hline 19 & Argentina & MERVAL & October 1991 & $\begin{array}{l}\text { Blustein, 2005; Johansen and Sornette, 2001; Kaufman et al., } \\
\text { 2980-2001 }\end{array}$ & Fearful & Yes \\
\hline 20 & Argentina & MERVAL & June 1992 & $\begin{array}{l}\text { Blustein, 2005; Johansen and Sornette, 2001; Kaufman et al., } \\
\text { 2980-2001; Ahmed et al., } 2010\end{array}$ & Fearless & No \\
\hline 21 & Argentina & MERVAL & February 1994 & $\begin{array}{l}\text { Blustein, 2005; Johansen and Sornette, 2001; Kaufman et al., } \\
\text { 2980-2001; Ahmed et al., } 2010\end{array}$ & Fearless & Yes \\
\hline 22 & Argentina & MERVAL & October 1997 & $\begin{array}{l}\text { Blustein, 2005; Johansen and Sornette, 2001; Kaufman et al., } \\
\text { 2980-2001; Ahmed et al., } 2010\end{array}$ & Fearless & Yes \\
\hline 23 & Brazil & IBOV & July 1997 & $\begin{array}{l}\text { Johansen and Sornette, 2001; Kaufman et al., 2980-2001; } \\
\text { Martin, 2004; Ahmed et al., } 2010\end{array}$ & Fearless & No \\
\hline 24 & Chile & IGPA & October 1991 & $\begin{array}{l}\text { Johansen and Sornette, 2001; Kaufman et al., 2980-2001; } \\
\text { Ahmed et al., } 2010\end{array}$ & Fearless & \\
\hline 25 & Chile & IGPA & February 1994 & $\begin{array}{l}\text { Johansen and Sornette, 2001; Kaufman et al., 2980-2001; } \\
\text { Ahmed et al., } 2010\end{array}$ & Fearful & Yes \\
\hline 26 & Mexico & MEXBOL & October 1997 & $\begin{array}{l}\text { Johansen and Sornette, 2001; Kaufman et al., 2980-2001; } \\
\text { Ahmed et al., } 2010\end{array}$ & Fearful & No \\
\hline 27 & Peru & IGBVL & October 1993 & $\begin{array}{l}\text { Johansen and Sornette, 2001; Kaufman et al., 2980-2001; } \\
\text { Ahmed et al., } 2010\end{array}$ & Fearful & Yes \\
\hline 28 & Peru & IGBVL & June 1997 & $\begin{array}{l}\text { Johansen and Sornette, 2001; Kaufman et al., 2980-2001; } \\
\text { Ahmed et al., } 2010\end{array}$ & Fearful & Yes \\
\hline 29 & Venezuela & IBVC & October 1997 & $\begin{array}{l}\text { Johansen and Sornette, 2001; Kaufman et al., 2980-2001; } \\
\text { Ahmed et al., } 2010\end{array}$ & Fearless & Yes \\
\hline 30 & Indonesia & JCI & January 1994 & $\begin{array}{l}\text { Johansen and Sornette, 2001; Kaufman et al., 2980-2001; } \\
\text { Ahmed et al., } 2010\end{array}$ & Fearful & No \\
\hline 31 & Indonesia & JCI & July 1997 & $\begin{array}{l}\text { Johansen and Sornette, 2001; Kaufman et al., 2980-2001; } \\
\text { Ahmed et al., } 2010\end{array}$ & Fearless & Yes \\
\hline 32 & Malaysia & FBMKLCI & January 1994 & $\begin{array}{l}\text { Johansen and Sornette, 2001; Kaufman et al., 2980-2001; } \\
\text { Ahmed et al., 2010; Rangel and Pillay, } 2007\end{array}$ & Fearless & No \\
\hline 33 & Philippines & PCOMP & January 1994 & Johansen and Sornette, 2001; Ahmed et al., 2010 & Fearful & \\
\hline 34 & Russia & ROSI & October 1997 & Johansen et al., 1999; Kotz, 1999; Ahmed et al., 2010 & Fearless & Yes \\
\hline 35 & Oil & USO ETF & July 2008 & Khan, 2009; Eckaus, 2008; Lammerding et al., 2013 & Fearful & \\
\hline 36 & Platinum & $\begin{array}{l}\text { Front } \\
\text { Future }\end{array}$ & May 2010 & Darst, 2013; Sornette et al., 2009 & Fearless & \\
\hline 37 & Palladium & $\begin{array}{l}\text { Front } \\
\text { Future }\end{array}$ & May 2010 & Bloomberg News, 2010; Darst, 2013; Sornette et al., 2009 & Fearful & \\
\hline 38 & Sugar & $\begin{array}{l}\text { Front } \\
\text { Future }\end{array}$ & November 2010 & $\begin{array}{l}\text { ETF Database, 2010; Business Insider, 2010; The observer, } \\
\text { 2010; Sornette et al., } 2009\end{array}$ & Fearless & \\
\hline 39 & Gold & GLD ETF & September 2011 & $\begin{array}{l}\text { The Gold Bubble; Baur and Glover, 2012; Bloomberg News, } \\
2011\end{array}$ & Fearful & \\
\hline 40 & Swiss Franc & FXF ETF & August 2011 & FT.com, 2011 & Fearless & \\
\hline
\end{tabular}


2008 and the subsequent Great Recession (Sornette and Cauwels, 2014).
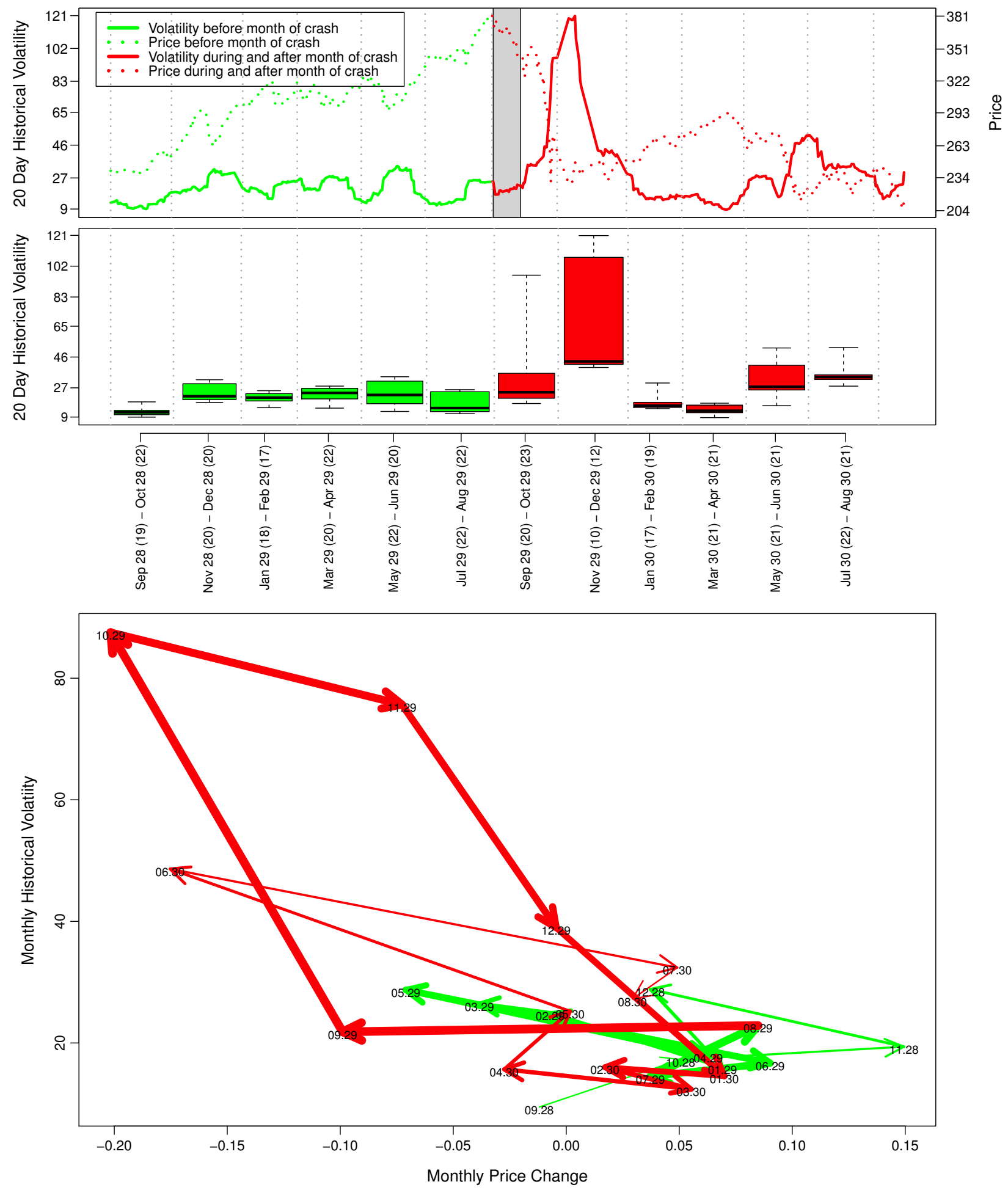

Figure 1. The US stock market bubble ending in October 1929: price and historical volatility of the Dow Jones Industrial Average index (see section 4 for a detailed methodological explanation). 
The top panel of figure 1 shows the 20-day moving average of the historical volatility of the Dow Jones Industrial Average index before (green) and after (red) its peak on September 3, together with the historical price level of the index itself. The grey area represents the one month period after the peak. One can see the volatility increasing from a rather low level around $10 \%$, more than one year before the peak, up to a stable level of approximately 20\% between December 1928 and October 1929. Except for some range-bound oscillations, no systematic increase of the volatility can be observed in the year 1929 until the moment of the crash in October that same year. These observations are confirmed by the box plot in the middle panel of figure 1, where one can actually observe a lower volatility in the two-months interval ending at the peak of the index, in July and August 1929.

The bottom arrow plot of figure 1 shows the monthly historical volatility as a function of the price change over that same period. The dynamics are clear. The green arrows in the period before the peak and its subsequent crash show a volatility at a constant level around $20 \%$, independent of the monthly price changes. Then, volatility shoots up massively, but this is clearly the direct consequence of the crash and cannot in any way be used as a precursory warning signal of the bubble. One can also notice that, after its explosive growth in October 1929, the volatility decreased in the four months following the crash, but started to increase again afterwards. This is a signature of the fact that the crash was only the beginning of what would develop into a multi-year depression that impacted severely the stock market, which would find an absolute low of 41 on July 8, 1932, corresponding to a total cumulative drop of $89 \%$ since the all-time peak on September 3, 1929.

Unfortunately, the historical time series from the Bank for International Settlements (BIS, 2017) do not go back until 1929. For coherence, we will only evaluate the credit conditions during the period of the bubble build-up when the data are available from that source.

We classify the stock market bubble, ending in September 1929, as a fearless bubble, meaning that there was no rise in volatility during the bubble period leading up to the crash.

\subsection{US stock market bubble ending in March 1962}

In contrast to the October 1929 crash, the "Tronics boom", which ended in March 1962, never reached the same level of attention. In a research paper, Johansen et al. (2000) describe how a systematic scanning for bubbles in the US stock market between 1910 and 1996 revealed this, almost forgotten, period of boom and bust. The frenzy started in the late 1950s and continued into the early 1960s. It was incited by the emergence of a new electronic industry that gave birth to companies with a high growth potential in what was called the "Tronics boom". Many companies, associated with the esoteric high-tech of space travel and electronics, sold in 1961 for over 200 times their previous year's earnings (Sornette, 2017). This period was followed by a slow crash with a gradual decline of $27 \%$ in three months. Zweig (2000) reported the uncanny similarities between the "flash crash" of May 28, 1962 and the most recent "flash crash" of May 6, 2010 (Sornette and von der Becke, 2011). The Wall Street Journal reported on May 29, 1962: “The stock market careened downward yesterday, leaving traders shaken and exhausted." The Dow Jones Industrial Average index fell 5.7\% that day, down 35 points, the second-largest decline then on record. "The drop took place on volume so heavy," added the newspaper, "that the ticker wasn't able to finish reporting floor transactions until 5:59 p.m., two hours and 29 minutes after the market closed."

The top panel of figure 2 shows the 20-day moving average of the historical volatility of the Dow Jones Industrial Average index before (green) and after (red) its peak in March 1962, together with 

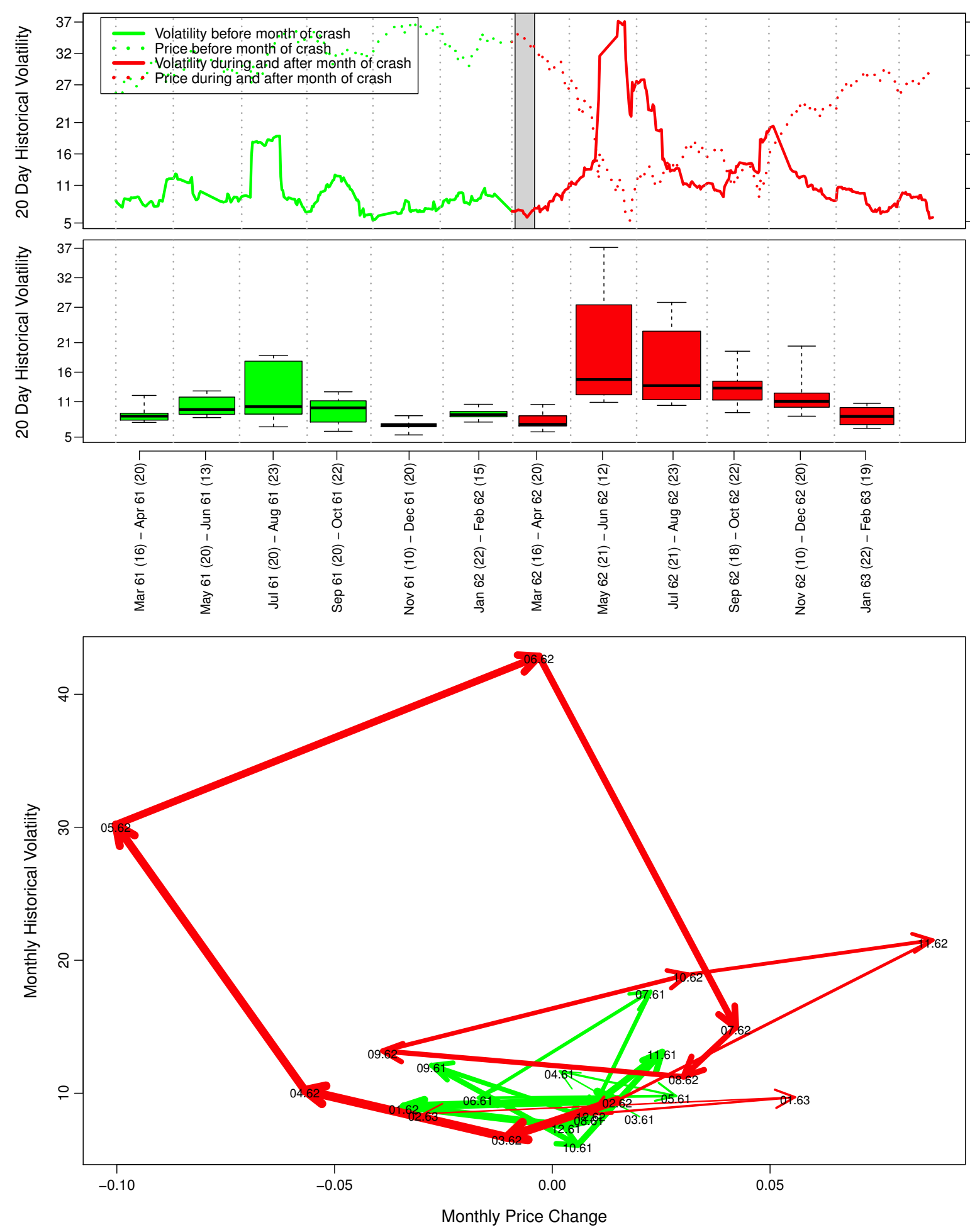

Figure 2. The US stock market bubble ending in March 1962: price and historical volatility of the Dow Jones Industrial Average index (see section 4 for a detailed methodological explanation). 
the historical price level of the index itself. The grey area represents the one month period around the peak. In the year before March 1962, some occasional volatility spikes can be seen, these were associated with minor price corrections. In general, it can be seen that, in that period, the historical volatility hovers around the annualized $10 \%$ level. Interestingly, when the slow crash sets in, volatility is practically at its lowest level and starts rising until reaching its peak around the $40 \%$ level simultaneous with the price reaching its bottom level. These observations are fully supported by the box plot in the middle and the arrow plot at the bottom of figure 2. For the "Tronics boom", it can be said that volatility is not a precursor but a consequence of the crash.

To understand the credit conditions during and after this period of boom and bust, figure 3 shows the credit from banks to the private non-financial sector as a percentage of the GDP of the US, together with its two-yearly growth rate. The historical time series are plotted starting five years before and ending five years after the peak. The data are from the Bank for International Settlements (BIS, 2017). It can be seen that the "Tronics boom" had been surfing on the secular trend of gradual expansion of credit to the private sector from 25\% of GDP in the mid 1950s up to 50\% of GDP in the mid 1970s. However, as this process started earlier and continued long after the "Tronics boom" had ended, this long-term trend in credit cannot be particularly associated with this specific industrial period.

We will classify the stock market bubble, ending in March 1962, as a fearless, non-leveraged bubble, the former meaning that there was no rise in volatility during the bubble, the latter meaning that the bubble was not specifically caused by a rise in credit, or leverage, in the financial and economic system.

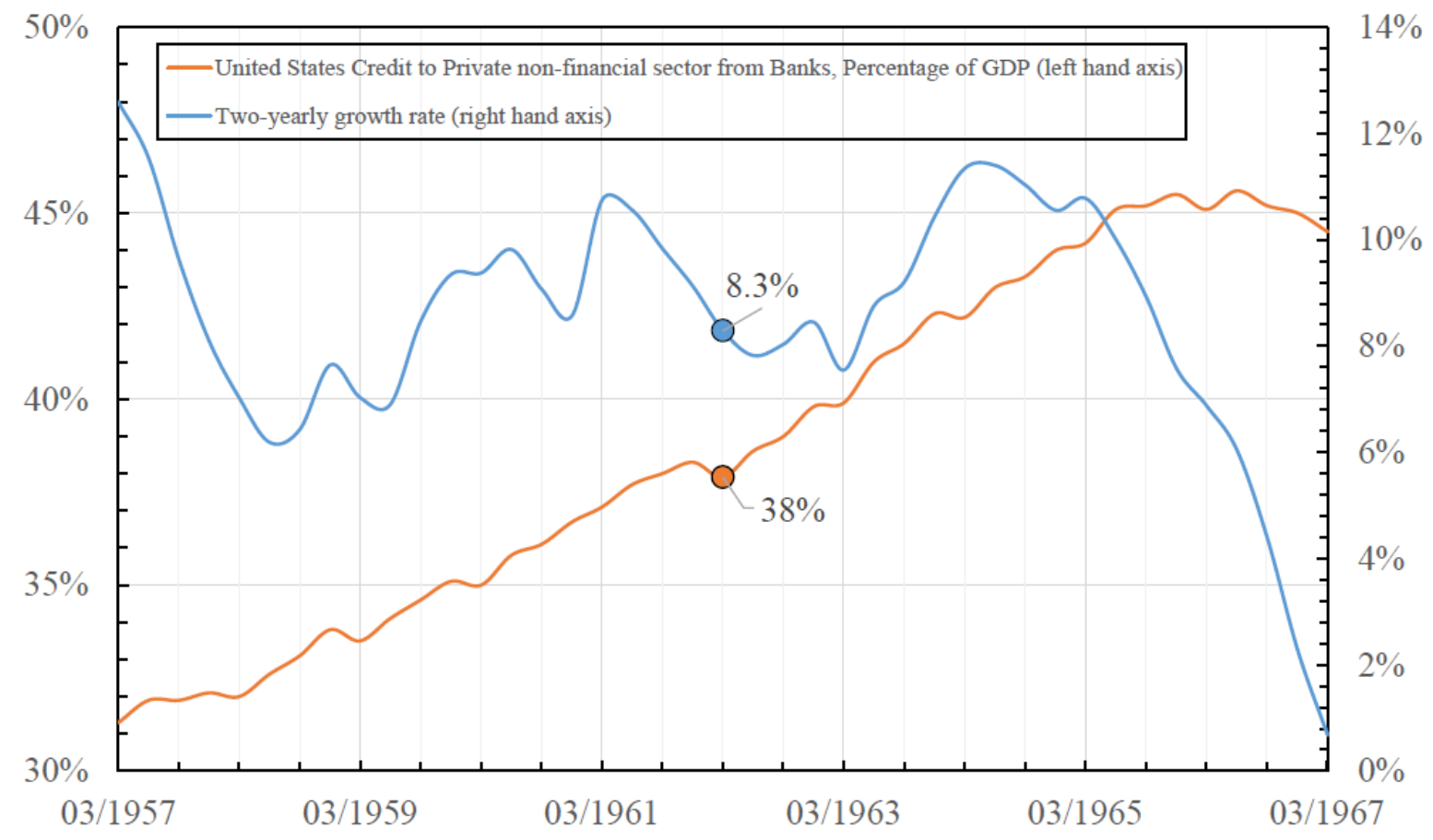

Figure 3. The credit conditions in the United States between 1957 and 1967, five years before and after the 1962 "Tronics boom". The two filled circles are the last observations from the data source (BIS, 2017) before the peak and the subsequent crash in March 1962. 


\subsection{US stock market bubble ending in October 1987}

The crash of the US stock market on October 19, 1987, also known as "Black Monday", was part of a worldwide phenomenon. From October 14, 1987 through the market close on October 19, the major US indexes declined by $30 \%$ or more. Interestingly, all major world markets declined substantially that month. In local currency units, the minimum decline was in Austria (-11\%) and the maximum was in Hong Kong (-46\%) (Sornette, 2017). A lot of work has been carried out to unravel the origin(s) of the crash (for a full overview, see the reviews in (Sornette et al., 1996; Sornette, 2017)), notably in the properties of trading and the structure of markets; however, no clear cause has been singled out. It is noteworthy, however, that the strong market decline during October 1987 followed what for many countries had been an unprecedented market increase during the first nine months of the year and even before (Sornette, 2017). Some commentators have suggested that the real cause of the crash was that overinflated prices were the result of a speculative bubble during the earlier period which pushed global stock markets into an unsustainable state. Like a ruler held up vertically on one's finger, any small disturbance could have triggered the fall, disrupted the state of the system and caused a major failure.

In a study based on options markets, Bates $(1991,2000)$ showed that out-of-the-money put options became unusually expensive during some short periods at the end of 1986 and in the summer of 1987. However, over most of the year 1987, the out-of-the-money calls were the options exhibiting the highest unusual valuation, likely pricing a belief in the continuation of the strong price appreciation. This paints a complex picture of a generally very optimistic mood interspersed by periods of short-lived implied "fear", but does not seem to be compatible with a progressive growth of implied volatility up to the crash.

The upper panel of figure 4 shows the 20-day historical price volatility of the S\&P 500 index before (green) and after (red) the peak preceding the crash in October 1987, together with the price level of the index. The grey area represents the one month period during the crash. Apart from a bump in the volatility during the months of April and May in that year, one cannot observe a significant systematic increase, which could be perceived as a precursor before the crash. Actually, the volatility decreased slightly to stabilise in June and July only to increase a bit later on, over the months of August and September. By construction, during the crash and in the months after, a strong jump in volatility can be seen with a progressive relaxation and a return to a lower, more common, background level. This observation is confirmed by the box plot in the middle panel of figure 4 . In fact, the same mechanism as in the "Tronics boom" can be observed: volatility is at a normal or even low level right at the peak of the index, only to shoot up during the crash to reach its highest level when the price bottoms. In these cases, the volatility is negatively correlated with the return. A negative correlation between return and volatility can often be observed and is called the "leverage effect" (Figlewski and Wang, 2000; Bouchaud et al., 2001).

The arrow plot in figure 4 only confirms the previous observations. The green arrows, representing the dynamics before the crash can be found in the bottom right corner corresponding to high positive returns and low volatility; the red arrows, representing the dynamics after the crash are more dispersed with extremes in the top left corner, corresponding to high negative returns and high volatility. Clearly also in this case, volatility is not a precursor but a consequence of the crash.

To understand the credit conditions during and after the October $1987 \mathrm{crash}$, figure 5 shows the credit from banks to the private non-financial sector as a percentage of the GDP of the US, together 

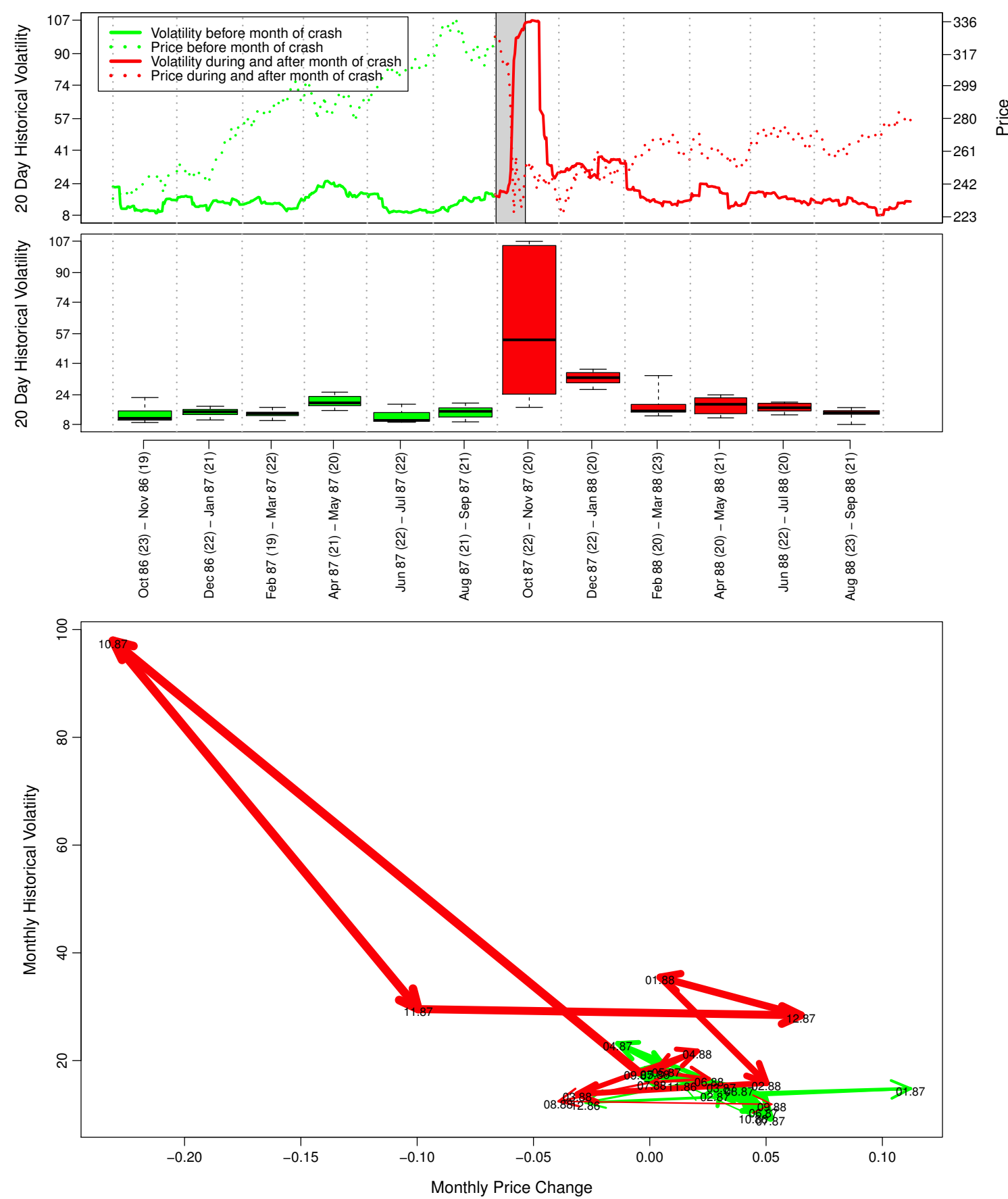

Figure 4. The US stock market bubble ending in October 1987: price and historical volatility of the S\&P 500 index (see section 4 for a detailed methodological explanation).

with its two-yearly growth rate. The historical time series are plotted starting five years before and ending five years after the peak. The data are from the Bank for International Settlements (2017). It is interesting to see that both the credit as a percentage of the GDP and its growth rate peak around the time of the crash. This data suggests that the crash of October 1987 was intimately linked with the long-term trend of credit growth from 30\% of GDP in 1967, twenty years before the crash, up to 
around $60 \%$ of GDP in 1987.

We will classify the stock market bubble, ending in the October $1987 \mathrm{crash}$, as a fearless, leveraged bubble, the former meaning that there was no rise in volatility during the bubble period leading up to the crash, the latter meaning that the bubble was fed by credit growth, or leverage, in the economic system.

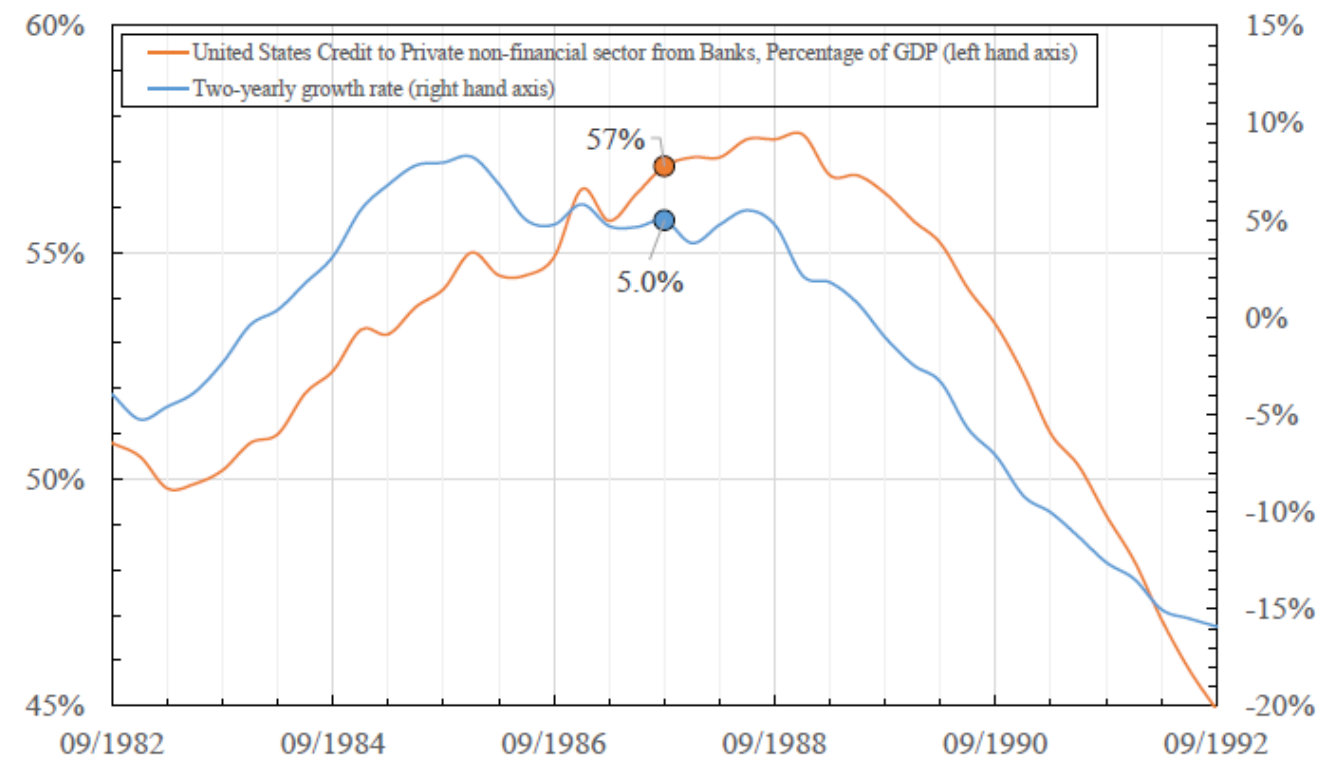

Figure 5. The credit conditions in the United States between 1982 and 1992, five years before and after "Black Monday". The two filled circles are the last observations from the data source (BIS, 2017) before the peak and the subsequent crash in October 1987.

\subsection{US stock market bubble ending in July 1998}

From its top, mid-July 1998, to its bottom at the end of August 1998, the U.S. S\&P 500 stock market index lost 19\%. A detailed account on this bubble, recognized ex-ante (before the crash) and analysed in real-time during its progression was published by Sornette and his colleagues in (Johansen et al., 1999) and in (Sornette, 2017) (on the pages 259-263). The turbulent behavior of the stock markets worldwide in that period has been widely attributed to the plunge of the Russian financial markets (which will be discussed in section 6.34), the subsequent devaluation of the Rouble, and the default of the Russian government on its domestic debt (Russia did not default on its foreign debt).

The upper panel of figure 6 shows the 20-day historical price volatility of the S\&P 500 index before (green) and after (red) the peak preceding the crash in September 1998, together with the price level of the index. The grey area represents the one month period around the peak. One can observe a large spike in the volatility from October to December 1997, which can be attributed to the "minicrash" of October 27, 1997 in connection with the Asian financial crisis ${ }^{\ddagger}$. As shown in the middle panel of the box plot, the historical volatility steeply dropped in the months following this event, down

\footnotetext{
"for an account of the real-time analysis and trading of put options in the period of this "mini-crash" see the book (Sornette, 2017), pp. 342-346
} 

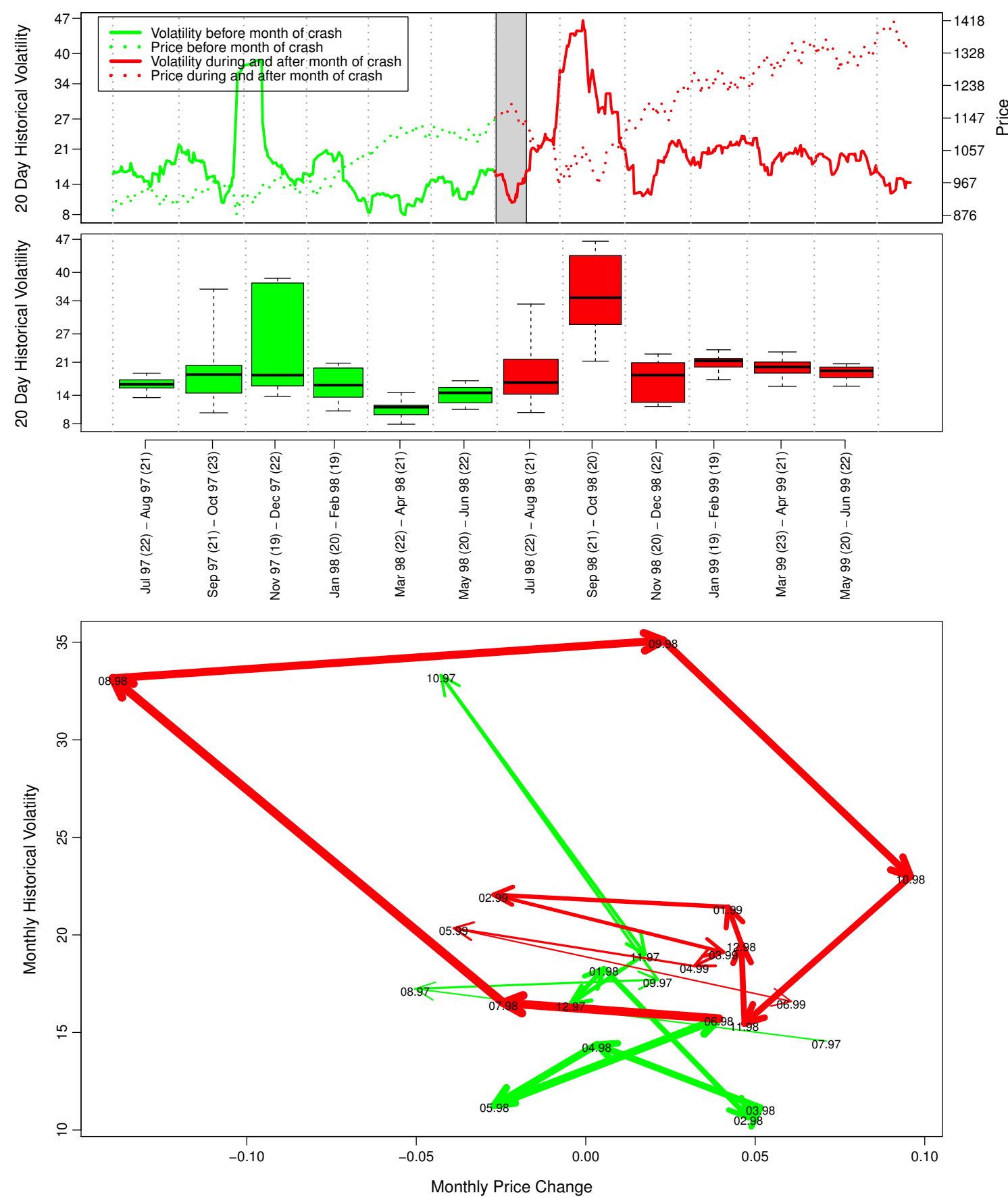

Figure 6. The US stock market bubble ending in August 1998: price and historical volatility of the S\&P 500 index (see section 4 for a detailed methodological explanation).

to a level as low as $13 \%$ in March-April 1998. After this, the volatility increased slightly again but never reached the levels observed in the preceding year. If anything can be concluded from this box plot, it is that on average the volatility decreased in the eight months before the peak in the market and the subsequent crash. The arrow plot in figure 6 only confirms this observation. One can clearly distinguish the October 1997 event previously mentioned as a short-lived singular spike of volatility 
lasting no more than two months as indicated by the two green arrows striking out between the low and the high volatility regions. As observed from the chaotic green arrow trajectories, there is no systematic significant growth of the volatility prior to the crash. If volatility was a precursor to the crash, then a clear tendency should be observed in this plot, which is not the case.

The analysis based on the implied volatility paints a similar picture, as can be seen in figure 7 . Again, one can observe the peak of volatility from October to November 1997 followed by a progressive decrease to a stochastic background level of low implied volatility until the time of the price peak in August 1998 coinciding exactly with the bottom of the implied volatility.

To understand the credit conditions prior and after this crash, figure 8 shows the credit from banks to the private non-financial sector as a percentage of the GDP in the US, together with its two-yearly growth rate. The historical time series are plotted starting five years before and ending five years after the peak. The data are from the Bank for International Settlements (BIS, 2017). This bubble was surfing and taking advantage of the tailwind caused by the long-term growth in credit from $40 \%$ in 1993 up to $60 \%$ early 2008 leading up to the most recent credit crisis. However, this bubble is not intimately connected with this process of credit growth, so, it will be classified as non-leveraged.

We identify the stock market bubble, ending in the July 1998 crash, as a fearless, non-leveraged bubble, the former meaning that there was no rise in volatility during the bubble period leading up to the crash, the latter meaning that the bubble was not specifically caused by a rise in credit, or leverage, in the economic system.

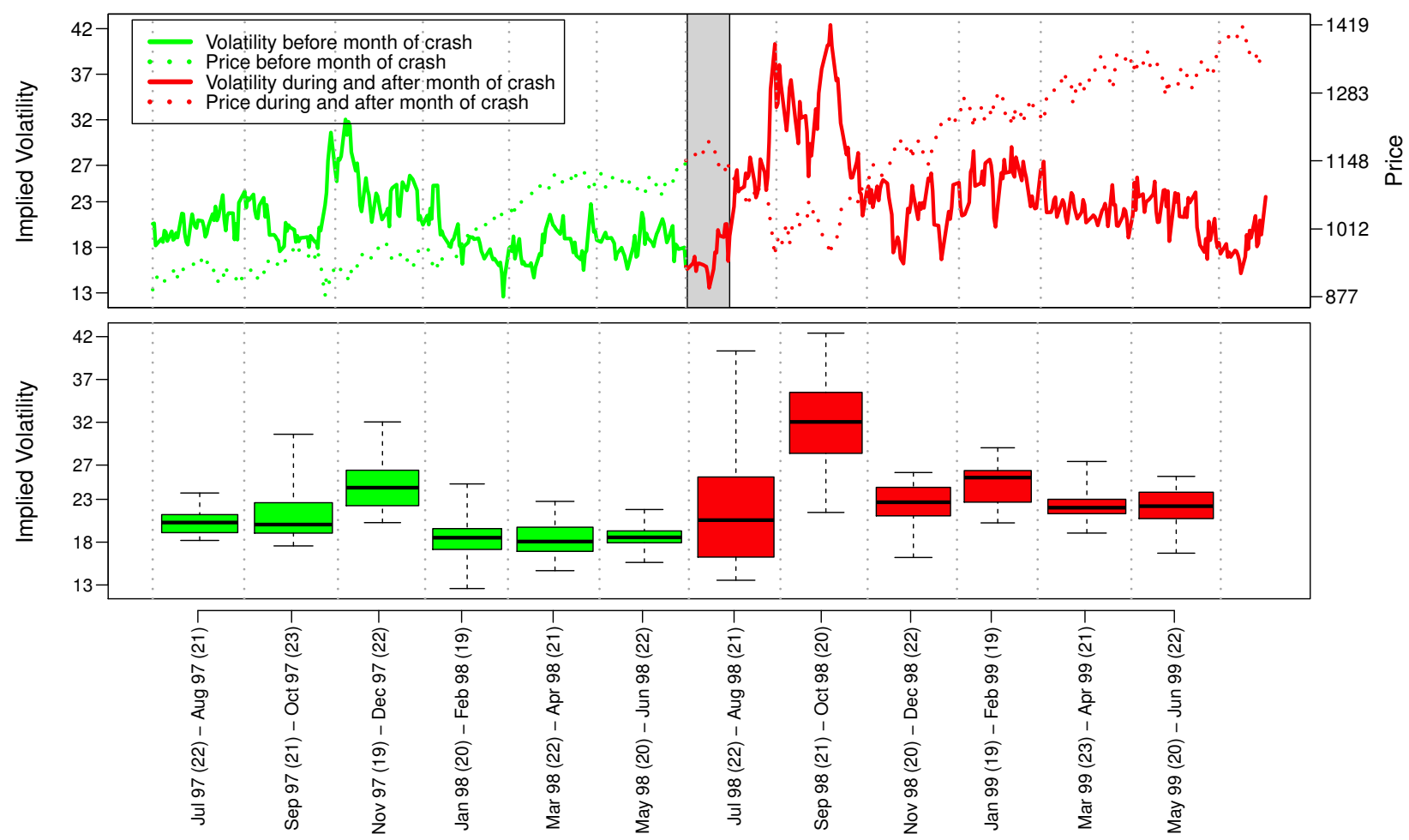

Figure 7. The US stock market bubble ending in August 1998: price and implied volatility of the S\&P 500 index (see section 4 for a detailed methodological explanation). 


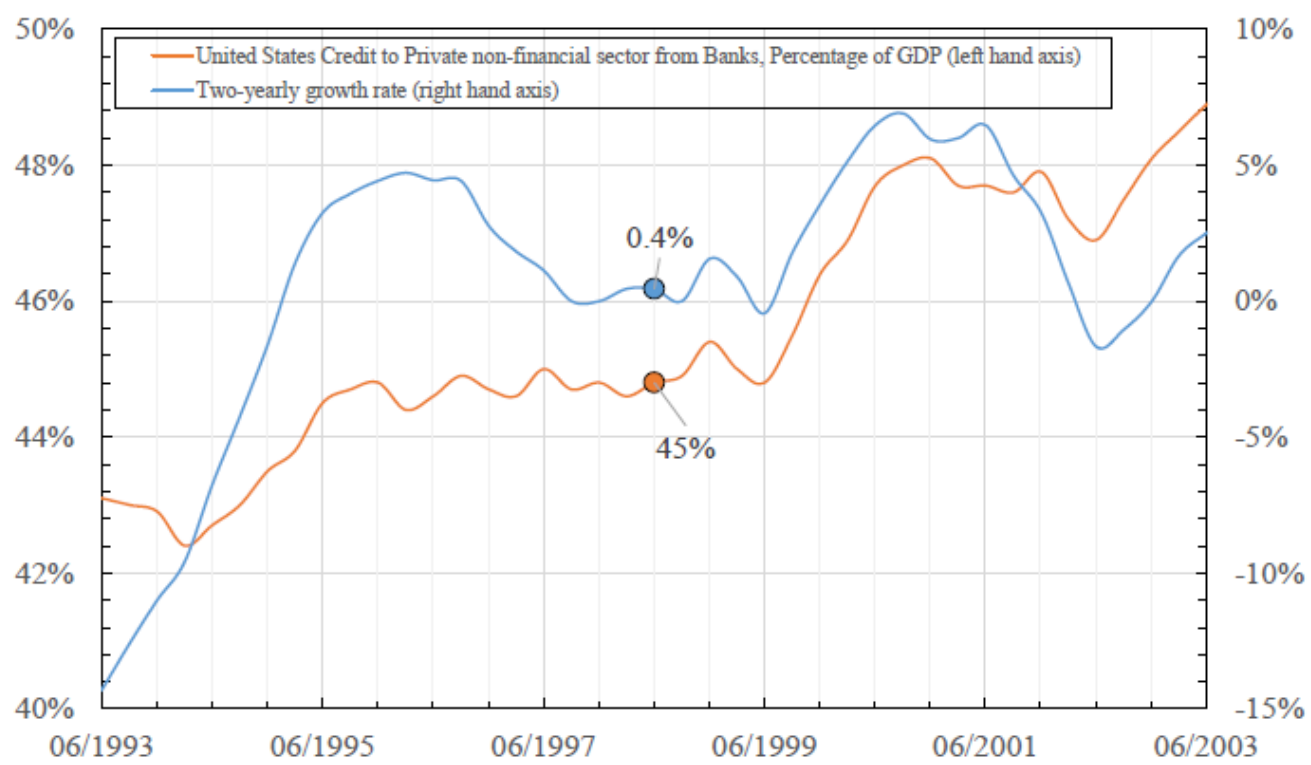

Figure 8. The credit conditions in the United States between 1993 and 2003, five years before and after the bubble ending in July 1998. The two filled circles are the last observations from the data source (BIS, 2017) before the peak and the subsequent crash.

\subsection{US Dotcom bubble ending in March 2000}

The so-called Dotcom or internet bubble is often regarded as the archetype of a bubble (Phillips et al., 2011; Homm and Breitung, 2012) because of the large divergence that was seen in the years leading up to the crash, in the price appreciation between the internet stocks and the broad market (Johansen and Sornette, 2000) ${ }^{\S}$. Over these two years, the internet-related stocks realized a return of over $1300 \%$ compared to $40 \%$ for non-internet stocks. Over the whole year of 1998, the return of the internet stock index (the NASDAQ) was $117 \%$, while for non-internet stocks, this was $6.5 \%$. Over 1999 , the return of the internet stock index surged to $816 \%$, while for non-internet stocks, this number was 16.6\% (Kaizoji et al., 2015). By March 2001, one year after the bubble ended, the cumulative sum of these astronomical returns for internet stocks had completely evaporated.

The upper panel of figure 9 shows the 20-day historical volatility of the NASDAQ Composite index before (green) and after (red) its peak on March 10, 2000, preceding the crash in April, together with the price level of the index. The grey area represents the one month period around the peak. One can observe that the volatility went through a dynamical pattern. The crash of August 1998 that was discussed in the previous section 6.4 lifted volatility to a generally higher level in all markets, including the NASDAQ. It remained high for several months before starting to decline from May 1999 to December 1999 (this can be seen in the top panel and in the box plot in figure 9). What is really interesting to see is the short-term jump in volatility from the end of 1999 until mid-February 2000. This coincides with two subsequent small corrections in the market. These suggest that markets were tense and that traders were aware of the bubble and the corresponding risk of a large correction.

\footnotetext{
${ }^{\S}$ see also the book (Sornette, 2017) (pp. 269-275)
} 
After this incident, markets regained traction, prices uplifted and volatility quickly dropped back to its previous lower levels. The box plot clearly shows that the volatility rose sharply and remained elevated and highly volatile itself over the whole year after the crash and beyond as a result of the bear market that hit US stocks until bottoming out in October 2002 (Sornette and zhou, 2002; Zhou and Sornette, 2003).
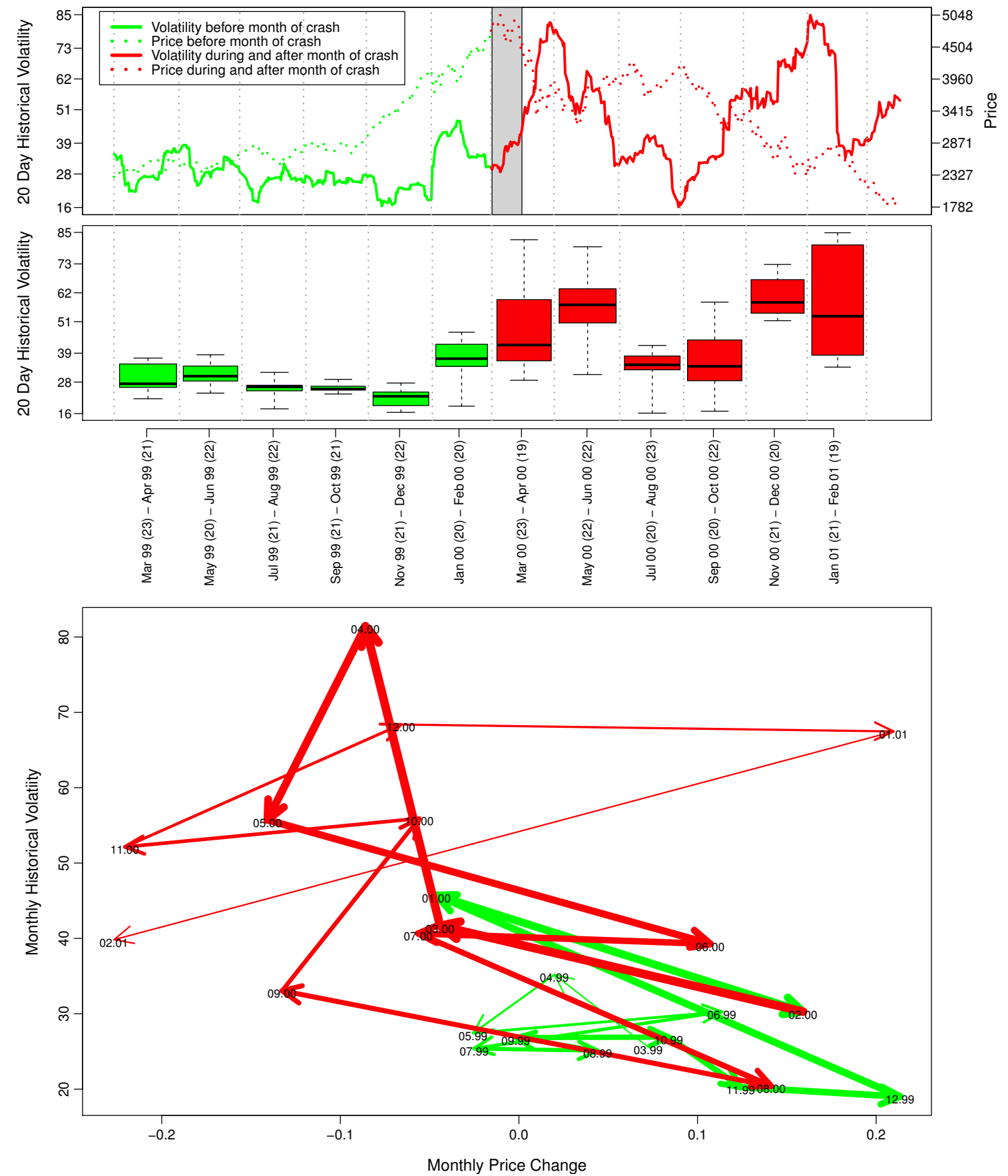

Figure 9. The Dotcom bubble ending in March 2000: price and historical volatility of the NASDAQ index (see section 4 for a detailed methodological explanation). 
The bottom arrow graph of figure 9 paints a similar picture. Some extreme movements in volatility can be observed before the crash. Hence, we will classify the Dotcom bubble as fearful.

To understand the credit conditions prior and after this crash, figure 10 shows that, in exactly the same manner as the July 1998 crash, the Dotcom bubble had been surfing and taking advantage of the tailwind caused by the long-term growth in credit from 40\% in 1993 up to $60 \%$ early 2008 leading up to the most recent credit crisis. However, it was not intrinsically connected with this process of credit growth, so it will be classified as non-leveraged.

We identify the Dotcom bubble as a fearful, non-leveraged bubble, the former meaning that there were spikes of volatility during the bubble period leading up to the crash, suggesting a sense of fear in the market, an awareness of the imminent crash risk, the latter meaning that the bubble was not specifically caused by a rise in credit, or leverage, in the economic system.

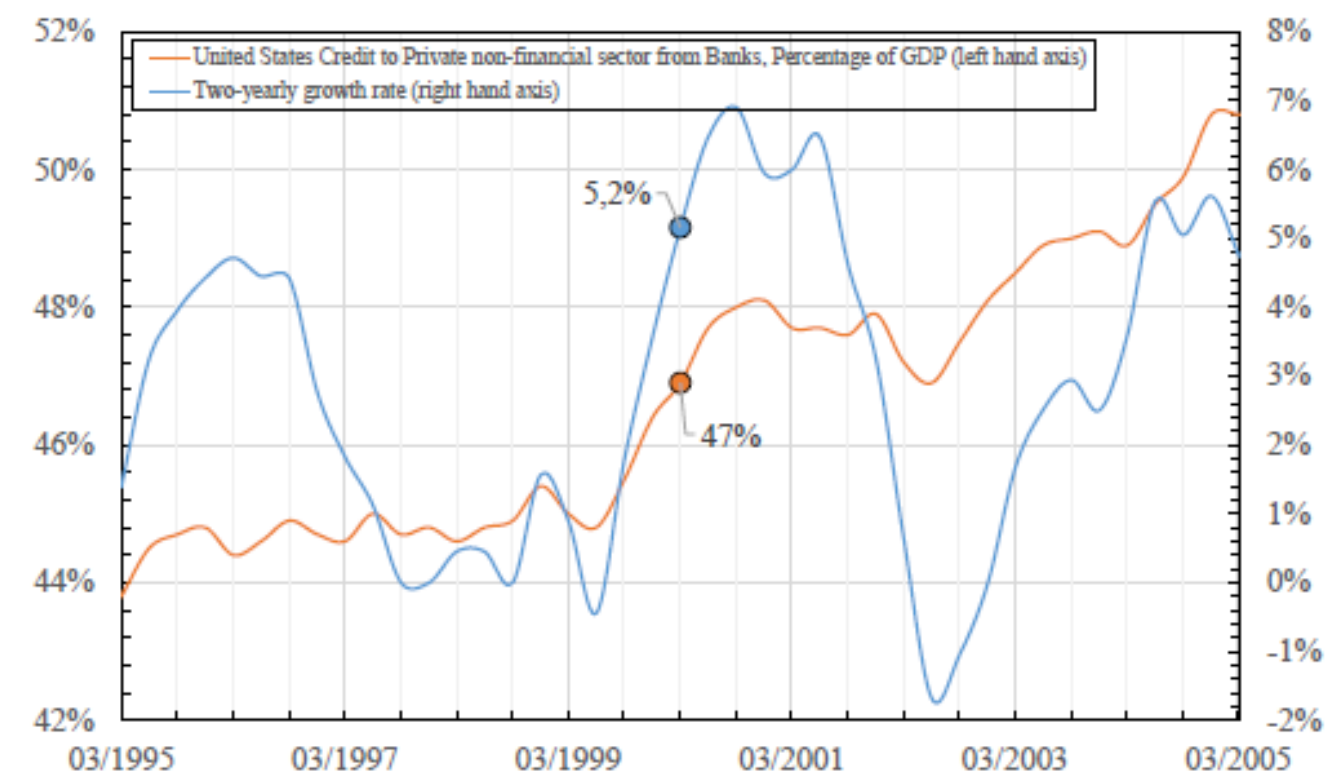

Figure 10. The credit conditions in the United States between 1995 and 2005, five years before and after the Dotcom bubble burst. The two filled circles are the last observations from the data source (BIS, 2017) before the peak and the subsequent crash in March 2000.

\subsection{US stock market bubble ending in October 2007}

It is generally accepted that the global crash, at the end of 2007, was triggered, in some way, by a correction in the housing market after its peak around mid 2006. As house prices started to level off, wealth extraction, associated with mortgage renegotiations and purchases made for pure capital gains, began to stall. As a consequence, a growing number of home-owners found themselves owing more on their mortgages than their houses were worth. Consequently, the rate of defaults and foreclosures sky-rocketed, especially in the sub-prime segment, with the particularly loose underwriting standards that had previously led to its disproportional growth. Additionally, the previous years had seen a wave of financial innovations. New structured credit products, like CDO's (Collateralised Debt Obligations) and MBS's (Mortgage-Backed Securities), were developed. Because many of these products were 
insured against losses by AIG, the international insurance and financial services company acted as an infection channel through which the decline in house prices infected the global financial system, leading to the potential systemic risk of a global financial meltdown (Sornette and Cauwels, 2015).

Sornette and Cauwels argue that, however complicated this explanation may be, it is still quite superficial. In a 2014 paper (Sornette and Cauwels, 2014), the authors point to a much deeper mechanism explaining that the bubble, preceding the 2007-2008 crash and the Great Recession following it, was rooted in what they call "the illusion of the perpetual money machine". According to the authors, increasing debt, skewed incentive structures, ever-increasing consumption at the cost of savings, financial deregulation and innovation, loose monetary standards ... all made the financial system more prone to bubbles and crashes. They explain how one bubble fed upon another until the climax of 2007, which brought the financial system close to collapse (Sornette and Cauwels, 2014).

The upper panel of figure 11 shows the 20-day historical volatility of the S\&P 500 index before (green) and after (red) it peaked in September 2007. The grey area represents the one month period around the peak. A first spike in volatility can be seen from February to March 2007. At that time, the first losses on sub-prime related mortgage-backed securities were reported. Somehow, the financial markets managed to delude themselves into thinking that the risks were only ephemeral, so the volatility relaxed quickly back to its prior lower levels. This was only quite temporary and we can see it gradually picking up again from May to August 2007. This observation is clearly confirmed by the box plot on the lower panel of the figure 11 and by the evolution of the implied volatility in figure 12 . It is interesting to see the volatility shooting up around the bankruptcy of the Lehman Brothers Holdings and the bailout of AIG mid-September 2008.

The bottom arrow graph of figure 11 reveals a similar dynamic. Some extreme movements in volatility can be observed before the crash. Hence, we will classify this bubble as fearful.

Regarding the credit situation prior and after this crash, figure 13 shows that the conditions that led to the October 2007 crash are surprisingly similar to the ones that led to the October $1987 \mathrm{crash}$. In 1987, there had been a long-term trend of credit growth from 30\% of GDP in 1967, twenty years before the crash, up to around 60\% of GDP in 1987. After a period of deleveraging between 1987 and 1993 from the $60 \%$ to the $40 \%$ level, a new wave can be observed bringing credit levels of the private sector back to around $60 \%$ of GDP right before the 2007 crisis.

We will classify this bubble, leading to the sub-prime crisis, as a fearful, leveraged bubble. The former means that there was increased volatility during the time of the bubble before the crash, suggesting a sense of fear in the market, an awareness of the imminent crash risk. The latter means that the bubble can be connected to a rise in credit, or leverage, in the economic system.

\subsection{IBM stock bubble ending in July 1999}

The Internet bubble, discussed in the previous section 6.5, was accompanied by its own suite of bubbles, developing on individual stocks, some of them bursting earlier than the general Dotcom market. An example is IBM that reached its peak around \$138, at a price-to-earnings ratio of more than 30 on July 13, 1999, a level that would be attained again only ten years later in October 2010. On November 5, 1999, after a loss of more than $34 \%$, the listed stock price was $\$ 90$. A detailed analysis of the bubble and the subsequent crash in the IBM stock can be found in (Sornette, 2000; Johansen and Sornette, 2000) and in the book (Sornette, 2017).

The upper panel of figure 14 shows the 20-day historical volatility of the IBM share price before 

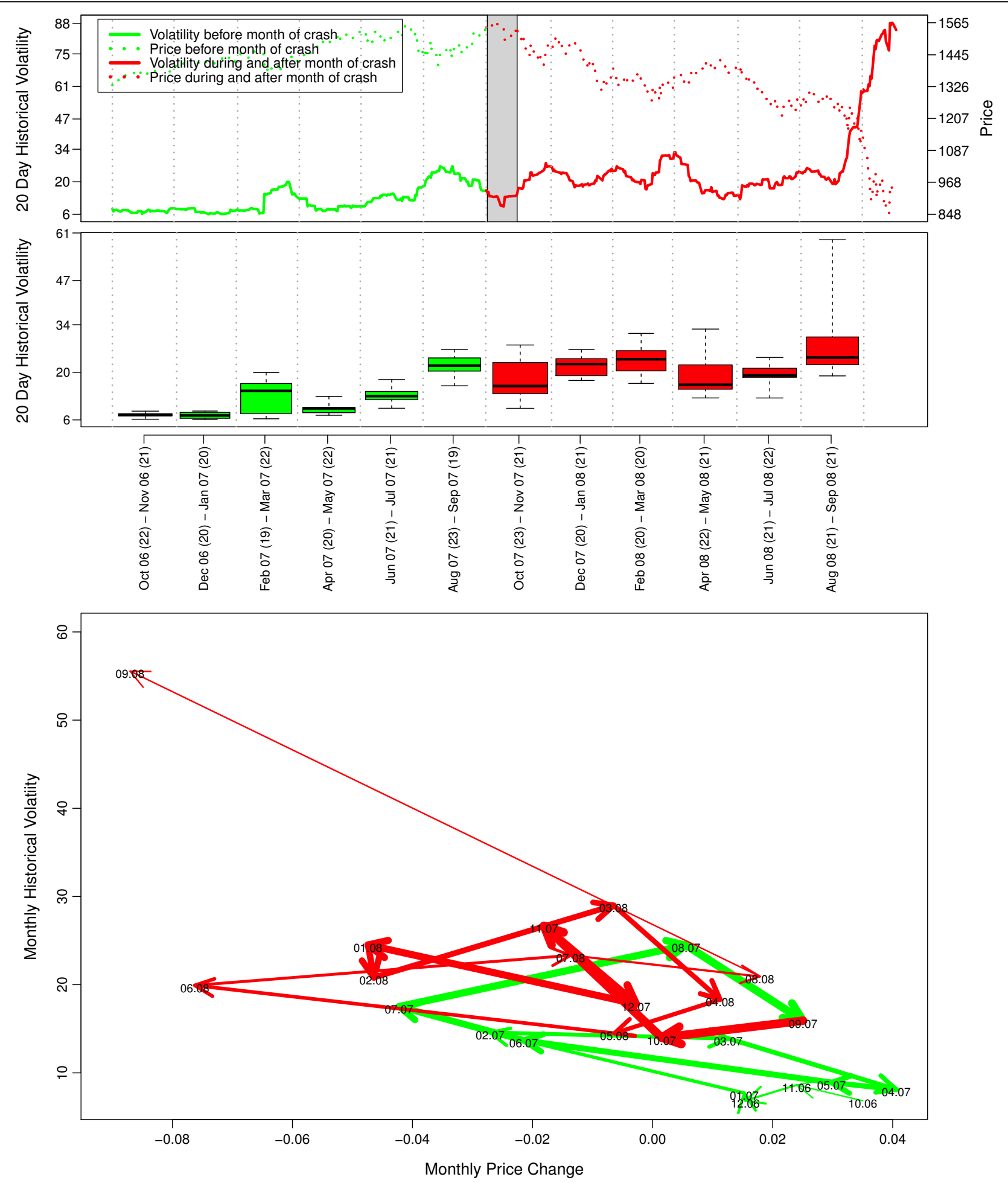

Figure 11. The housing bubble ending in the sub-prime crisis of October 2007: price and historical volatility of the S\&P 500 index (see section 4 for a detailed methodological explanation). 


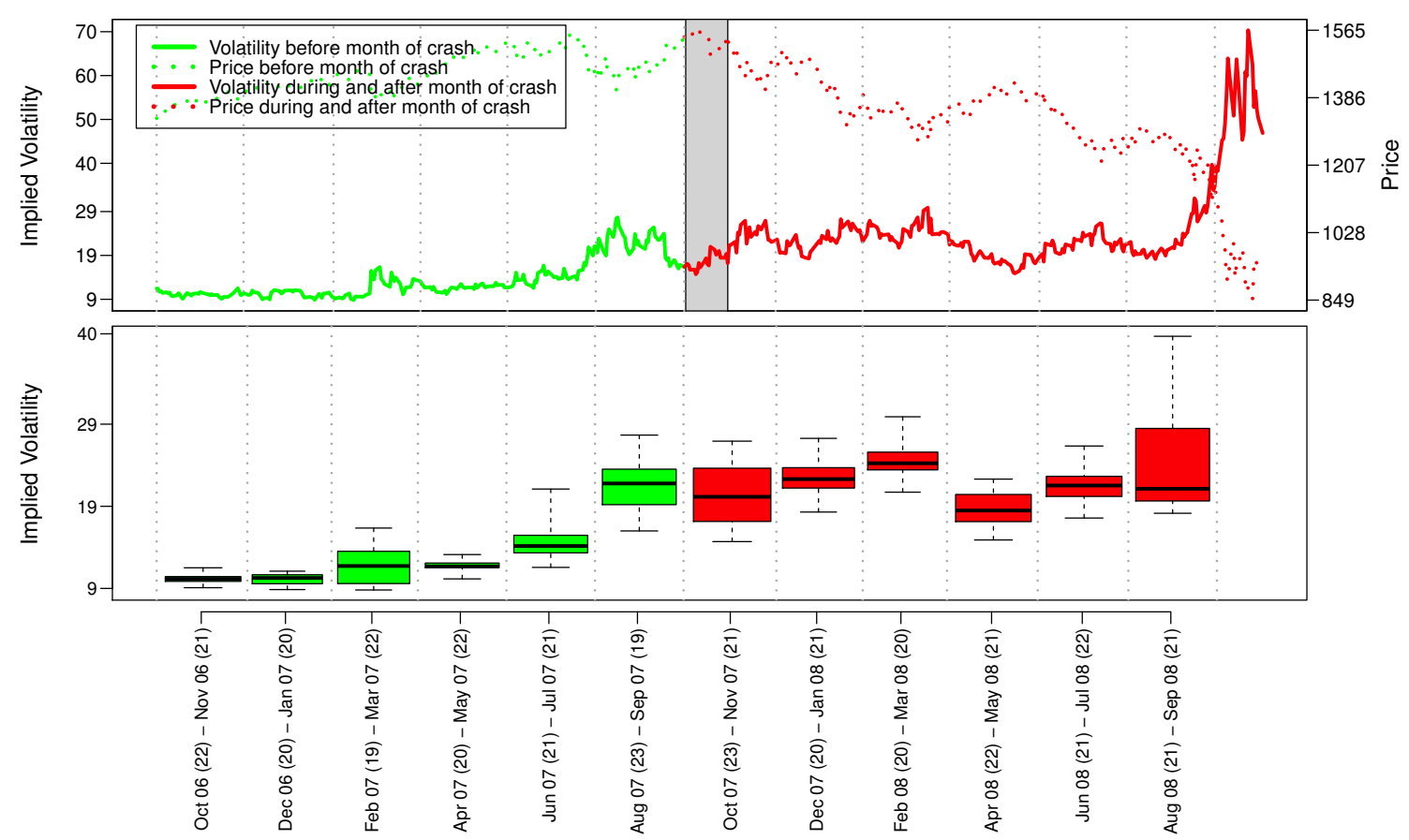

Figure 12. The housing bubble ending in the sub-prime crisis of October 2007: price and implied volatility of the S\&P 500 index (see section 4 for a detailed methodological explanation).

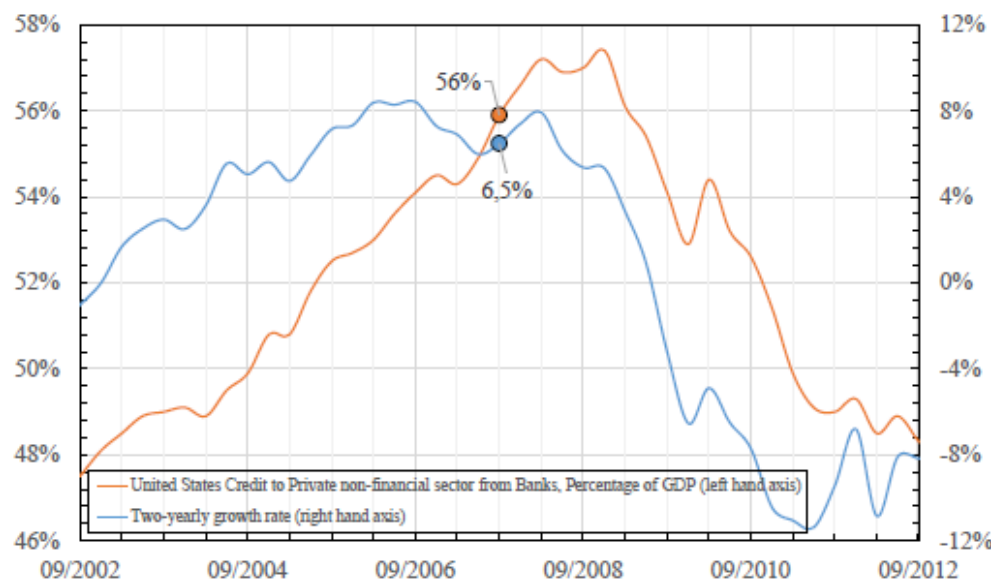

Figure 13. The credit conditions in the United States between 2002 and 2012, five years before and after the 2007 sub-prime crisis. The two filled circles are the last observations from the data source (BIS, 2017) before the peak and the subsequent crash in October 2007.

(green) and after (red) it peaked in July 1999. The grey area represents the one month period around the peak. In the year before the crash, three large bursts can be seen in the historical volatility, each corresponding to a short-lived correction in the stock price. A closer look beyond those spikes clearly shows the leverage effect at work (Figlewski and Wang, 2000; Bouchaud et al., 2001); the historical 

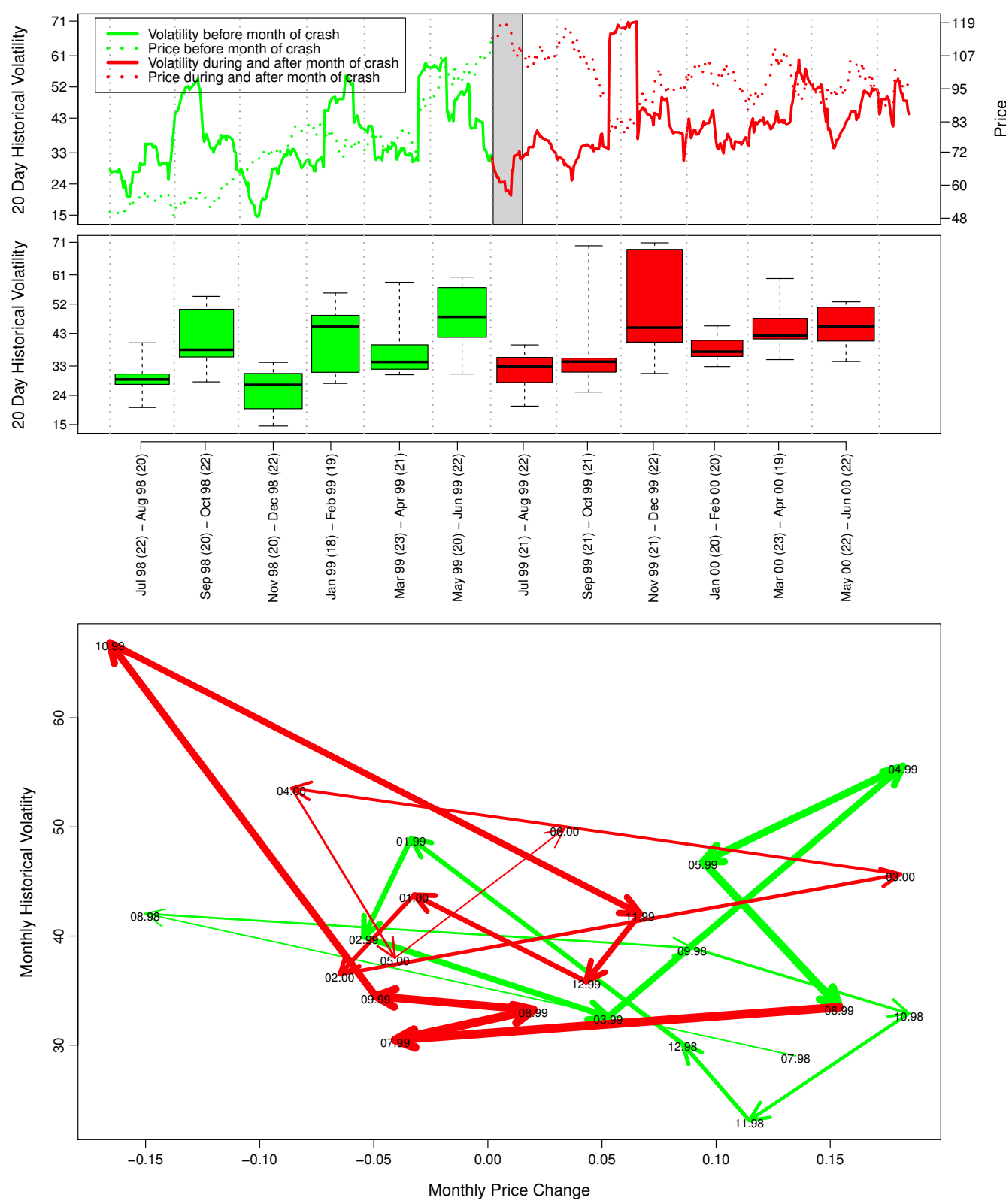

Figure 14. The bubble in the IBM stock ending in July 1999: price and historical volatility (see section 4 for a detailed methodological explanation).

volatility is the lowest at the peak of the stock price (in the middle of the grey shaded area of the figure 14), and, a few months later, the peak of this volatility coincides with the trough in the stock price around November 1999. The arrow graph in the bottom panel of figure 14, and the implied volatility in figure 15, also confirm the absence of any precursory signals.

We will classify this bubble as fearless. True, some spikes can be seen in the historical volatility in the year before the crash, but, these can all be linked to periods of short-term corrections. Right before and during the crash itself, we can clearly see the leverage effect at work in the historical volatility. The implied volatility shows no increased fear whatsoever. 


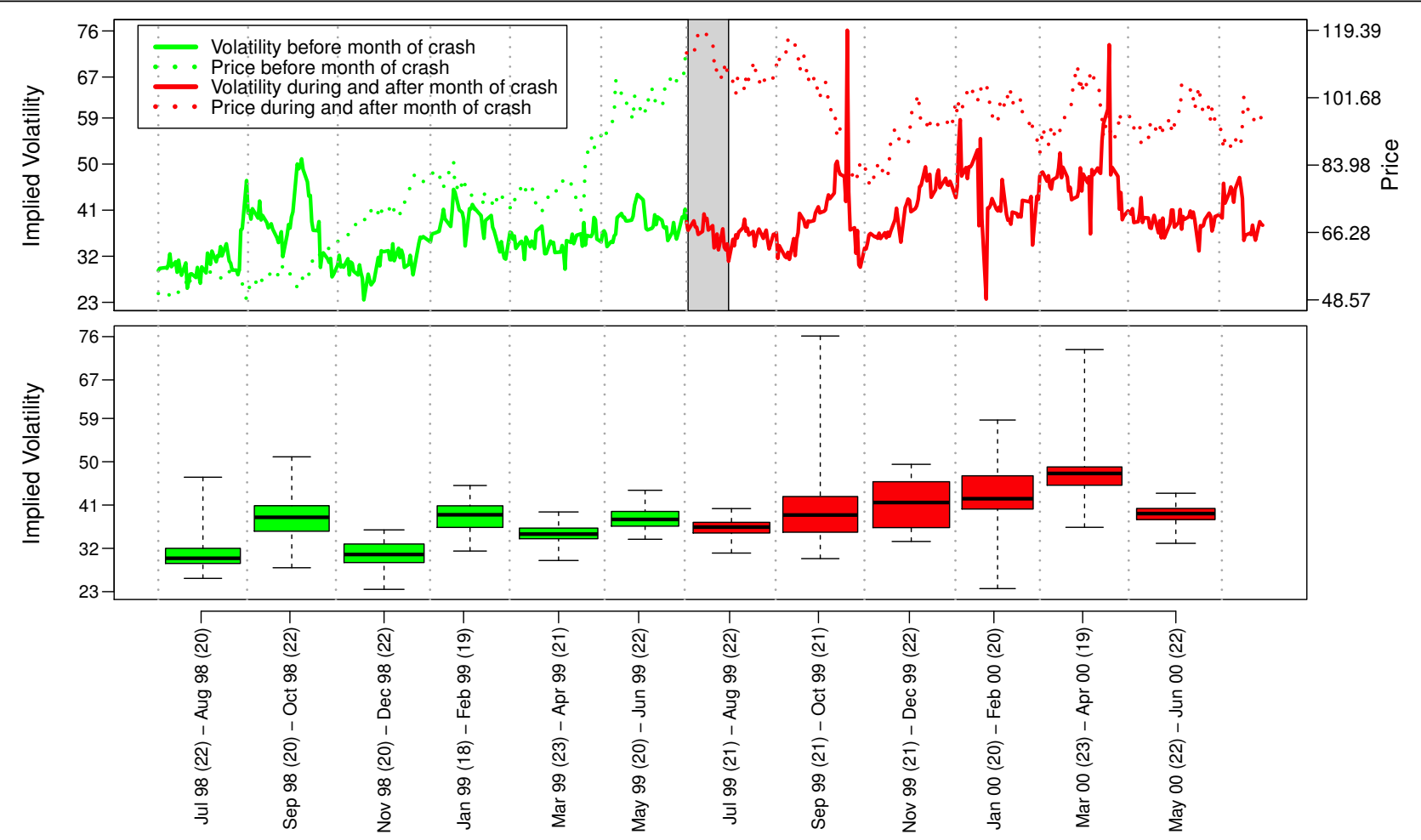

Figure 15. The bubble in the IBM stock ending in July 1999: price and implied volatility (see section 4 for a detailed methodological explanation).

\subsection{Procter $\mathcal{E}$ Gamble stock bubble ending in January 2000}

Half a year after the crash in IBM shares, a similar pattern was seen in the P\&G stock price, which reached a peak around $\$ 118$ on January 11,2000 , followed by a very strong correction in two waves. First a $26 \%$ continuous decline could be seen, with the share price dropping to a short-lived plateau. This was followed by a one-day-crash on March 7, 2000, corresponding to a single-day loss of 30\%, bringing the stock to its lowest level since April 1997. Ex-post, it was explained that this event had been triggered by a negative profit warning of $P \& G$ that sent its stock and the whole fast moving consumer goods sector in the United States and overseas plummeting, catching analysts and investors off guard. This $30 \%$ one day drop corresponded to a loss in market capitalization of about $\$ 22$ billion.

The upper panel of figure 16 shows the 20-day historical volatility of the $\mathrm{P} \& \mathrm{G}$ share price before (green) and after (red) its peak. The grey area represents the one month period around the peak. The same type of analysis, based on the implied volatility can be found in figure 17 . We can be brief. No increase in the volatility can be observed. Both the historical and the implied volatility were flat right up to the point of the crash. This is also quite clear from the arrows graph in the lower panel of figure 16. All the green arrows nicely cluster around the same volatility level only to go astray when the red arrows appear, that is after the crash. We identify this bubble as fearless.

\subsection{UK stock market bubble ending in October 1987}

It is generally accepted that the October 1987 crash in the UK was part of a worldwide phenomenon (as was discussed in section 6.3 for the US). As a case in point, the American 

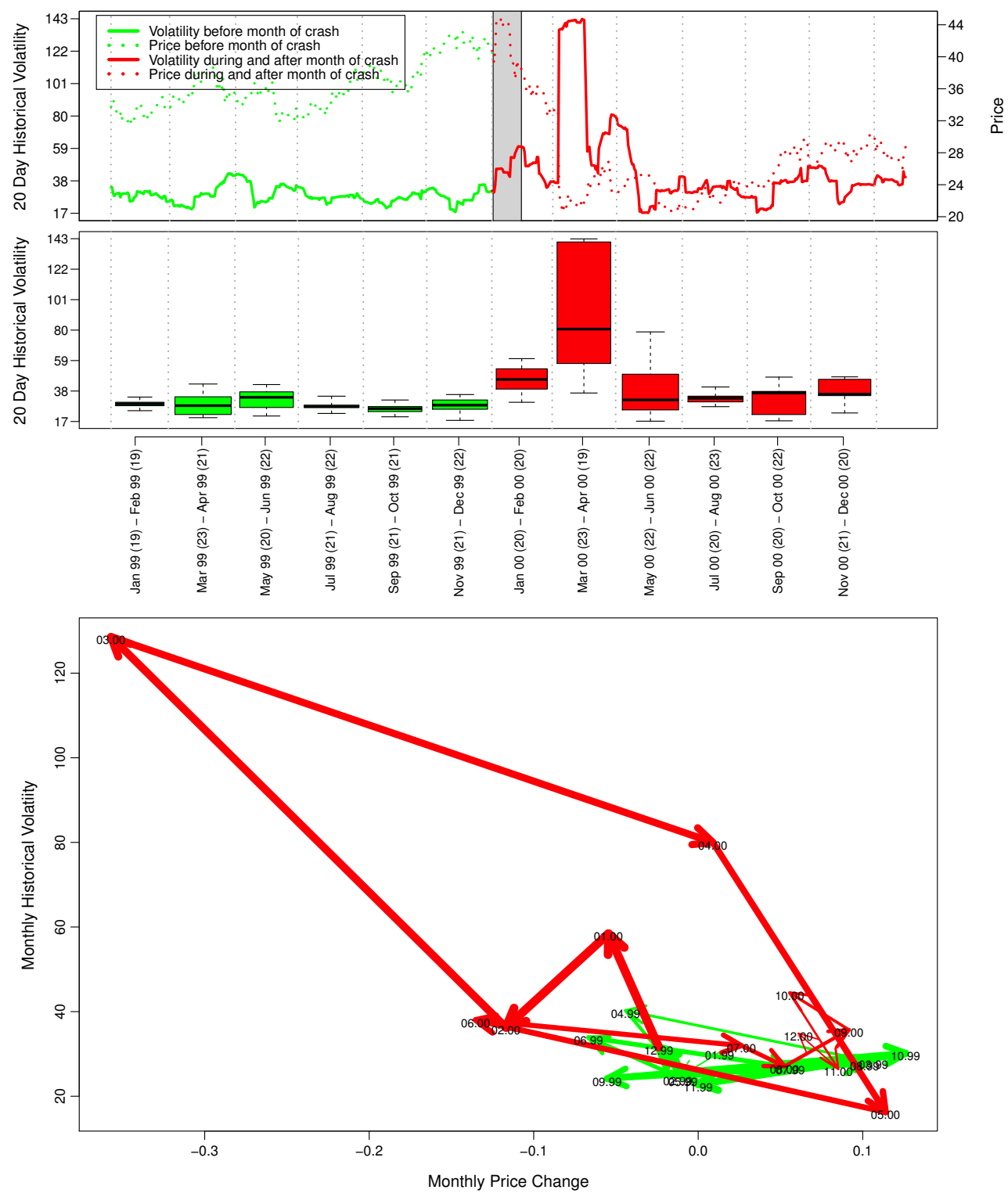

Figure 16. The bubble in the Procter \& Gamble stock ending in January 2000: price and historical volatility (see section 4 for a detailed methodological explanation).

presidential committee that was formed to analyse the event, quite self-referentially, concluded that the most statistically significant explanatory variable in the crash was the response of each country's stock market to a worldwide market movement (Barro et al., 1989). In section 6.3, the case for the US was discussed, and the bubble leading up to the crash was classified as fearless and leveraged.

In a study carried out by Malliaris et al. in 1992 (Malliaris and Urrutia, 1992) using unidirectional and bidirectional causality tests, based on the Granger methodology, no significant lead-lag relationships between the US S\&P 500 and the UK FTSE index could be found for the pre-crash and post-crash periods. Significant feedback relationships with unidirectional as well as contemporaneous causality were only detected for the month of the crash itself. Because of the lack of a statistically significant causality between the UK and the US bubbles, we will treat both as separate cases in the 


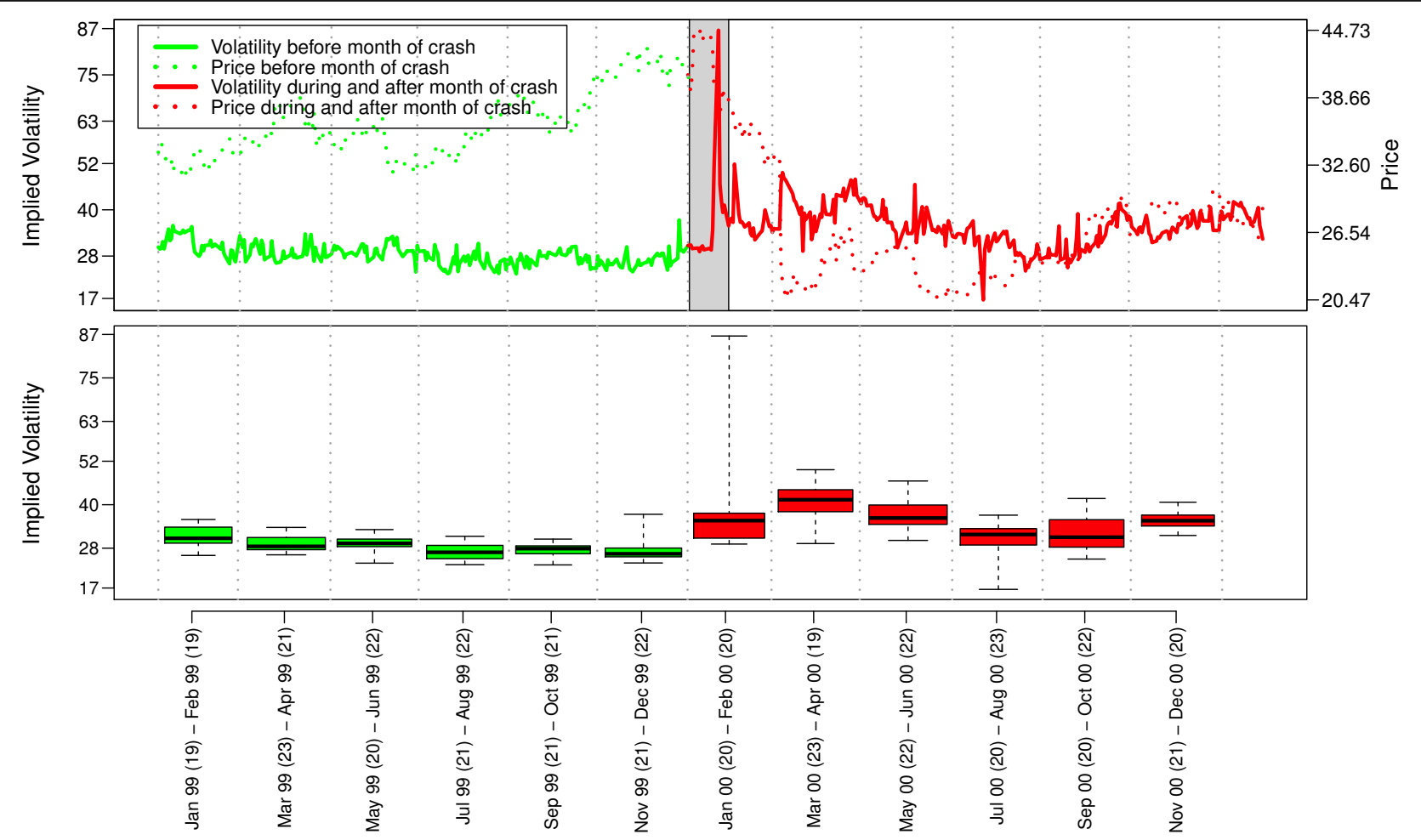

Figure 17. The bubble in the Procter \& Gamble stock ending in January 2000: price and implied volatility (see section 4 for a detailed methodological explanation).

current study.

The upper panel of figure 18 shows the 20-day historical volatility of the FTSE 100 index before (green) and after (red) it peaked in October 1987. The grey area represents the one month period after the peak. In line with observations in the US, studied in section 6.3, the volatility remains remarkably stable and low from December 1986 up to September 1987. The arrow graph in the bottom panel of figure 18 based on the historical volatility clearly confirms a total absence of any precursory signals in the volatility during the bubble period before the crash.

Figure 19 shows the credit from banks to the private non-financial sector as a percentage of the GDP of the UK, together with its two-yearly growth rate. The historical time series are plotted starting five years before and ending five years after the peak of the FTSE 100 index. The data are from the Bank for International Settlements (BIS, 2017). One can observe that credit was expanding at a strong growth rate at the time of the crash, and continued for another two years thereafter before starting to drop in 1990. This data suggests that the credit conditions were neither drivers of the bubble, nor of the crash.

We identify this UK stock market bubble, ending in the October 1987 crash, as a fearless, nonleveraged bubble, the former meaning that there was no rise in volatility during the bubble period leading up to the crash, the latter meaning that the bubble was not specifically caused by a rise in credit, or leverage, in the UK economy. 

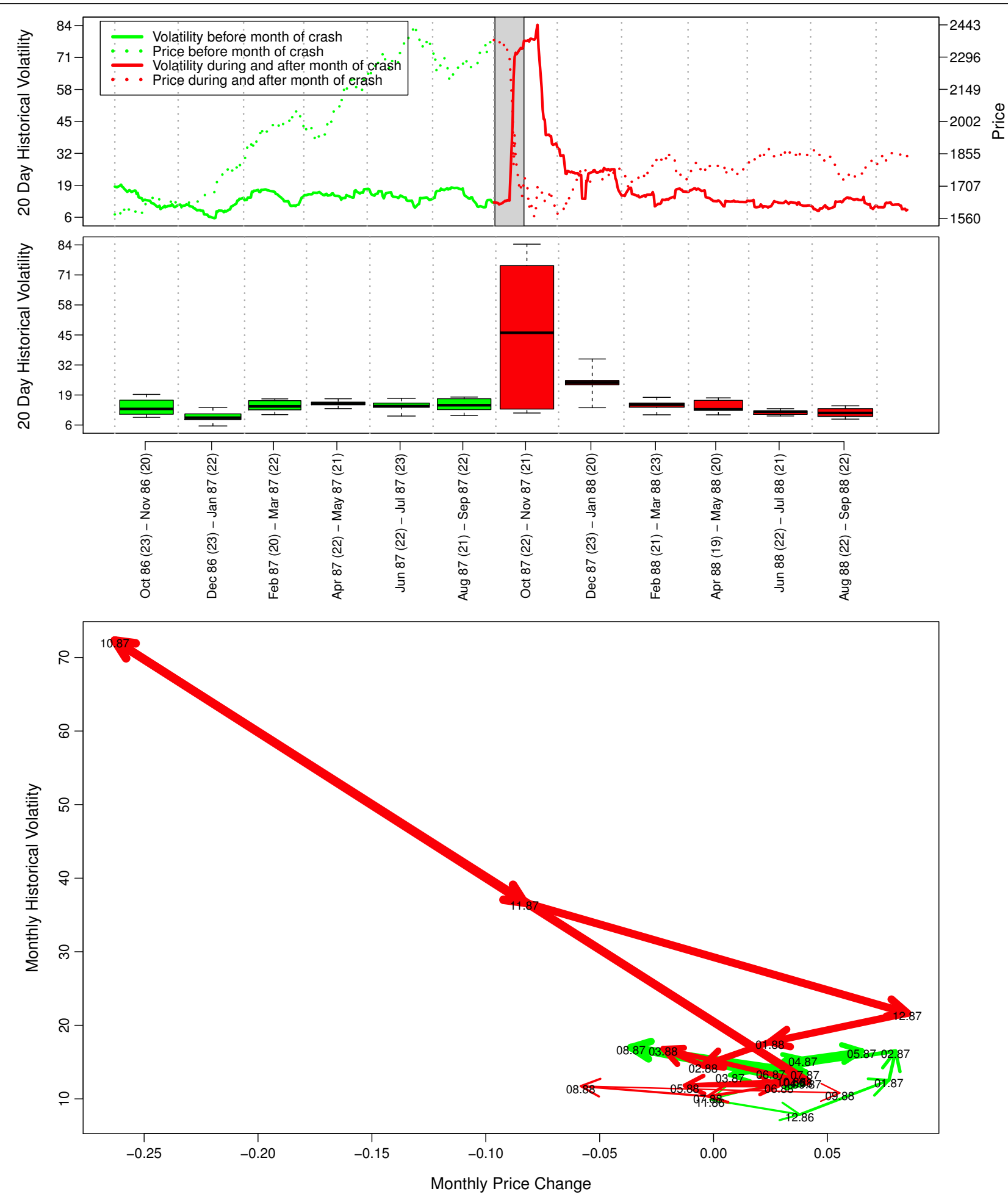

Figure 18. The UK stock market bubble ending in October 1987: price and historical volatility of the FTSE 100 index (see section 4 for a detailed methodological explanation). 


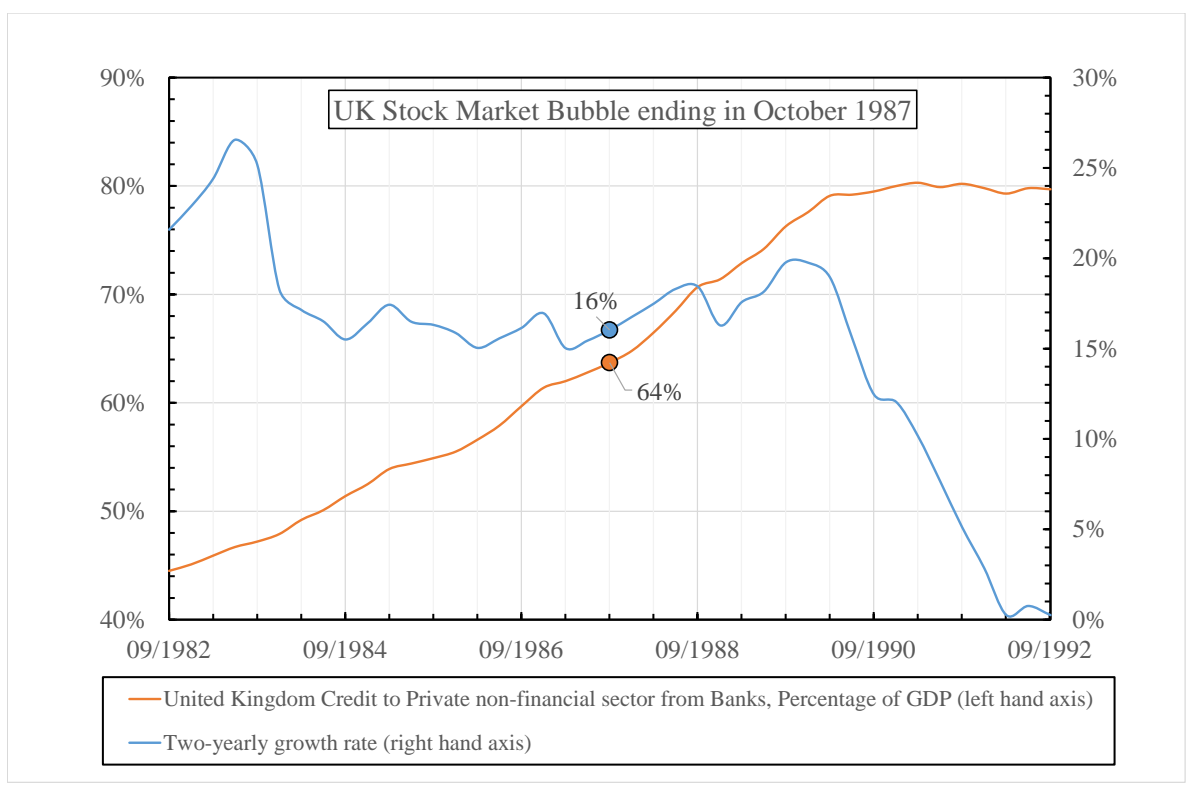

Figure 19. The credit conditions in the UK between 1982 and 1992, five years before and after the bubble ending in October 1987. The two filled circles are the last observations from the data source (BIS, 2017) before the peak and the subsequent crash.

\subsection{UK stock market bubble ending in October 1997}

In October 27, 1997, a worldwide so-called "mini" stock market crash caused by an economic crisis in Asia, systemically affected global markets. The crash started overnight in Asia as Hong Kong's Hang Seng index fell 6\%. The losses spread throughout the European markets with London's FTSE 100 index falling 99 points, about $2 \%$ for that day, the full picture of which can be seen in the figure below. When the US market opened, contagion continued, and the US Dow Jones Industrial Average index faced a daily loss of 554 points or 7.2\%; an event that ranks as the eighth biggest point loss and 15th largest percentage loss since the index' creation in 1896. On two occasions that day, the New York Stock Exchange briefly suspended trading as "circuit breakers" kicked in. In the UK, the total drawdown related to that event was a $11.6 \%$ loss from the close-price peak of 5331 on October 3, 1997 to the close-price bottom of 4711 on November 13, 1997. The full development of this drawdown can be seen in the grey band of figure 20 .

The upper panel of figure 20 shows the 20-day historical volatility of the FTSE 100 index before (green) and after (red) it peaked in October 3, 1997. Here, one can clearly observe an increasing volatility starting from at least half a year before the crash. This was caused by the Asian financial crisis, which started in the first half of 1997 . The first signs of the imminent collapse were the massive speculative attacks against the Thai Baht on May 14 and 15. These attacks marked the end of a remarkable economic growth the decade before, during which Thailand's economy grew at an average rate of over $9 \%$ per year. However, this had been a debt-fuelled growth that left Thailand with an 

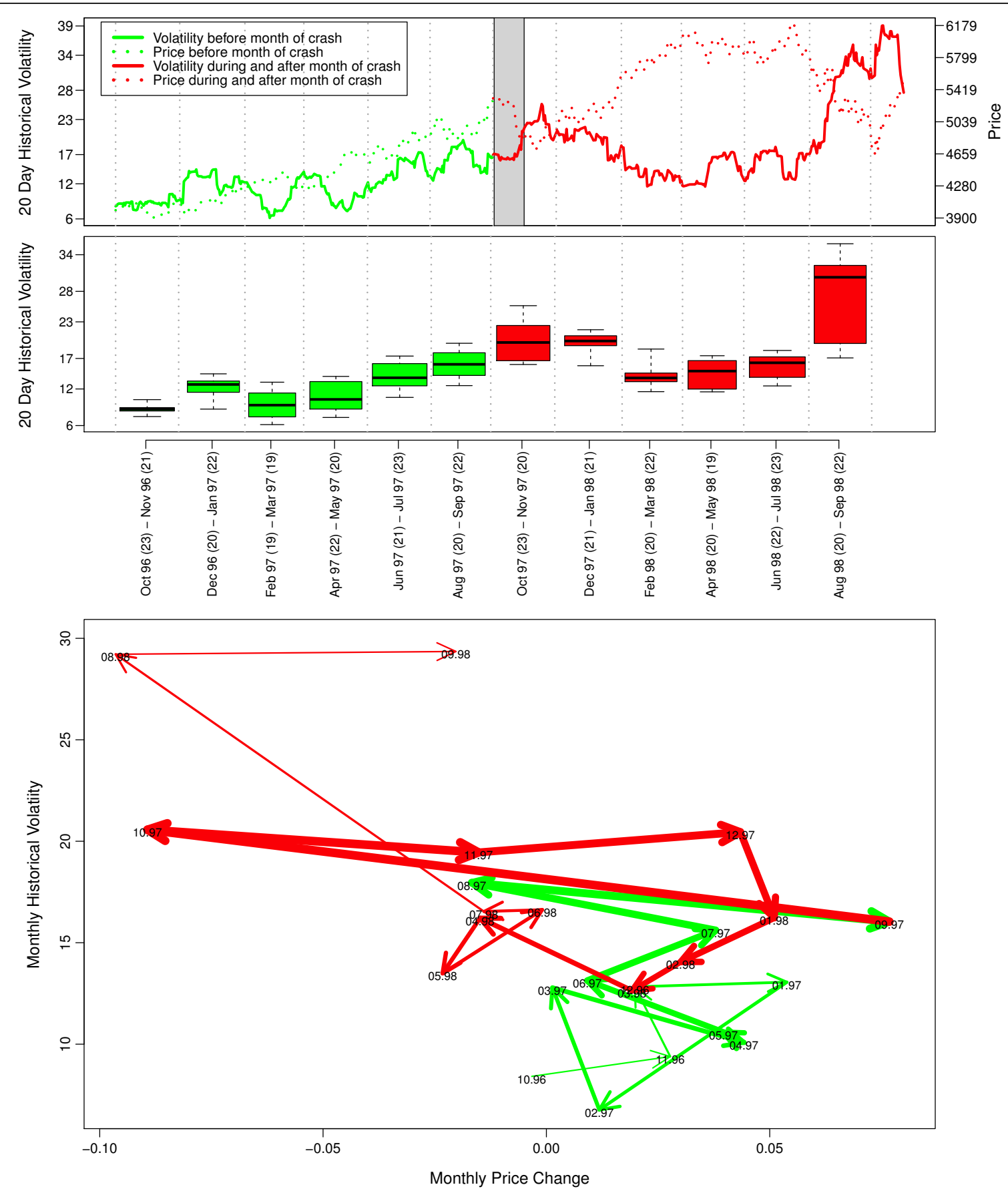

Figure 20. The UK stock market bubble ending in October 1997: price and historical volatility of the FTSE 100 index (see section 4 for a detailed methodological explanation).

unbearably large foreign debt which made any further economic development unsustainable (Johansen and Sornette, 2001). The result was foreign capital flight. The final collapse had systemic proportions as it spread throughout Indonesia, South Korea, The Philippines, Hong Kong, Malaysia and Singapore.

The arrow-plot in the bottom panel of figure 20 confirms this observation and shows that the volatility had grown during the build-up phase of the bubble. After the "mini-crash", the volatility 
decreased but did not reach the pre-crisis low as the 1997 Asian crisis was soon followed by the 1998 Russian crisis (see section 6.4 for a detailed discussion).

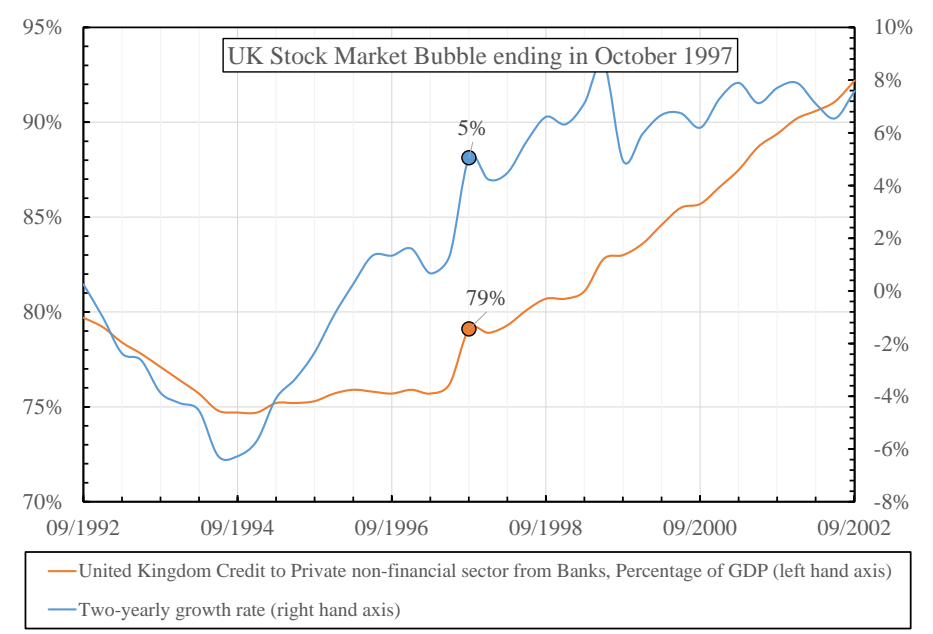

Figure 21. The credit conditions in the UK between 1992 and 1997, five years before and after the bubble ending in October 1997. The two filled circles are the last observations from the data source (BIS, 2017) before the peak and the subsequent crash.

To understand the credit conditions during and after this period of boom and bust, figure 21 shows the credit from banks to the private non-financial sector as a percentage of the GDP of the UK, together with its two-yearly growth rate. The historical time series are plotted starting five years before and ending five years after the peak of the FTSE 100 index in October 1997. The data are from the Bank for International Settlements (BIS, 2017). It is interesting to see that both the credit as a percentage of the GDP and its growth rate peak around the time of the crash. The crash occurred after a very strong acceleration of credit creation. As mentioned above, the "mini-crash" was more a contagion effect from the crisis of over-leveraged Eastern Asian countries. The exposition of the UK market can be understood from its deep geopolitical and economic connections with the region over the previous century, exemplified by the historical handover of Hong Kong from the United Kingdom to China on July 1st, 1997, as the crisis was progressively engulfing the East Asian countries. However, the peak in credit was soon overtaken by a renewed sustained growth dynamics.

We will classify the stock market bubble, ending in the October 1997 crash, as a fearful, leveraged bubble, the former meaning that there was a significant rise in volatility during the bubble period leading up to the crash, the latter meaning that the bubble was clearly linked with a sudden extremely rapid rise in credit, or leverage, in the UK economy. 


\subsection{UK stock market bubble ending in July 1998}

From its top, on July 20, 1998 at the close-price of 6179, to its bottom on October 5, 1998 at the close-price of 4649, the FTSE 100 index lost 24.8\%. As mentioned for the US market in section 6.4, this crash is widely attributed to the plunge of the Russian financial markets, the subsequent devaluation of the Rouble and the default of the Russian government on its internal debt. Johansen and Sornette (2010) have argued however that there were deeper endogenous causes for the crash, stemming from the exuberance of western markets reflected in unsustainable, super-exponential price growth, which is one of the most visible hallmarks of a bubble (Johansen and Sornette, 1999; Sornette, 2017; Hüsler et al., 2013; Leiss et al., 2015; Sornette and Cauwels, 2015). In this interpretation, the Russian crisis was part of a global bubble.
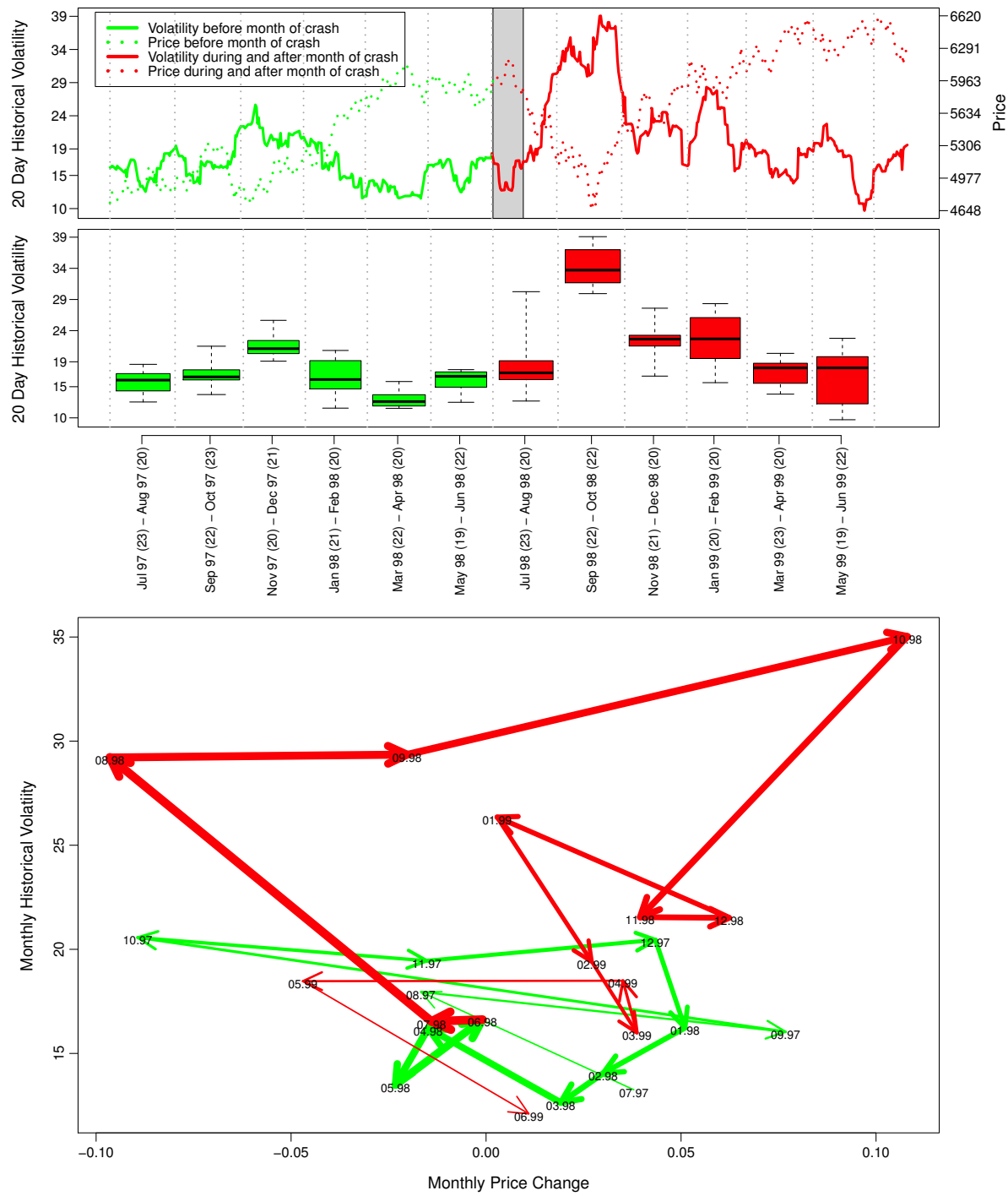

Figure 22. The UK stock market bubble ending in July 1998: price and historical volatility of the FTSE 100 index (see section 4 for a detailed methodological explanation).

The upper panel of figure 22 shows the 20-day historical volatility of the FTSE 100 index before 
(green) and after (red) the peak in July 1998. The grey area represents the one month period around the peak. Both prices as well as volatilities of the FTSE 100 and the S\&P500 indices show very similar trajectories over that particular period. The volatility stayed nearly flat for a long time before the crash. As usual, it jumps up when there is a (small) correction: at the end of April 1998, in November 1997, March 1997, and so on, but with no well-defined trend. The arrow plot in the bottom panel of figure 22 confirms this observation and shows that there was no increase in volatility as the FTSE 100 ramped up to its maximum before the crash. If anything, one can see rather a broad decrease of the volatility from its peak in October 1997, which was discussed in the previous section 6.10.

To understand the credit conditions during and after this period of boom and bust, figure 23 shows the credit from banks to the private non-financial sector as a percentage of the GDP of the UK, together with its two-yearly growth rate. The historical time series are plotted starting five years before and ending five years after the peak of the FTSE 100 index in July 1998. The data are from the Bank for International Settlements (BIS, 2017). One can observe that credit was expanding at an approximate steady growth rate at the time of the crash, and continued for another five years thereafter. This data suggests that credit conditions were neither immediate drivers of the bubble, nor of the crash.

We will classify the stock market bubble, ending in the July 1998 crash, as a fearless, non-leveraged bubble, the former meaning that there was no rise in volatility during the bubble period leading up to the crash, the latter meaning that the bubble was not significantly correlated with a rise in credit, or leverage, in the UK economy.

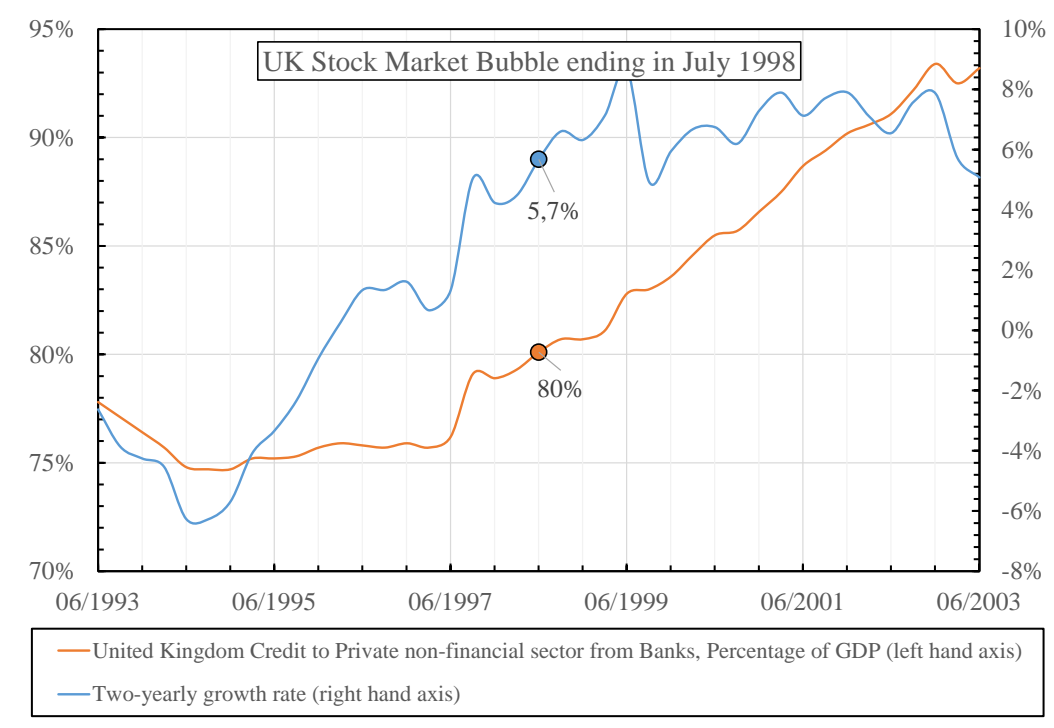

Figure 23. The credit conditions in the UK between 1993 and 2003, five years before and after the bubble ending in July 1998. The two filled circles are the last observations from the data source (BIS, 2017) before the peak and the subsequent crash. 


\subsection{German stock market bubble ending in July 1998}

From its top on July 21, 1998 at the close-price of 6176, to its bottom on October 9, 1998 at the close-price of 3895, the DAX index lost nearly 37\%. On average, German stocks suffered a significantly higher loss than US or UK stocks. This can be explained by the fact that the German banks were, by far, the biggest creditors to Russian counterparts, facilitated by the German government through an export-agency called Hermes, which had the mission to support German exports to and investments in Russia. Consequently, German banks and exporters were particularly exposed to the crisis that hit Russia (which will be discussed in section 6.34).
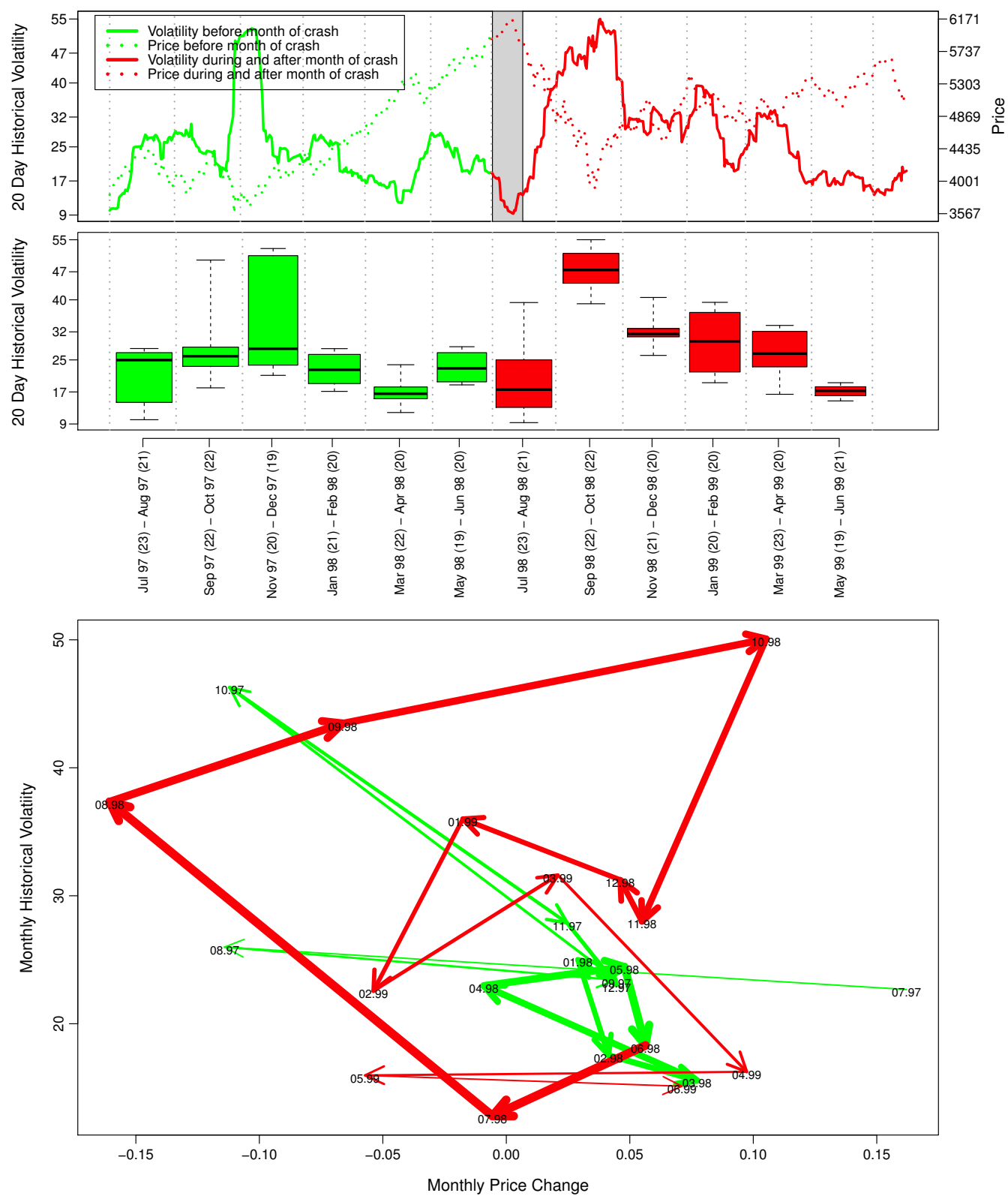

Figure 24. The German stock market bubble ending in July 1998: price and historical volatility of the DAX index (see section 4 for a detailed methodological explanation). 
The upper panel of figure 24 shows the 20-day historical volatility of the DAX index before (green) and after (red) it peaked in July 1998. The grey area represents the one month period around the peak. The behavior of the DAX index is very similar to that of the S\&P500 and the FTSE 100 during the same period and the volatilities of these indexes also follow parallel paths. The volatility remained at about the same level, for most of 1998, tending to decrease in the last few month until the beginning of the crash. The arrow plot in the bottom panel of figure 24 based on the historical volatility confirms that there was no apparent growth of the volatility as the DAX ramped up to its maximum before the crash. If anything, one can see rather an overall decrease of the volatility from its peak in November 1997 associated with the global mini-crash that was discussed before.

To understand the credit conditions during and after this period of boom and bust, figure 25 shows the credit from banks to the private non-financial sector as a percentage of the GDP of Germany together with its two-yearly growth rate. The historical time series are plotted starting five years before and ending five years after the peak of the DAX index in July 1998. The data are from the Bank for International Settlements (2017). The credit was expanding at a constant steady growth rate at the time of the crash, and continued for another two years thereafter before plateauing. This data suggests that credit conditions were neither drivers of the bubble, nor of the crash.

We will classify this stock market bubble, ending in July 1998, as a fearless, non-leveraged bubble, the former meaning that there was no rise in volatility during the bubble period leading up to the crash, the latter meaning that the development of the bubble was not related to credit, or leverage, in the German economy.

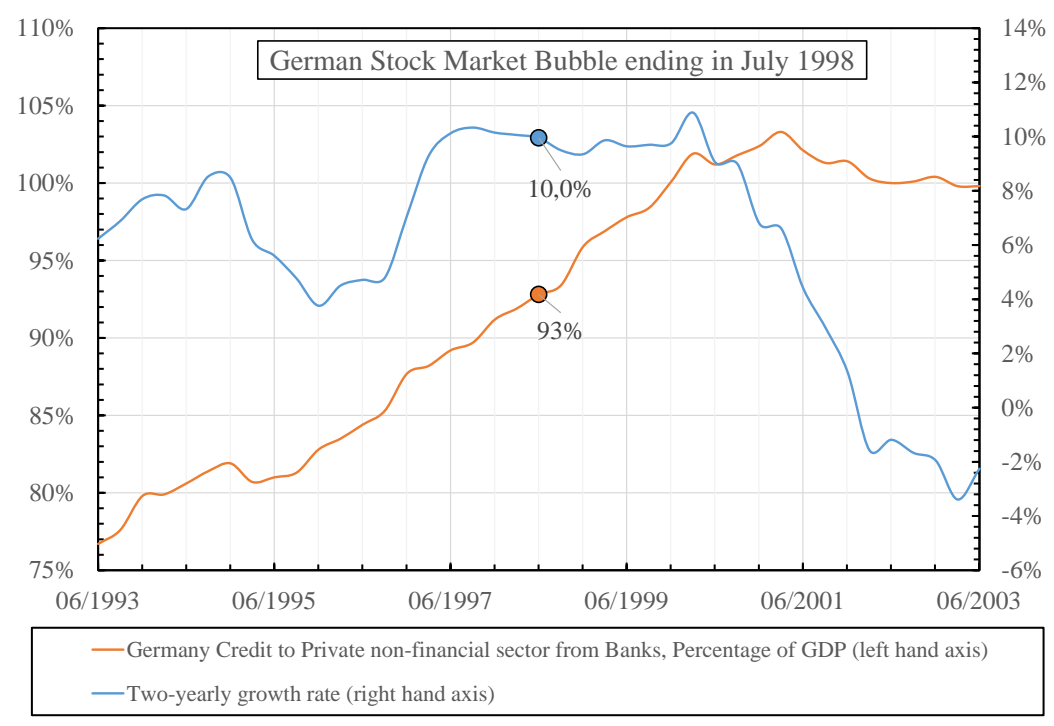

Figure 25. The credit conditions in Germany between 1993 and 2003, five years before and after the bubble ending in July 1998. The two filled circles are the last observations from the data source (BIS, 2017) before the peak and the subsequent crash. 


\subsection{Japanese stock market bubble ending in January 1990}

In the five years before the end of December 1989, the Japanese NIKKEI index had gained more than $224 \%$. By that time, the gross value of the Japanese market capitalisation had exceeded that of the US and amounted to about $35 \%$ of the global world capitalisation. The trading volume in Japanese stocks was also $40 \%$ higher than in US stocks, amounting to $37.5 \%$ of the total world stock market volume. This extraordinary performance resulted from a combined export boom, growing liquidity in the banking system and financial deregulation that promoted credit growth and risk taking by banks (Colombo, 2012). Optimistic sentiments about the future of the Japanese economy and its financial and real-estate markets, encouraged by the Bank of Japan's loose monetary policy in the mid-to-late 1980s, promoted aggressive speculation in domestic stocks and real estate from Japanese as well as foreign investors (Hardouvelis, 1988; Sato, 1995; Barsky, 2009; Hamao et al., 2003; Werner, 2005). This pushed up asset prices to previously unseen levels. It was also at this time that a corporate invention, known as "zaitech", that will become known in later bubble regimes in the West as "financial engineering", emerged. In this system, speculative profits and capital gains were reported as income on corporate financial statements. The firms using this practice profited from low interest rate loans to purchase stocks and real estate, further increasing their "financially engineered" reported income, and so on, in a positive feedback loop reminiscent of the spirals of real-estate market appreciation and wealth extraction via loans that characterised the 2003-2007 US boom (Greenspan and Kennedy, 2005, 2007). Towards the end of this massive Japanese bubble, it was estimated that 40 to $50 \%$ of Japanese corporate earnings were the result of this "zaitech". The bank of Japan tried to cool down the frenzy by progressively raising its target rate from $2.5 \%$ in 1985 to $6 \%$ in 1990 . The stock market bubble eventually came to a halt, turning to a protracted contraction over the following decades (Johansen and Sornette, 1999, 2000a). This peak of the stock market in December 1989, followed by a later peak in 1991 in Japanese real-estate prices, ushered Japan into what has been called its "two lost decades", a period characterised by a stagnating economy and a large growth in government debt.

The upper panel of figure 26 shows the 20-day historical volatility of the NIKKEI index before (green) and after (red) it peaked in December 1989. The grey area represents the one month period after the peak. The volatility remained at about the same level for most of 1989 , with very low values in the last months before the turning point and the subsequent correction. The arrow plot in the bottom panel of figure 26, based on the historical volatility, confirms this picture and clearly shows an extremely low volatility of the volatility itself, which remains confined within a very small area in this plot. There was thus no apparent growth of the volatility as this massive bubble developed.

To understand the credit conditions during and after this period of boom and bust, figure 27 shows the credit from banks to the private non-financial sector as a percentage of the GDP of Japan together with its two-yearly growth rate. The historical time series are plotted starting five years before and ending five years after the peak of the NIKKEI index in January 1990. The data are from the Bank for International Settlements (2017). It can be seen that the level of credit to GDP reached a peak at the end of the bubble. This suggests that credit growth was a driver of the bubble.

We will classify this stock market bubble, ending in January 1990, as a fearless, leveraged bubble, the former meaning that there was no rise in volatility during the bubble period leading up to the crash, the latter meaning that the bubble was fed by a continuous rise in credit, or leverage, in the Japanese economy. 

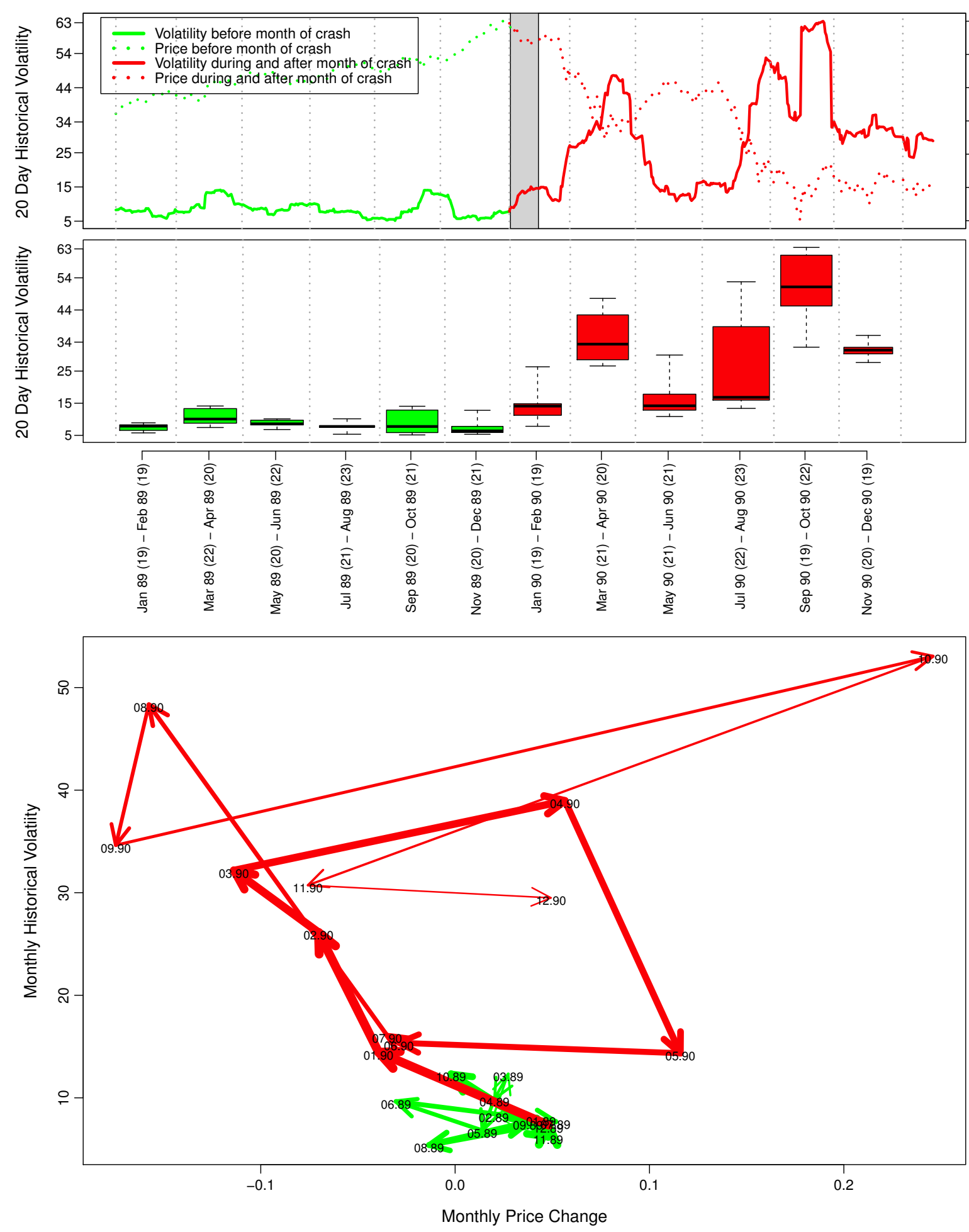

Figure 26. The Japanese stock market bubble ending in January 1990: price and historical volatility of the NIKKEI index (see section 4 for a detailed methodological explanation). 


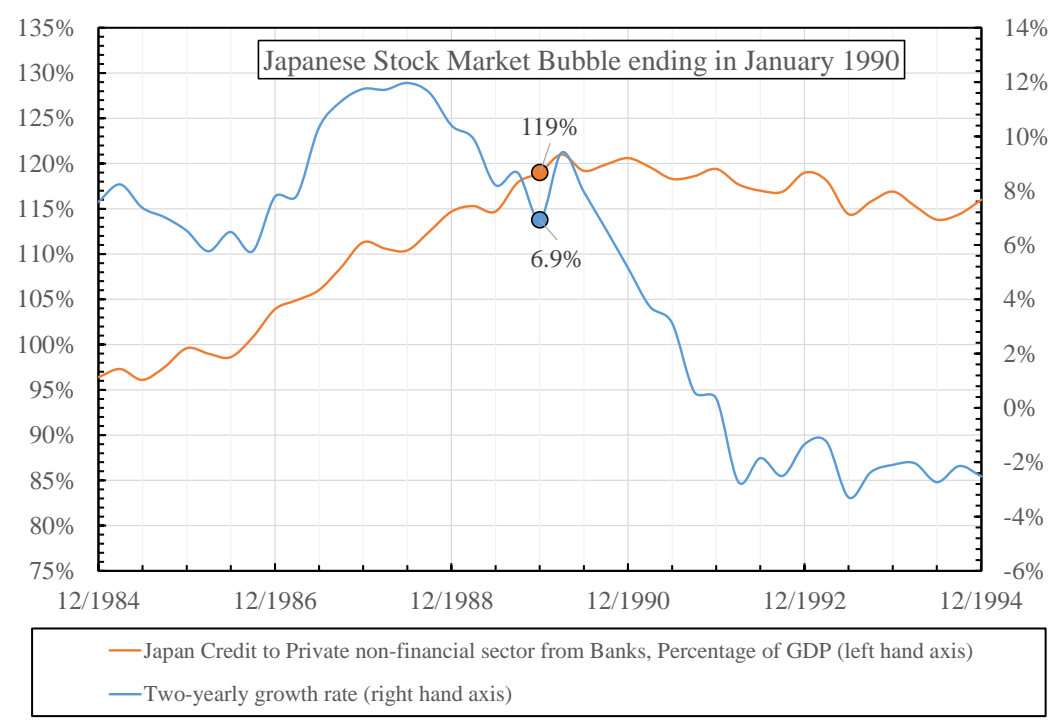

Figure 27. The credit conditions in Japan between 1984 and 1994, five years before and after the end of the bubble in January 1990. The two filled circles are the last observations from the data source (BIS, 2017) before the peak and the subsequent crash.

\subsection{South Korean stock market bubble ending in November 1994}

After the South Korean KOSPI 200 index more than doubled from its low at 450 in July 1992 to its peak at 1130 in November 1994, all the signs where there that a stock market bubble (Johansen and Sornette, 2001) had been maturing. The subsequent correction was swift with the index dropping more than $25 \%$, in just a few months, to a level below 850 . This was the beginning of a secular bearish trend, marked by high volatility, culminating in the crises of 1997 and 1998, when the index dropped below 300 in the middle of 1998.

To understand the sharp rise between July 1992 and November 1994, one needs to look at the bigger macroeconomic and geopolitical picture. In the two decades after the military coup of 1961, South Korea's real income per capita more than tripled. In 1992, a civilian president was elected for the first time after three decades of authoritarian regime. He promised to boost economic growth by encouraging investment in export-oriented industries. As a consequence, South Korea's diversified giant-conglomerates, the chaebol, progressively increased their net debt up to a level, on average, equal to four times their common equity. This fuelled the economic boom between 1994 and 1995 (Nam, 2008). On top of that, in August 1991, the Ministry of Finance announced that from January 1992 onwards, foreigners would be allowed to directly participate in listed South Korean stocks. Even though a liberalisation program had begun in 1985 allowing direct foreign investment in its industries, the South Korean stock market was still tightly controlled before that time. This led to a significant inflow of foreign capital (Kim and Rogers, 1995), a factor well-known to contribute to and fuel asset 
bubbles (Sornette and Zhou, 2004).

Another dimension needs to be factored in. Following the strong appreciation of the Japanese Yen with respect to the US dollar in 1985, production costs in Japan rapidly increased relative to the US. This catalysed a relocation of Japanese production facilities to the so-called "Asian tigers" (Taiwan, South Korea, Hong Kong and Singapore). The available domestic resources in the financial sector of South Korea could not meet the increasing demand of the corporate sector. Consequently the extra credit supply was provided by the steady and strong expansion of external debts and foreign-currency denominated assets (Nam, 2008). This was further supported by the low interest rates in Japan which led to a significant outflow of capital from Japan to South Korea and Taiwan (Bergsten, 1997; Krugman, 1998).

The upper panel of figure 28 shows the 20-day historical volatility of the South Korean KOSPI 200 index before (green) and after (red) it peaked in November 1994. The grey area represents the one month period around the peak. The price and the volatility often moved in opposite directions until the crash at the end of 1994. This is a manifestation of the leverage effect. Note in particular that they are negatively correlated at the "end" of the bubble, when the price increases steadily for the last time while the volatility goes down. There is also a period during which they do go together in the same direction (from December 1993 to April 1994), but this happens many months before the crash. Also note the spike in the volatility associated with the correction in June 1994.

The arrow plot in the bottom panel of figure 28 confirms this observation and clearly shows that the volatility did not exhibit any precursory increase towards the end of the bubble and the upcoming crash. From September to November 1994 in particular, the volatility decreased even though the crash and the regime change had already set in.

To understand the credit conditions during and after this period of boom and bust, figure 29 shows the credit from banks to the private non-financial sector as a percentage of the GDP of South Korea together with its two-yearly growth rate. The historical time series are plotted starting five years before and ending five years after the peak of the KOSPI 200 index in November 1994. The data are from the Bank for International Settlements (2017). One can observe that the credit as a percentage of GDP and its growth rate peaked around the time of the end of the bubble.

We will classify this stock market bubble, ending at the end of November 1994, as a fearless, leveraged bubble, the former meaning that there was no systematic rise in volatility during the bubble period leading up to the crash, the latter meaning that the bubble was developing together with a solid growth of the credit to GDP ratio.

\subsection{Hong Kong stock market bubble ending in October 1987}

In a 2001 study of the Hong-Kong stock market, based on a detailed analysis of the Hang-Seng Composite index, Sornette and Johansen (2001) found a remarkable pattern of quasi-periodical periods of boom and bust. Between November 1969 and September 1999, in a market appreciating with an average annual growth rate of $13.6 \%$, they diagnosed eight bubbles, each followed by a crash with a loss of at least $15 \%$ over a period of less than three weeks. The eight bubbles culminated respectively in October 1971, February 1973, September 1978, October 1980, October 1987, April 1989, January 1994 and October 1997. Each of them was characterised by a transient, faster-than-exponential growth, that is a process where the growth rate itself is growing (Hüsler et al., 2013; Leiss et al., 2015; Sornette and Cauwels, 2015). In this paper, we will discuss two of these eight periods. The crash of October 

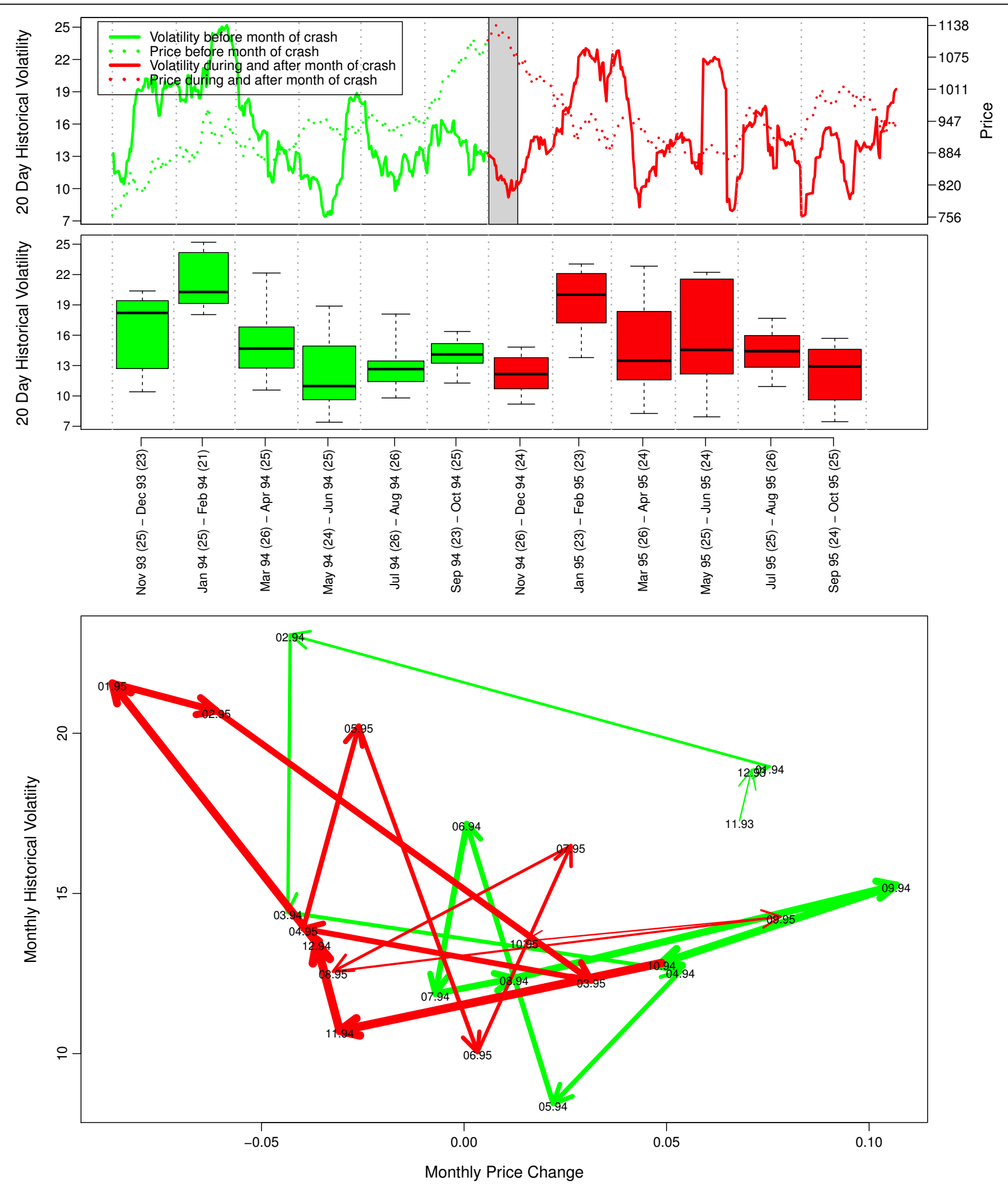

Figure 28. The South Korean stock market bubble ending in November 1994: price and historical volatility of the KOSPI 200 index (see section 4 for a detailed methodological explanation). 


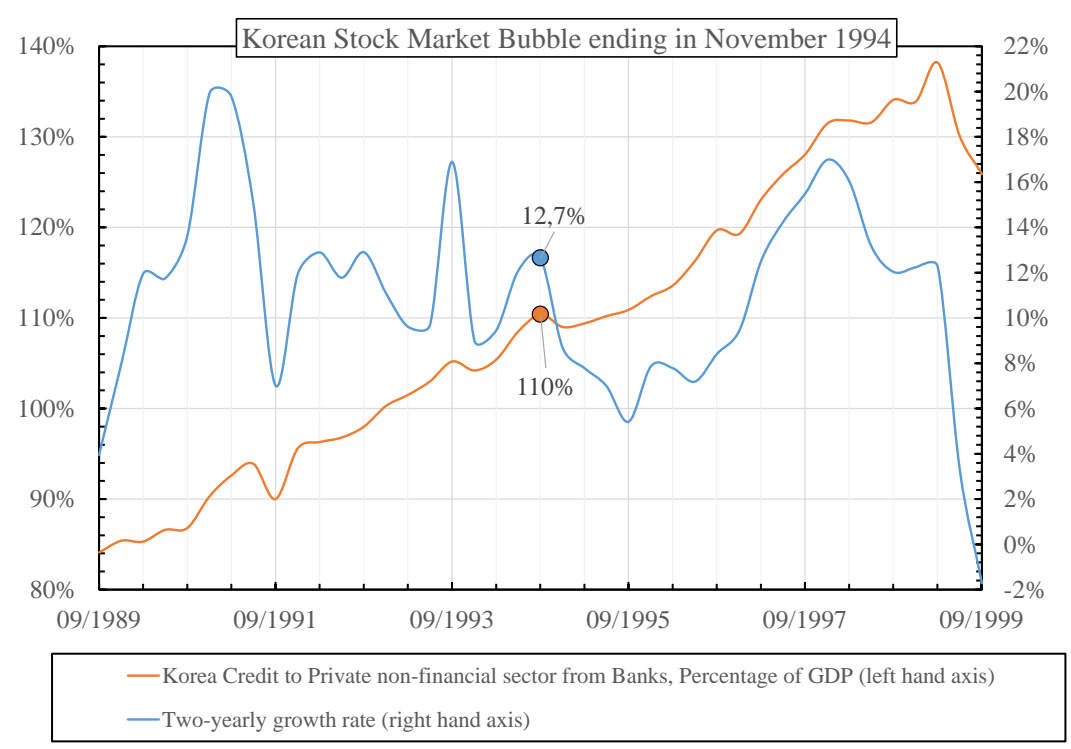

Figure 29. The credit conditions in South Korea between 1989 and 1999, five years before and after the bubble ending in November 1994. The two filled circles are the last observations from the data source (BIS, 2017) before the peak and the subsequent crash.

1987, which was a global phenomenon, will be covered in this section, the crash of January 1994, which was linked to the first systemic Asian crisis of the 1990s, will be covered in the next.

The global stock market crash of October 1987 has already been discussed in section 6.3 for the US and in section 6.9 for the UK. Based on the study carried out by Malliaris and Urrutia (1992), showing the lack of a statistically significant causality between the indices, and following the same reasoning as in section 6.9, we will treat the US S\&P 500, the UK FTSE 100 and the Hang Seng Composite indices as separate cases in the current study.

The upper panel of figure 30 shows the 20-day historical volatility of the Hang Seng Composite index before (green) and after (red) it peaked in October 1987. The grey area represents the one month period after the peak. The volatility remained at low levels until the time of the crash, showing even a tendency to decrease during the four months preceding the crash. The arrow plot in the bottom panel of figure 30 confirms this observation; the green arrows are clearly confined to the small area of low volatility and high return before the crash, only to go astray after the correction. During the bubble, no precursory increase in volatility can be observed that could be interpreted as a looming end to the bubble and the coming crash.

To understand the credit conditions during and after this period of boom and bust, figure 31 shows the credit from banks to the private non-financial sector as a percentage of the GDP of Hong Kong together with its two-yearly growth rate. The historical time series are plotted starting five years before and ending five years after the peak of the Hang Seng Composite index in October 1987. The data 
are from the Bank for International Settlements (2017). It can be seen that the level of credit to GDP reached a peak at the end of the bubble. This suggests that credit growth was a driver of the bubble.

We will classify this stock market bubble, ending at the end of October 1987, as a fearless, leveraged bubble, the former meaning that there was no systematic rise in volatility during the bubble period leading up to the crash, the latter meaning that the bubble was developing during a period of strong credit expansion.

\subsection{Hong Kong stock market bubble ending in January 1994}

The crash in the Hong Kong stock market, that ended in January 1994, marked the end of the seventh bubble period among a series of eight boom and bust cycles that developed in that particular market between November 1969 and September 1999 (Sornette and Johansen, 2001). It occurred at a time when there was widespread concern about Hong Kong's competitiveness compared to Singapore, South Korea, Taiwan and the other emerging economies of East Asia (Jao, 2001). In a study Lowell et al. (1998) present a detailed quantitative analysis of contagion risk of financial crises in emerging market countries between 1989 and 1997. One remarkable period is described by them as "a rash of crises spanning January-June 1994". According to their results, this crisis impacted stock markets in Chile, Hungary, India, Indonesia, Malaysia, Philippines, Poland, South Africa, Turkey, Venezuela, Germany, Hong Kong, Singapore, the UK and the US. The possible root cause of this crisis is generally attributed to sharply rising interest rates in the United States. After a detailed causality analysis, the authors claim, however, that this could not have been the single trigger of this global crisis and that also country specific events must have exacerbated this global financial crisis.

In 1993, the year before the correction, the price of the Hong Kong stock market had more than doubled following a faster-than-exponential growth rate, which is often seen as the fingerprint of a bubble regime (Sornette and Cauwels, 2015). After the bubble peaked in January 1994, a regimeswitch occurred and a bearish trend set in resulting in a cumulative loss in the Hang Seng Composite index of more than $40 \%$ over the full year 1994. This downturn in the stock market was associated with a decrease of the real GDP growth from 5.4\% in 1994 to 3.9\% in 1995 and with a mild rise of unemployment. As Hong Kong was one of the dominos that fell during this "rash of crises spanning January-June 1994", its root cause is generally associated with sharply rising interest rates in the US. The country-specific factors that most plausibly worsened the Hong Kong situation were a bubble dynamics in its stock market, rising interest rates in Hong Kong and economic adjustments in China.

The upper panel of figure 32 shows the 20-day historical volatility of the Hang Seng Composite index before (green) and after (red) it peaked in January 1994. The grey area represents the one month period after the peak. It can be seen that the volatility had been gradually increasing during the maturation of the bubble in the second half of 1993. The arrow plot in the bottom panel of figure 32 confirms this observation by showing a gradual rise in the green arrows in the months before the crash.

To understand the credit conditions during and after this period of boom and bust, figure ?? shows the credit from banks to the private non-financial sector as a percentage of the GDP of Hong Kong together with its two-yearly growth rate. The historical time series are plotted starting five years before and ending five years after the peak of the Hang Seng Composite index in January 1994. The data are from the Bank for International Settlements (2017). It can be seen that the level of credit to GDP reached a low right at the end of the bubble. From this data it is clear that credit growth was no driver of the bubble. 

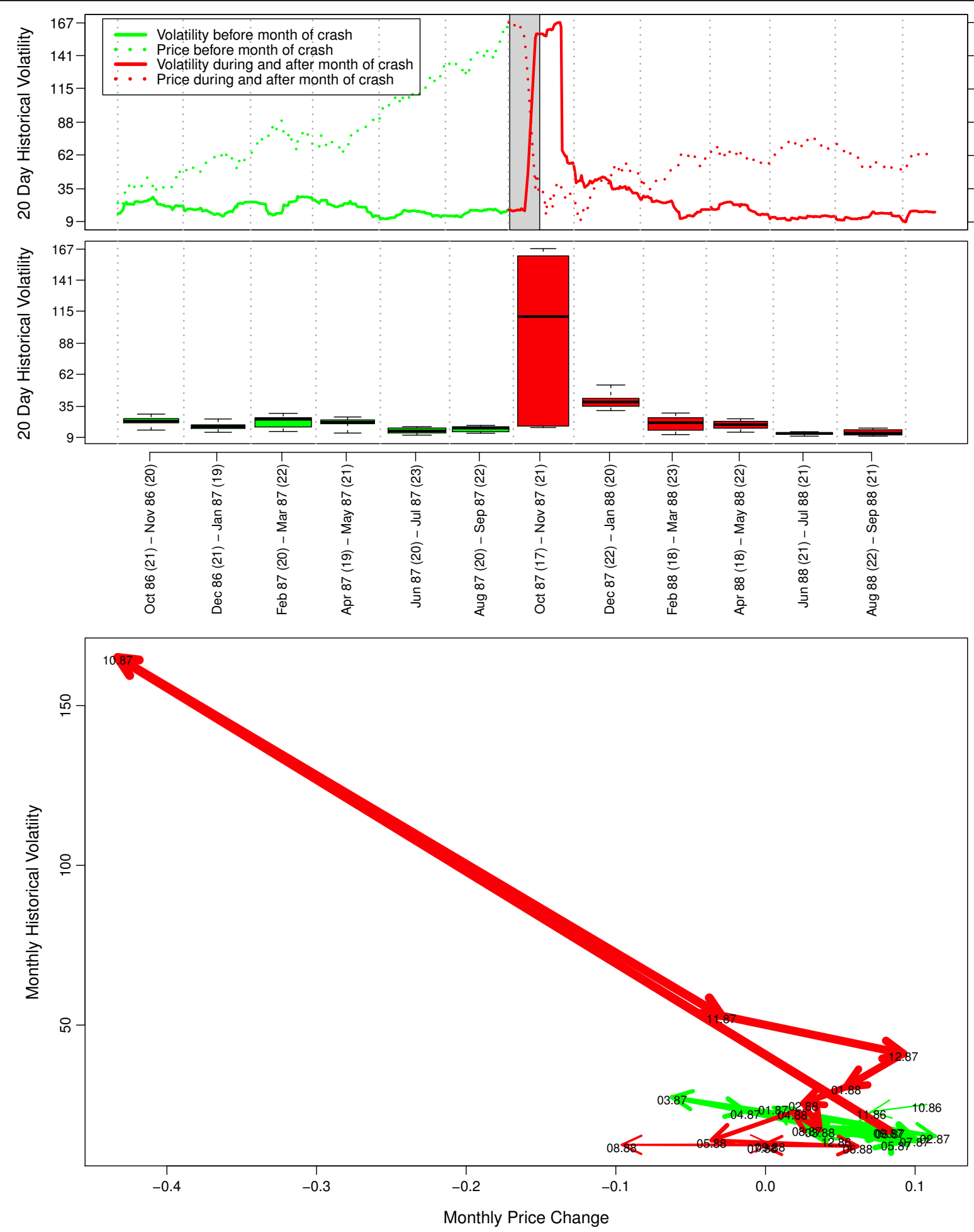

Figure 30. The Hong Kong stock market bubble ending in October 1987: price and historical volatility of the Hang Seng Composite index (see section 4 for a detailed methodological explanation). 


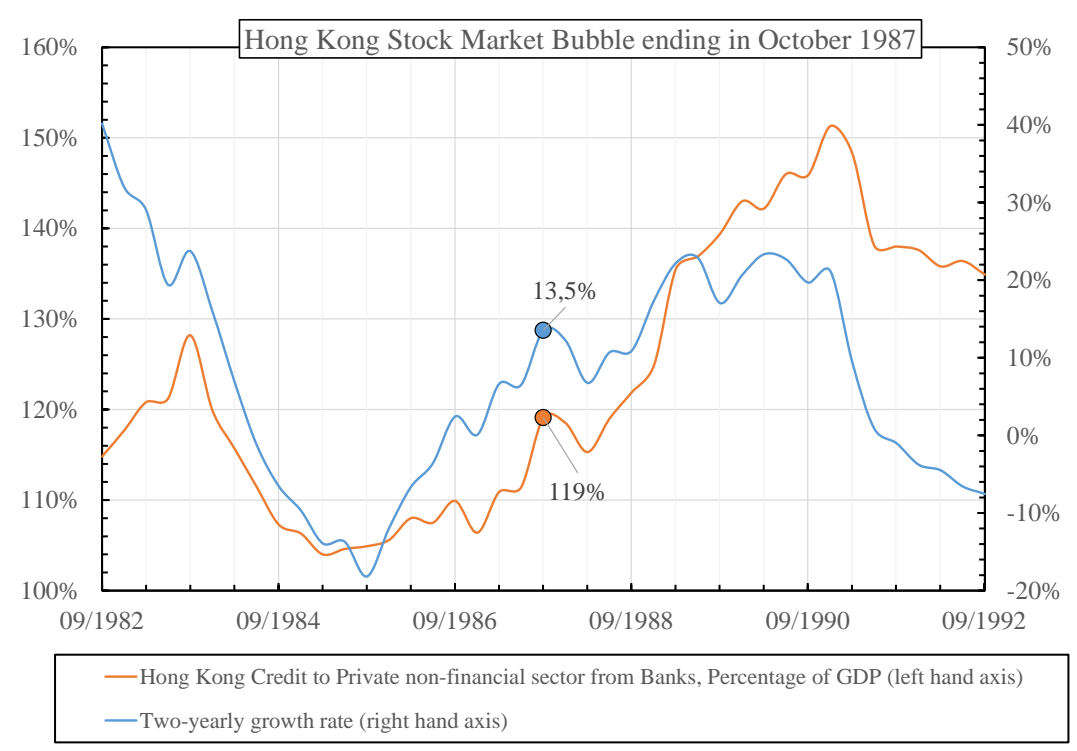

Figure 31. The credit conditions in Hong Kong between 1982 and 1992, five years before and after "Black Monday". The two filled circles are the last observations from the data source (BIS, 2017) before the peak and the subsequent crash in October 1987.

We will classify this stock market bubble, ending in January 1994, as a fearful, non-leveraged bubble, the former meaning that there was a significant rise in volatility during the maturation of the bubble, the latter meaning that the bubble did not develop during a period of credit expansion.

\subsection{Chinese (Shanghai) stock market bubble ending in October 2007}

In a study, Jiang et al. (2009) explain in detail how two different bubbles matured in the Chinese stock market, the first over the period 2005-2007, which will be discussed in this section and the second over the period 2008-2009, which will be the subject of the next section. For both bubbles, the fingerprint of a faster-than-exponential increase in asset prices could clearly be observed. The time windows for these two crashes were successfully predicted, ex ante, by two different research groups (Jiang et al., 2010; Bastiaensen et al., 2009).

The 2007 bubble in the Chinese stock market started out with the split share structure reform of listed companies which took effect in September in 2005 (Jiang et al., 2010). Before, only about one third of the shares of any listed company in the Chinese stock market were liquid, while the rest, the so-called non-tradable shares were owned by State-Owned Enterprises (SOEs). According to an ECB working paper from 2011 (Bortolotti et al., 2011), this was a value-creating measure because it accelerated the privatization process, which led to an improvement in corporate governance, it had a strong positive effect on liquidity and it eliminated a source of non-diversifiable (political) risk. It is generally accepted that this reform was a turning point which triggered the recovery of the Chinese 

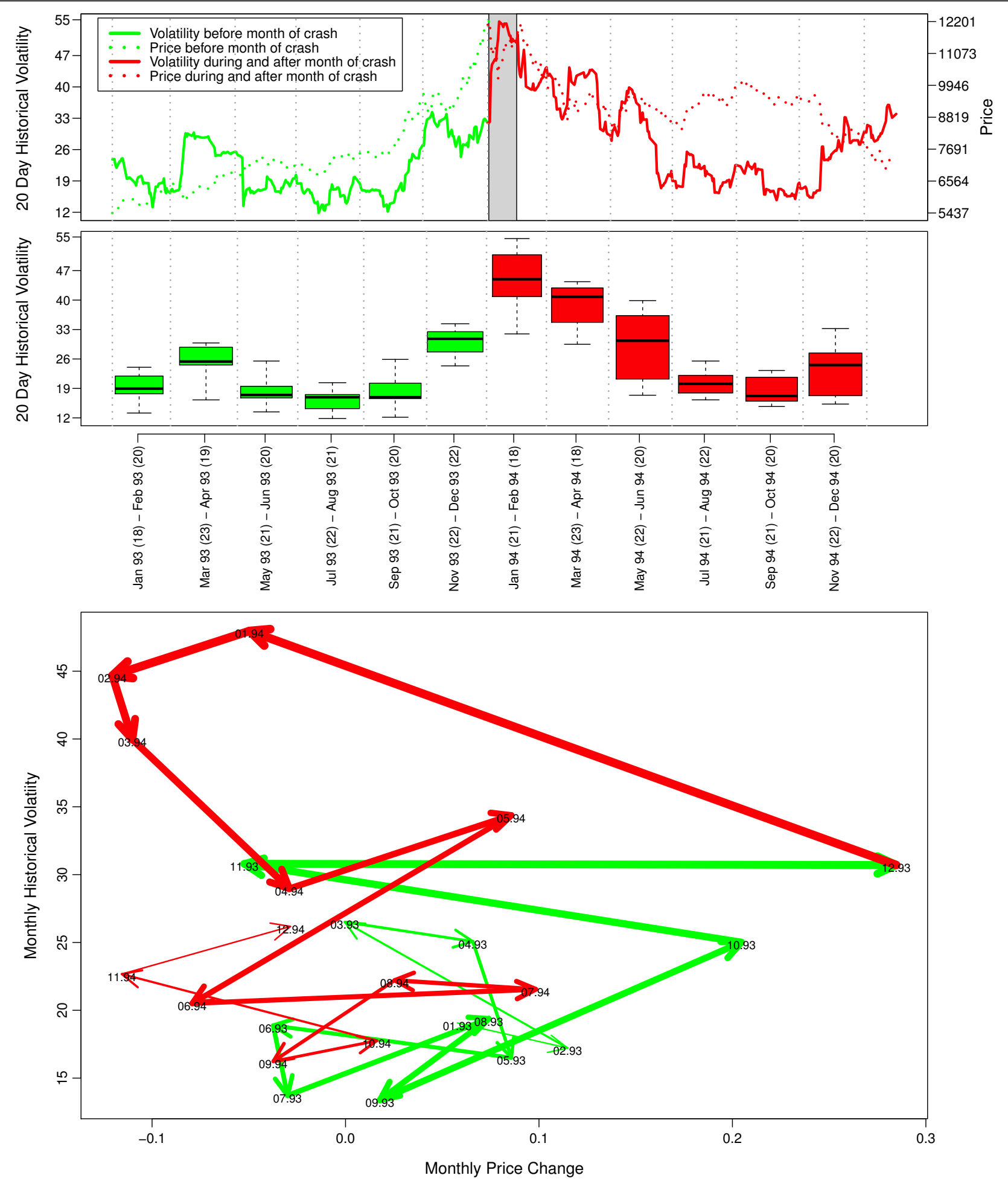

Figure 32. The Hong Kong stock market bubble ending in January 1994: price and historical volatility of the Hang Seng Composite index (see section 4 for a detailed methodological explanation). 


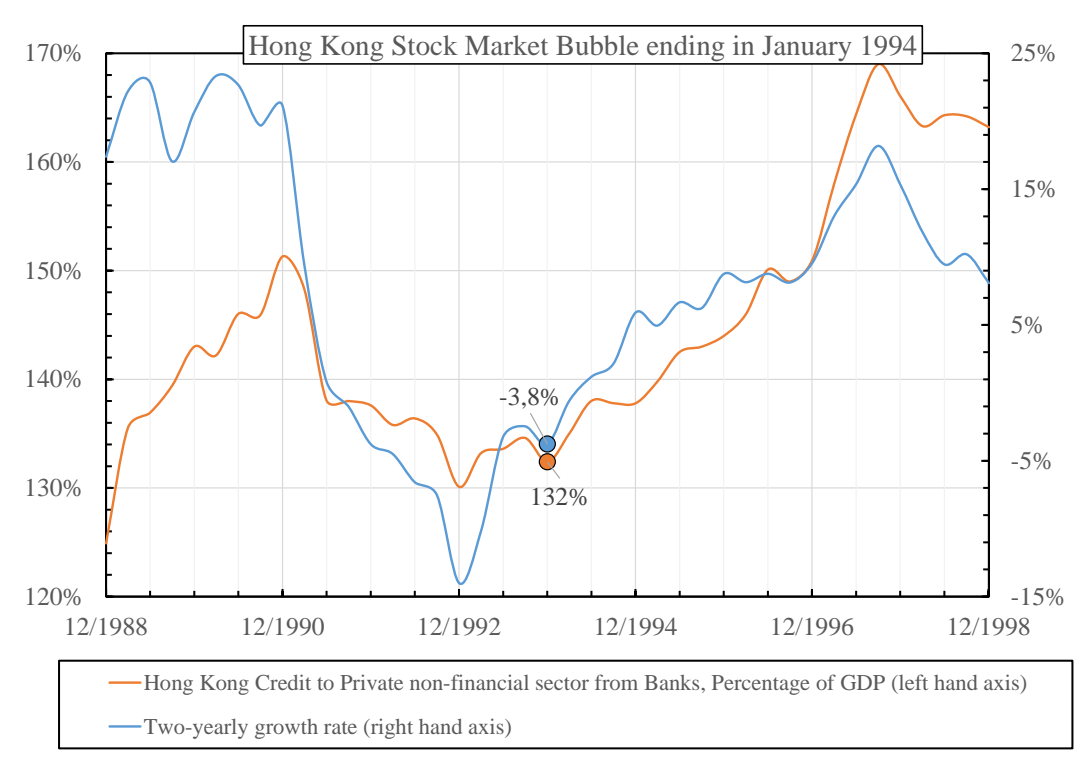

Figure 33. The credit conditions in Hong Kong between 1988 and 1998, five years before and after January 1994. The two filled circles are the last observations from the data source (BIS, 2017) before the peak and the subsequent crash.

stock market from its previous bearish regime. According to Jiang et al. (2010), it was the precipitating factor which catalysed the first Chinese stock market bubble of the twenty-first century.

In mainland China, Shanghai (with the SSE index) and Shenzhen (with the SZSE index) are the two major exchanges. Both showed similar behavior in price appreciation and volatility during the boom and bust period in the time interval between 2005 and 2009. In this study, we will proxy the Chinese stock market by the SSE Composite index. From mid-2005 until October 2007, this index went through an amazing sixfold appreciation, which was followed by a massive correction of more than $70 \%$ in the year after the peak between October 2007 and October 2008. As explained by Jiang et al., this crash was predicted by the research group of Didier Sornette (2007) and communicated, ex ante, at a large macro hedge-fund conference in Stockholm on October 18, 2007.

The upper panel of figure 34 shows the 20-day historical volatility of the Shanghai Composite index before (green) and after (red) it peaked in October 2007. The grey area represents the one month period around the peak. Two peaks can be seen in the historical volatility, one in February 2007 and another one in June 2007. Both clearly occurred during a transient phase, when the SSE was indecisively going sideways. These periods were associated with an increased volatility, as if market participants were anticipating a correction. When a new rally set in, after the price plateaued, the volatility went down again. Each rally was associated with a relief and we can see the volatility dropping as prices went up. This is also the case during the final rally. Consequently, the volatility was at a low right before the crash. This observation is clearly confirmed by the arrow plot in the lower panel of the same figure. 

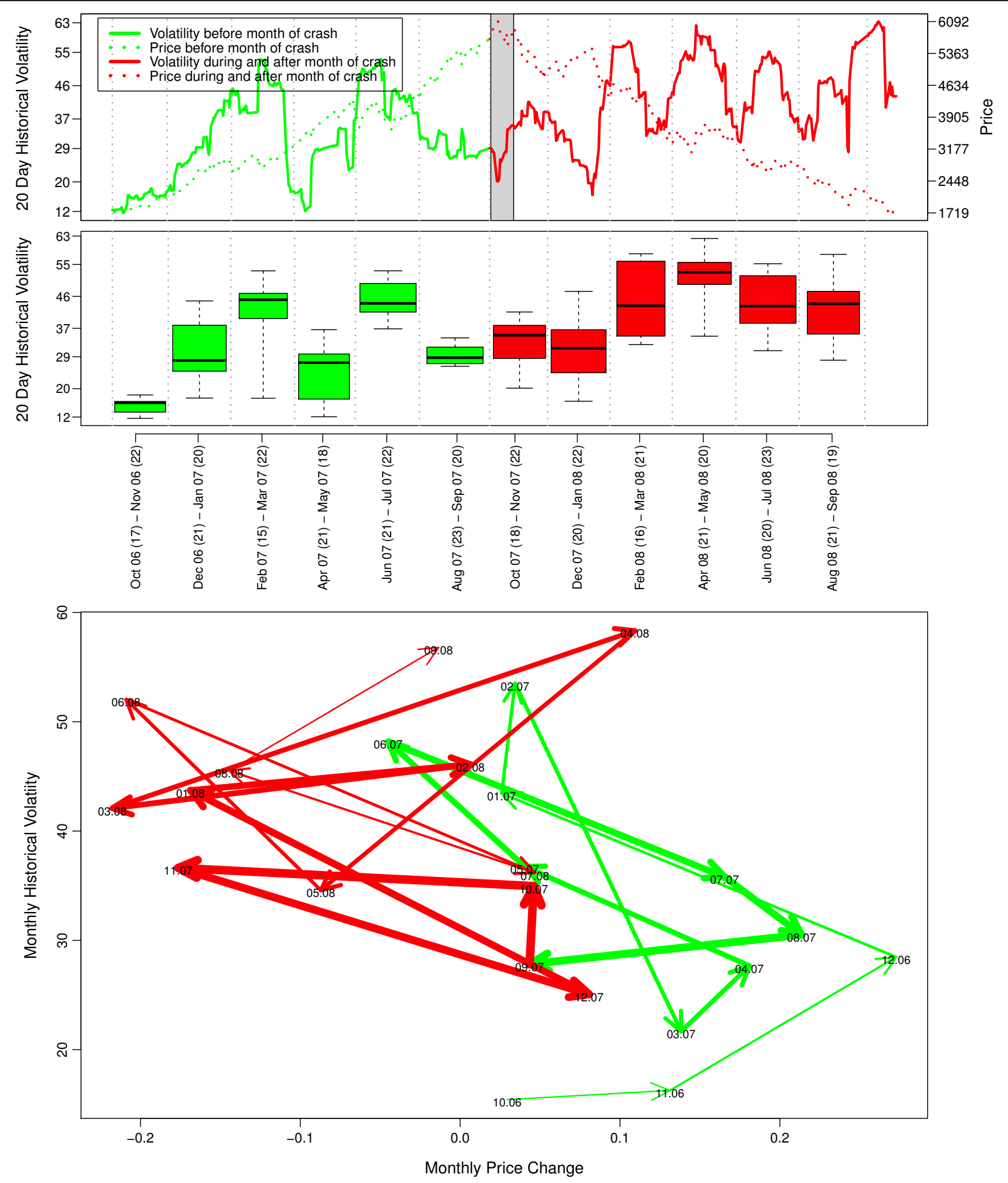

Figure 34. The Chinese stock market bubble ending in October 2007: price and historical volatility of the Shanghai Stock Exchange Composite index (see section 4 for a detailed methodological explanation). 


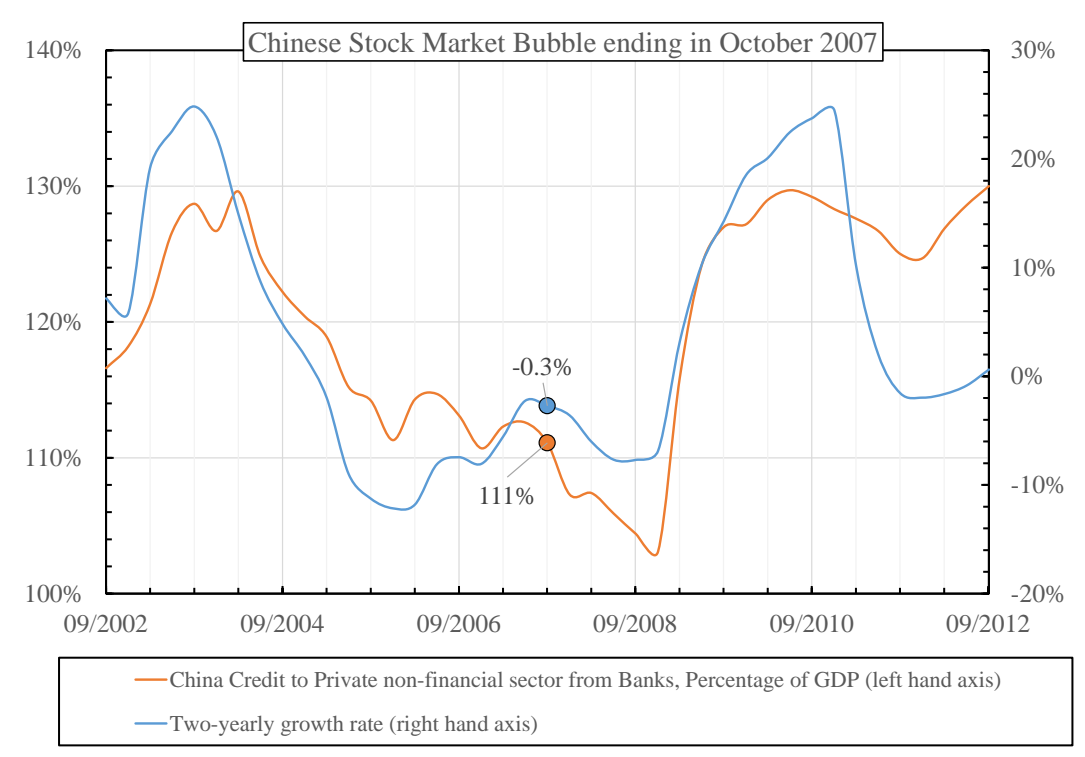

Figure 35. The credit conditions in China between 2002 and 2012, five years before and after the October 2007 crash. The two filled circles are the last observations from the data source (BIS, 2017) before the peak and the subsequent crash.

Therefore we classify this as a fearless bubble.

To understand the credit conditions during and after this period of boom and bust, figure 35 shows the credit from banks to the private non-financial sector as a percentage of the GDP of China together with its two-yearly growth rate. The historical time series are plotted starting five years before and ending five years after the peak of the SSE index in October 2007. The data are from the Bank for International Settlements (2017). The credit as a percentage of GDP and its growth rate were decreasing and at low levels around the time of the end of the bubble.

We will classify this stock market bubble, ending at the end of October 2007, as a fearless, nonleveraged bubble, the former meaning that there was a significant decrease in volatility towards the end of the bubble, starting approximately four months before its peak, the latter summarising the fact that the credit level and its growth rate were at historically low levels during the bubble build-up phase.

This section focusses entirely on the Shanghai Composite index. For completeness, it is worthwhile mentioning here that a similar behavior in price appreciation and volatility was observed in the Shenzhen Composite index over that same time period.

\subsection{Chinese (Shanghai) stock market bubble ending in July 2009}

Over the first half of 2009, the Shanghai Composite had been the best performing large stock market index, globally. It had gone up more than $60 \%$ for the year, after a very strong bull ride that was the result of a wide range of monetary, economic and fiscal stimulus packages, instigated by the People's 


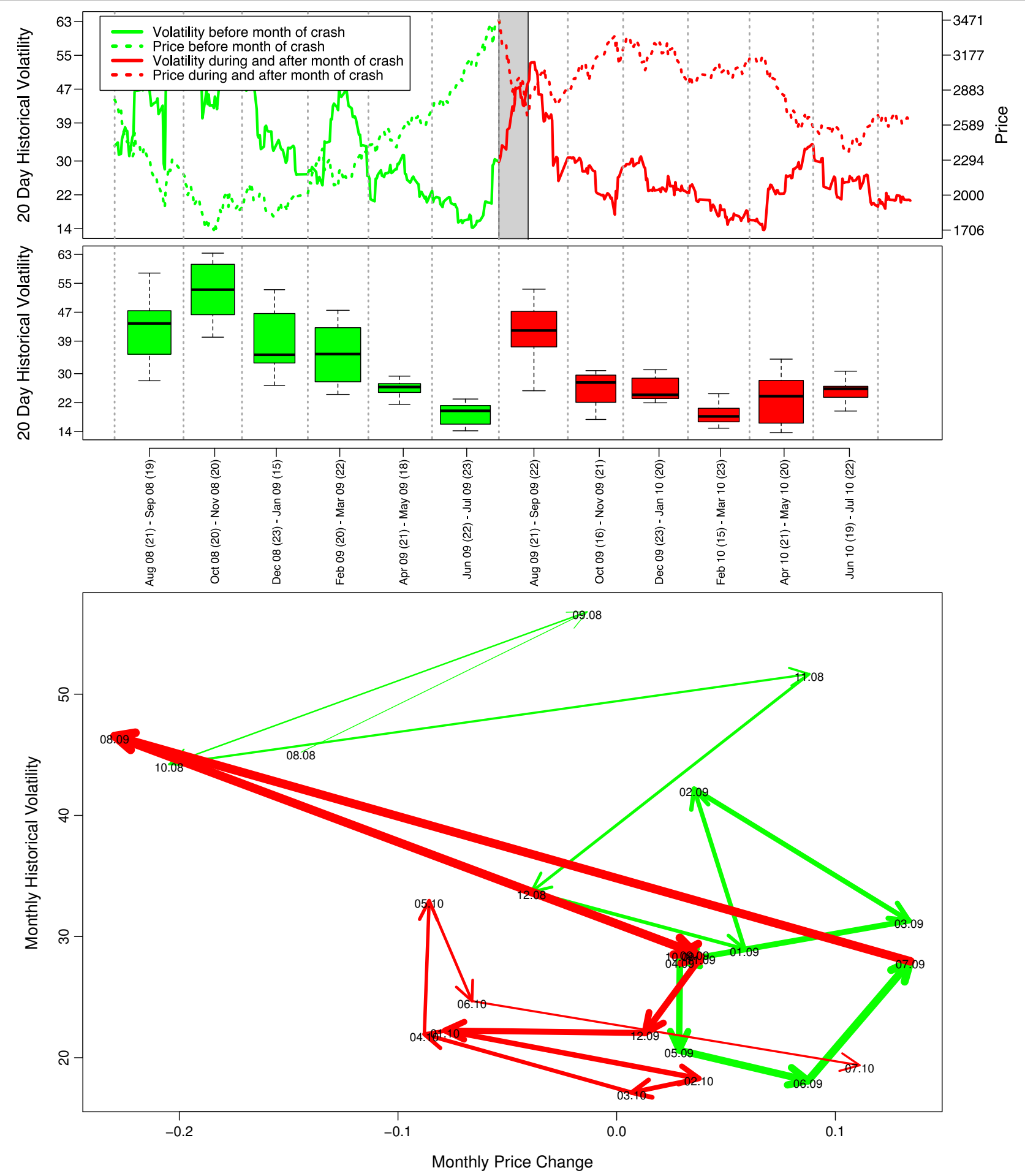

Figure 36. The Chinese stock market bubble ending in July 2009: price and historical volatility of the Shanghai Stock Exchange Composite index (see section 4 for a detailed methodological explanation). 


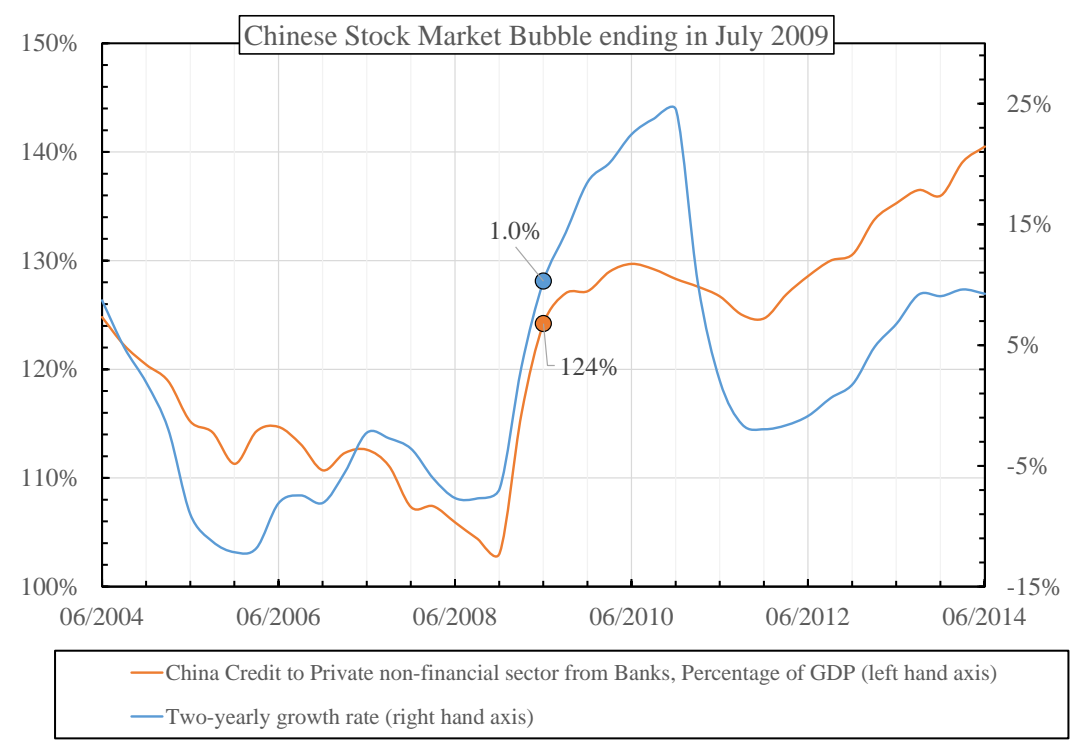

Figure 37. The credit conditions in China between 2004 and 2014, five years before and after the July 2009 crash. The two filled circles are the last observations from the data source (BIS, 2017) before the peak and the subsequent crash.

Bank of China and the People's Republic of China as an attempt to minimize the impact of the global financial crisis on the world's second largest economy.

On July 10, 2009, Bastiaensen et al. submitted a working paper on the Cornell University on-line Library arxiv.org (Bastiaensen et al., 2009), where they presented a detailed quantitative analysis of the SSE index, claiming the presence of signatures of a bubble build up and predicting a most likely crash date between July 17 and 27, 2009, within the 20\% to 80\% confidence interval (and between July 10 and August 102009 within the $10 \%$ to $90 \%$ confidence interval). The very good accuracy of this prediction is commented by Jiang et al. (2010). On July 29, 2009, the SSE suffered its steepest drop since November 2008, reaching an intra-day bottom of more than $8 \%$ below the opening price and an open-to-close loss of more than 5\%. After that, the market rebounded for a few days, reaching a peak on August 4, 2009 before plummeting during the following weeks. In August, the SSE slumped $22 \%$, under-performing strongly the other global benchmark indices, in stark contrast with its prior solid out-performance.

The upper panel of figure 36 shows the 20-day historical volatility of the Shanghai Composite index before (green) and after (red) it peaked the end of July, 2009. The grey area represents the one month period after the peak. In the figure (and more specifically in the box plot), it can be seen that the volatility had been on a gradually decreasing course during the build-up of the bubble. It is only at the time of the crash, when a price correction sets in, that the volatility jumps upward strongly. Again we can clearly see the leverage effect in action. This observation is confirmed by the arrow plot in the 
lower panel of the same figure.

To understand the credit conditions during and after this period of boom and bust, figure 37 shows the credit from banks to the private non-financial sector as a percentage of the GDP of China together with its two-yearly growth rate. The historical time series are plotted starting five years before and ending five years after the peak of the SSE in July 2009. The data are from the Bank for International Settlements (2017). The credit as a percentage of GDP and its growth rate were increasing strongly before the time of the end of the bubble. This is in line with the claim that monetary easing was one of the root causes of this bubble.

We will classify this stock market bubble, ending at the end of July 2009, as a fearless, leveraged bubble, the former meaning that there was a significant decrease in volatility towards the end of the bubble, starting approximately a half year before its peak, the latter summarising the fact that the credit level and its growth rate were strongly increasing during the bubble build-up phase.

This section focusses entirely on the Shanghai Composite index. For completeness, it is worthwhile mentioning here that a similar behavior in price appreciation and volatility was observed in the Shenzhen Composite index over that same time period.

\subsection{Argentinian stock market bubble ending in October 1991}

In their research paper from 2001, Johansen and Sornette (2001) give a detailed account on the boom and bust cycles in the Argentine stock market during the 1990s. After an extensive quantitative research based on the identification of a faster-than-exponential growth in the price series, four distinct bubble-periods, each followed by a very large drawdown were found around October 1991, June 1992, February 1994 and October 1997.

According to Nochteff (1996), the combination of high peso rates, a fixed exchange rate and financial decontrol prompted a large-scale influx of capital in Argentine in the 1990s. The bulk of this was used to finance the acquisition of public enterprises by conglomerates, but also to finance a consumption boom, particularly in non-essential goods. The implementation of neo-conservative economic policies based on financial globalisation, a reduced role for the state, external indebtedness, privatisations, deregulation and weak institutions, instigated great expectations, leading to stock market excesses, and cycles of boom and bust. As such, these policies can be seen as the precipitating factors leading to over-promising and over-expectation as described in Kindleberger's "Manias, Panics, and Crashes" from 1978 (Kindleberger, 1978), causing the four boom and bust cycles in the Argentine stock market in the 1990s.

We will use the MERVAL index (MERcado de VALores, meaning Stock Market), which is the most important index of the Buenos Aires Stock Exchange for our analysis. When evaluating returns, one has to take into consideration the period of hyper-inflation that peaked in 1989 at an annual rate of more than $2000 \%$, after which a so-called "shock programme" was introduced fixing the peso by law at par to the dollar, restricting the money supply to the level of hard-currency reserves. This curbed down inflation gradually to an average of $172 \%$ in $1991,24.9 \%$ in $1992,10.6 \%$ in $1993,4.2 \%$ in 1994 and $0.52 \%$ in 1997 .

The upper panel of figure 38 shows the 20-day historical volatility of the MERVAL index before (green) and after (red) it peaked in October 1991. The grey area represents the one month period around the peak. One can observe an almost tenfold increase in the index between the end of 1990 and its peak in October 1991. As explained above, this was partially impacted by the high inflation that was 

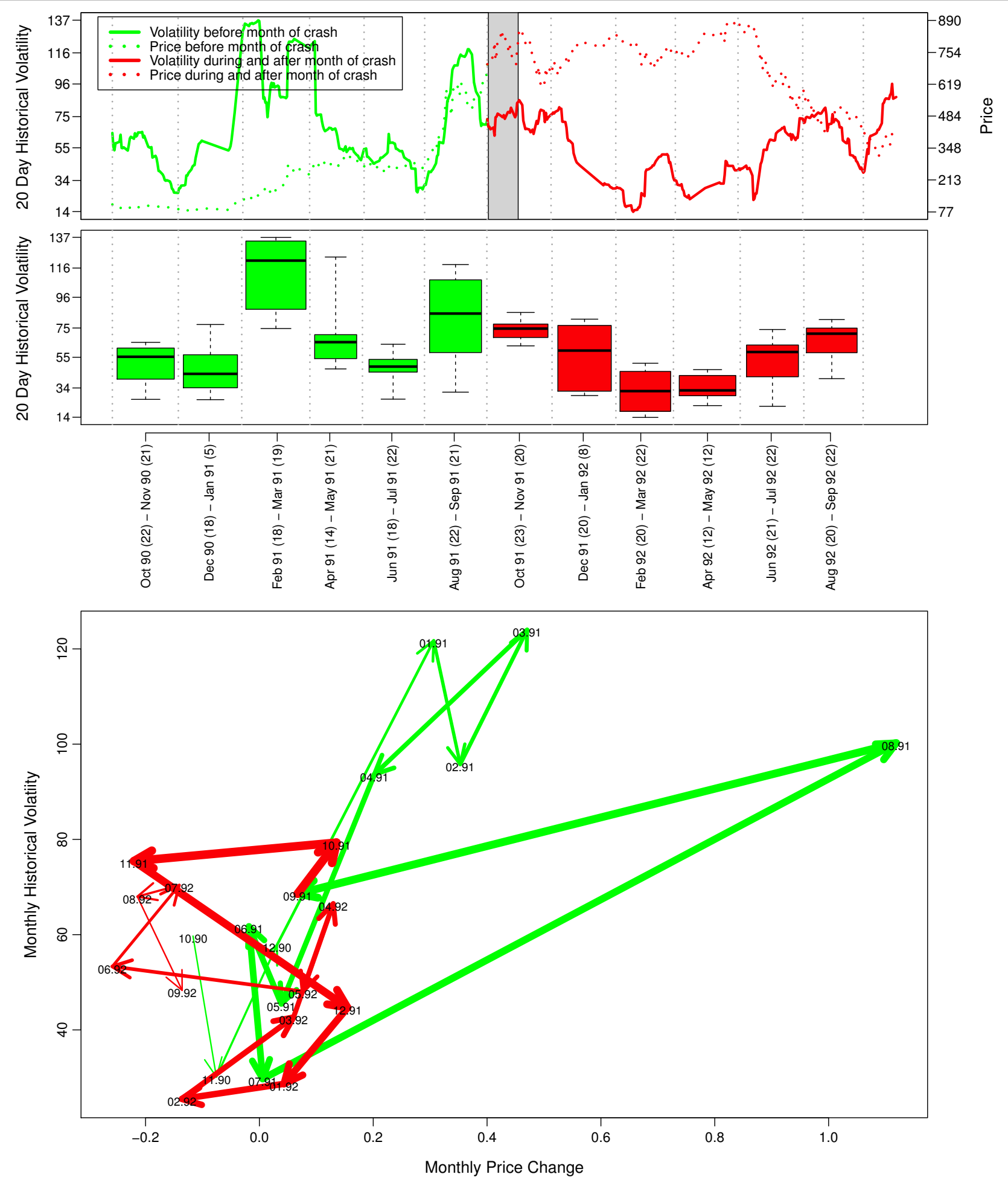

Figure 38. The Argentine stock market bubble ending in October 1991: price and historical volatility of the MERVAL index (see section 4 for a detailed methodological explanation).

still way over $100 \%$, in 1991 . One can see from this figure, and also from the arrow plot in the bottom panel, that the volatility is extremely spiky and as such volatile itself during the bubble build-up phase. 
Before the correction, a steep increase can be observed in the volatility, peaking right at the crest of the bubble, only to decrease gradually in the following six months, as the market rebounded, preparing for the next bubble regime. As such, we identify this bubble as fearful.

To understand the credit conditions during this bubble and its aftermath, figure 39 shows the credit from banks to the private non-financial sector as a percentage of the GDP of Argentina, together with its two-yearly growth rate. The historical time series are plotted starting five years before and ending five years after the peak of the MERVAL index in October 1991. The data are from the Bank for International Settlements (BIS, 2017). One can see the credit as a percentage of GDP and its growth rate increase in a very volatile fashion during the years preceding as well as during the development of the bubble.

We will classify the Argentinian stock market bubble from October 1991, as a fearful, leveraged bubble, the former meaning that there was a significant increase in volatility towards the end of the bubble, starting approximately two months before its peak, the latter summarising the fact that the credit level and its growth rate had increased significantly during the bubble ramp-up.

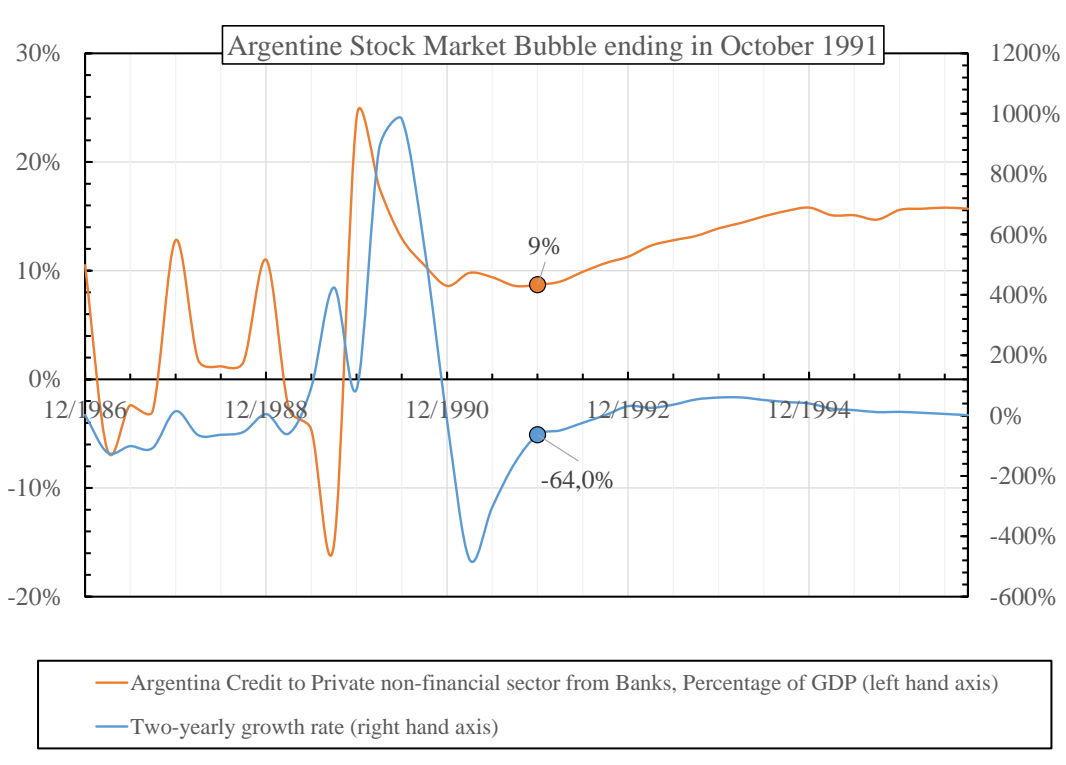

Figure 39. The credit conditions in Argentina between 1986 and 1996, five years before and after October 1991. The two filled circles are the last observations from the data source (BIS, 2017) before the peak and the subsequent crash.

\subsection{Argentinian stock market bubble ending in June 1992}

After the correction in October 1991, the Argentinian stock market recovered quickly. In June 1992, a new high was reached surpassing the peak of 1991. This time, however, the bust that followed was much more protracted with losses accumulating to approximately 60\% between the peak of June 1992 
and the bottom of October 1992.
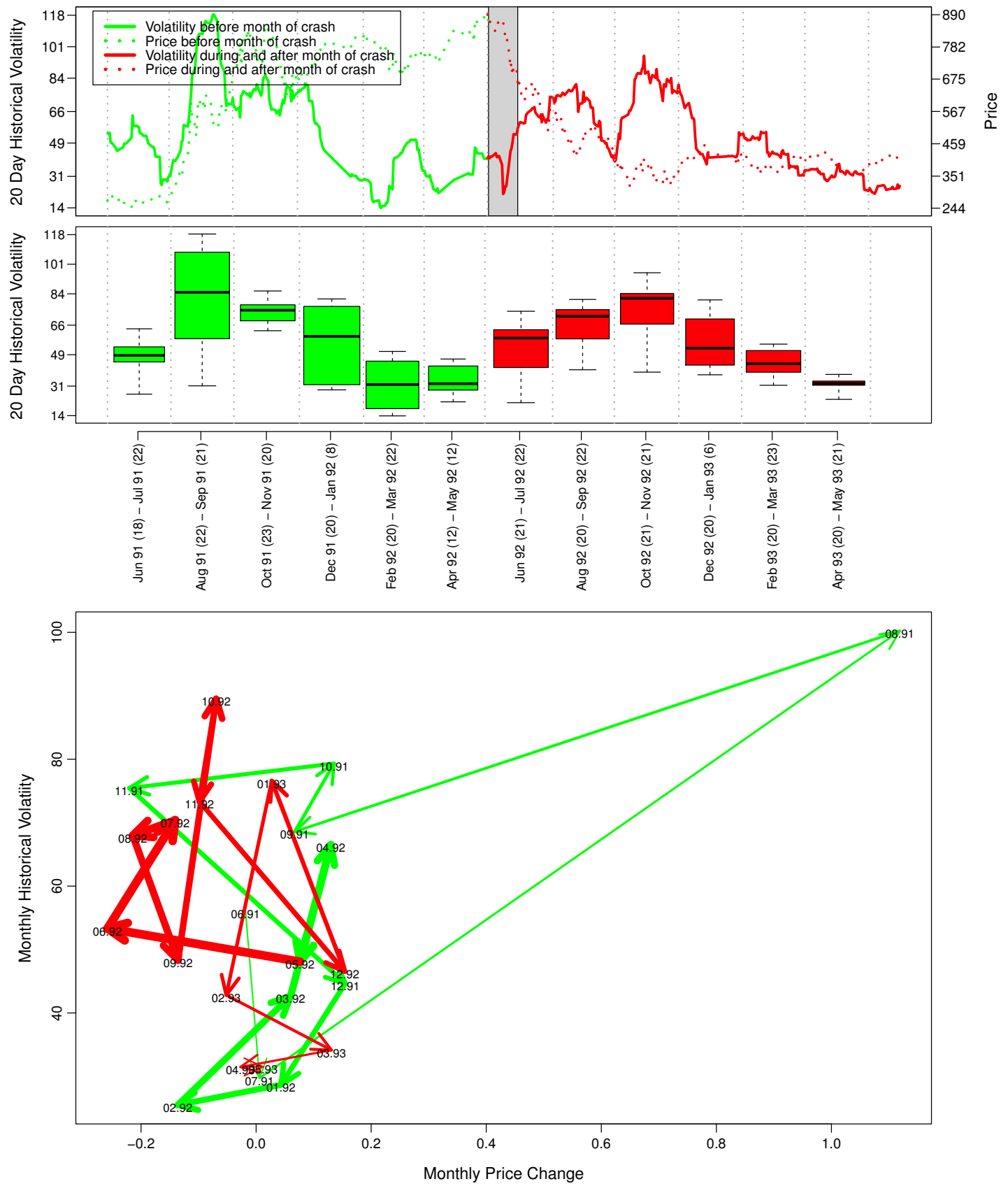

Figure 40. The Argentine stock market bubble ending in June 1992: price and historical volatility of the MERVAL index (see section 4 for a detailed methodological explanation).

Figure 40, shows the 20-day historical volatility of the MERVAL index before (green) and after (red) this second peak in June 1992. The grey area represents the one month period after the peak. In both panels (the box plot and the arrow plot), one can clearly see the volatility decreasing in the aftermath of the October 1991 correction, which was described in the previous section 6.19. The volatility remains low right up to the point of the crash, only to increase steadily in lock step with decreasing stock prices. 
There is absolutely no increased volatility that could be interpreted as a warning signal for the investors who were facing a $60 \%$ loss in the following months.

Figure 41 is similar to figure 39 from the previous section; the observations are only shifted nine months forward in time. The plot shows the credit from banks to the private non-financial sector as a percentage of the GDP of Argentina together with its two-yearly growth rate, starting five years before and ending five years after the peak of the Argentinian stock market in June 1992. The data are from the Bank for International Settlements (BIS, 2017). The credit as a percentage of GDP has stabilised over the time interval of this bubble with a growth rate converging to zero.

We will classify this stock market bubble, ending at the end of June 1992, as a fearless, nonleveraged bubble, the former meaning that the volatility decreased during the ramp up of the bubble, the latter summarising the fact that the credit levels were stable over that same period.

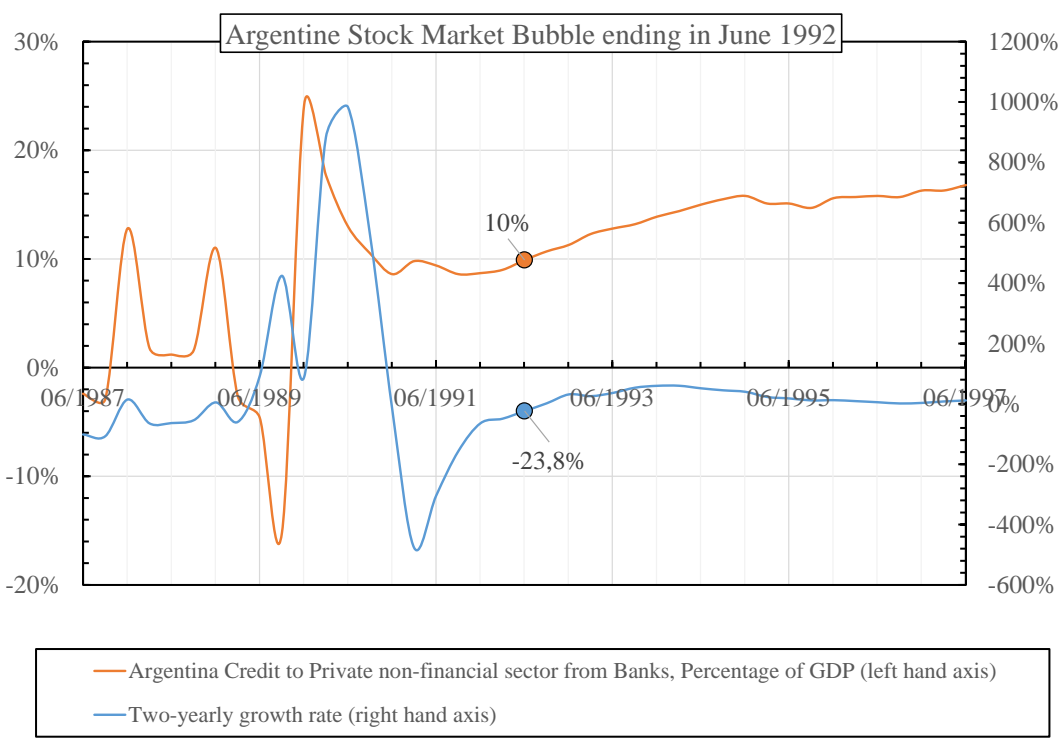

Figure 41. The credit conditions in Argentina between 1987 and 1997, five years before and after June 1992. The two filled circles are the last observations from the data source (BIS, 2017) before the peak and the subsequent crash.

\subsection{Argentinian stock market bubble ending in February 1994}

With its weak financial system, an inflexible exchange rate regime, and a heavy reliance on short-term foreign capital inflow, Argentina in the 1990s exhibited many indicators of vulnerability, according to Lowell et al. (1998). However, prior to the 1994 crisis, its economy seemed to be doing well with an average GDP growth rate of $7.7 \%$ and an inflation that had fallen to $4.2 \%$ in 1994 . This was priced-in heavily in the Argentinian stock market, which had approximately doubled between the first quarter of 1993 and its peak in February 1994. This period was identified as the third Argentinian 
bubble of the 1990s by Johansen and Sornette (2001).

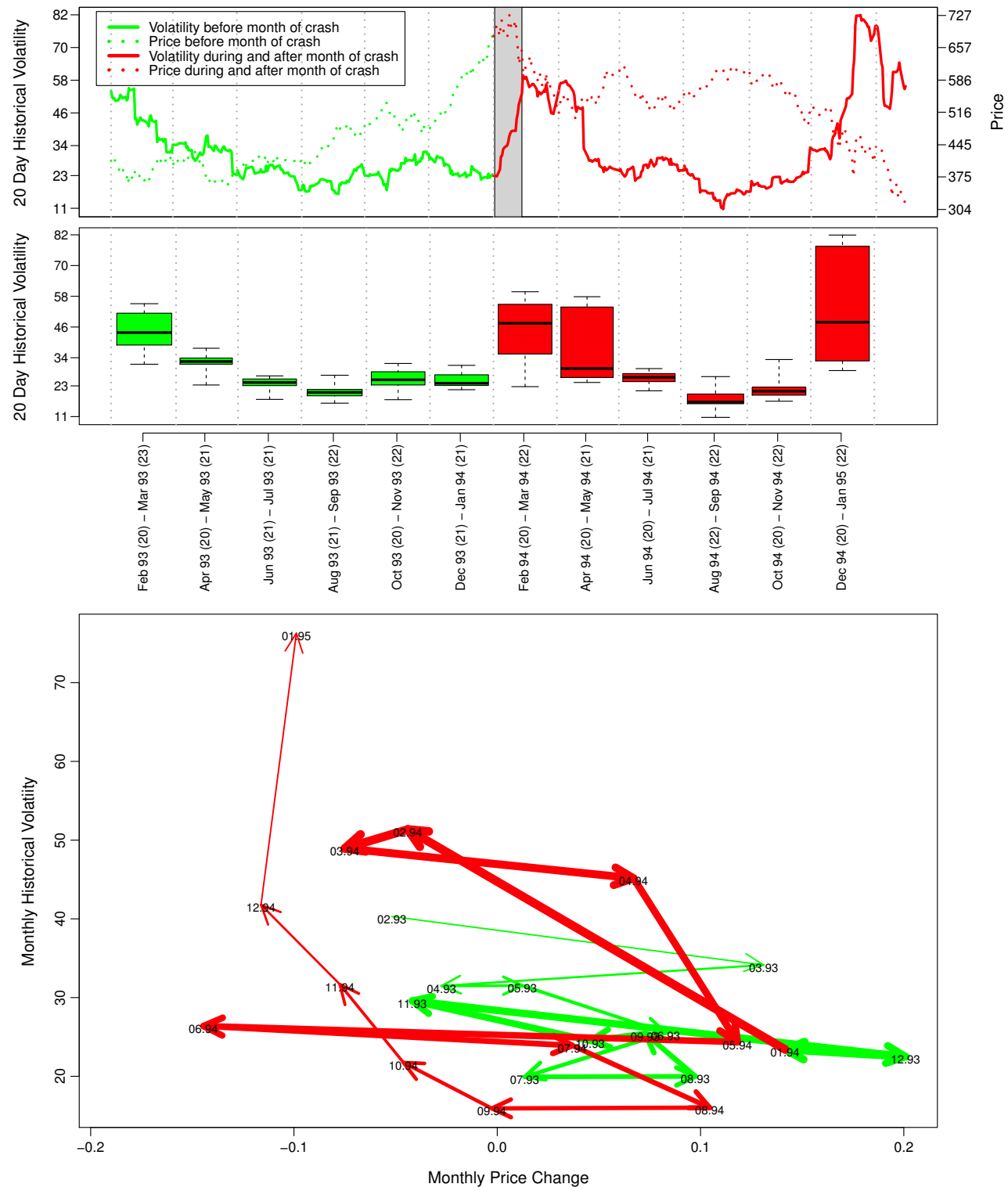

Figure 42. The Argentine stock market bubble ending in February 1994: price and historical volatility of the MERVAL index (see section 4 for a detailed methodological explanation).

This strong market appreciation, in a climate of low inflation and strong economic performance, occurred with an overall decreasing volatility, as can be seen in figure 42. During the bubble buildup phase, only a momentary rise in the historical volatility can be observed around November 1993. This coincided with a minor transient correction in the stock market. However, in the following three months, until the peak in February 1994, the volatility declined again.

Figure 43 is similar to the figure 41 from the previous section; the observations are only shifted twenty months forward in time. The plot shows the credit from banks to the private non-financial sector as a percentage of the GDP of Argentina together with its two-yearly growth rate, starting five years before and ending five years after the peak of the Argentinian stock market in February 1994. 
The data are from the Bank for International Settlements (BIS, 2017). In contrast to 1992, the credit as a percentage of GDP has resumed its growth with a two-year average growth rate of close to $60 \%$ (compared to $-24 \%$ in 1992).

We will classify this stock market bubble, ending in February 1994, as a fearless, leveraged bubble, the former meaning that the volatility was stable over the development of the bubble, the latter summarising the fact that the credit level had been increasing significantly over the period of this bubble.

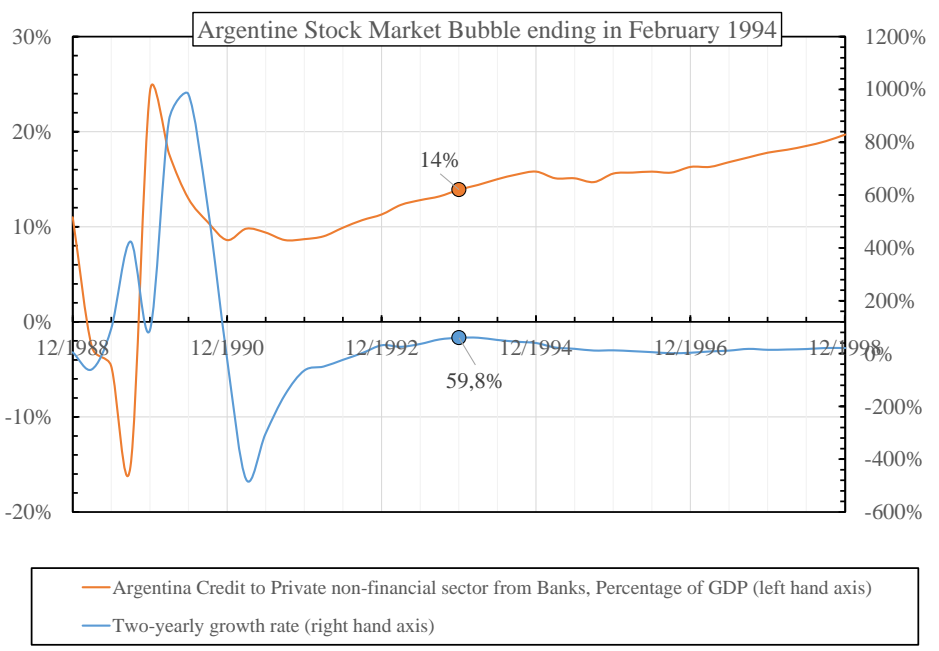

Figure 43. The credit conditions in Argentina between 1988 and 1998, five years before and after February 1994. The two filled circles are the last observations from the data source (BIS, 2017) before the peak and the subsequent crash.

\subsection{Argentinian stock market bubble ending in October 1997}

The 1997 emerging markets crisis began in July in Southeast Asia when foreign bankers, investors, currency speculators, and market analysts lost confidence in Thailand's ability to cope with a deteriorating economic situation (Sornette, 2017). The main ingredients of the 1997 Asian crisis were a rising trade deficit funded by international debt denominated in a foreign currency, over-dependence on short-term debt, over-investment in real estate and excess manufacturing capacity, inadequate supervision of financial institutions, politically influenced allocations of credit to unsound companies, overly expansive fiscal and macroeconomic policies and distorted exchange rates through the pegging of local currencies to the US Dollar (Sornette, 2017).

According to Lowel et al. (1998), the 1997 emerging markets crisis was a clear case of contagion with stock prices being affected on a global scale, almost like the spreading of an infectious disease. As explained in section 6.10, this is illustrated by the so-called "mini" crash which affected world-wide stock markets in October 1997. The wave started in Hong Kong, passed to Europe and the US and in 

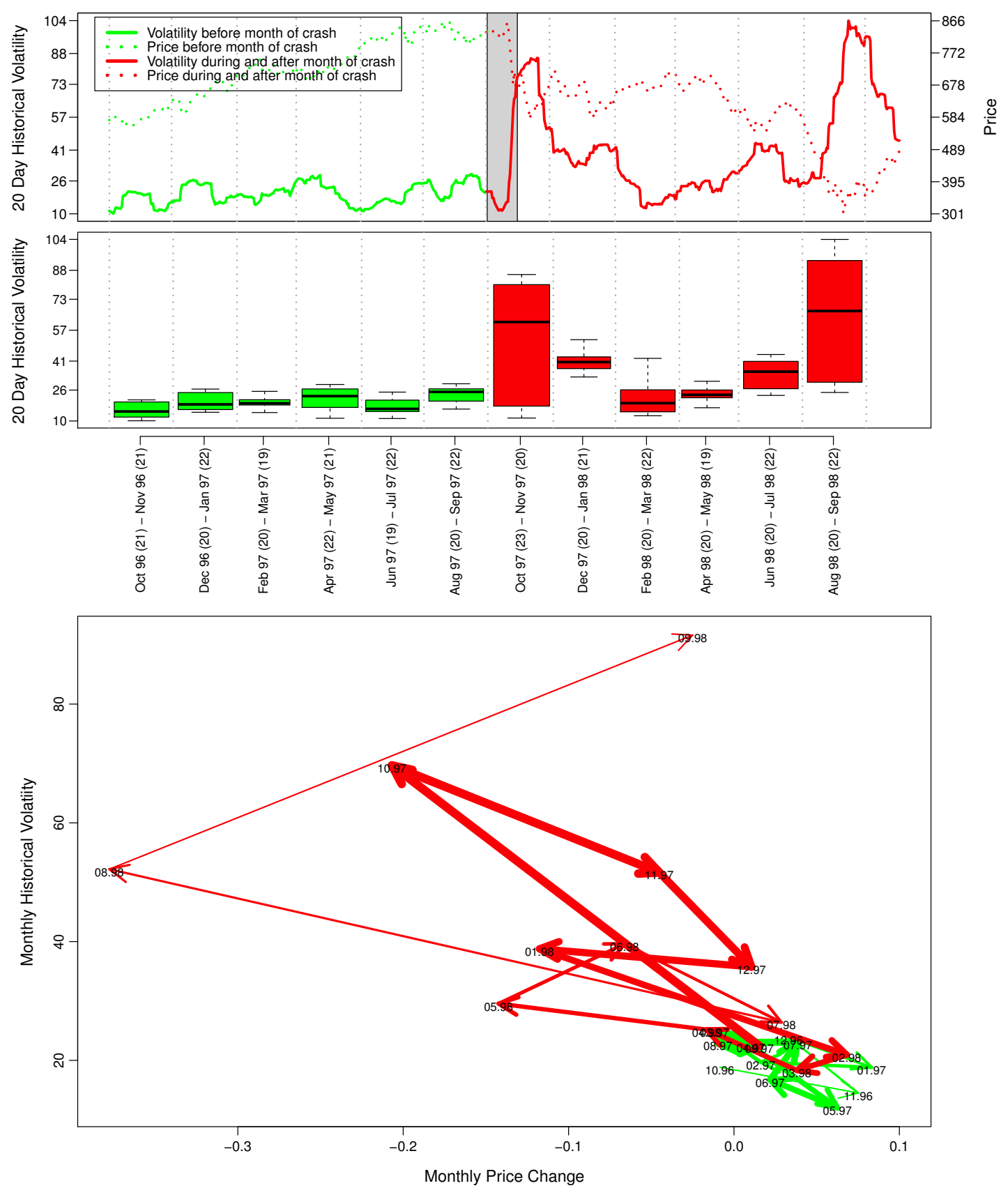

Figure 44. The Argentine stock market bubble ending in October 1997: price and historical volatility of the MERVAL index (see section 4 for a detailed methodological explanation).

its wake also impacted Argentinian stocks where the total loss reached $27 \%$ over a few weeks. This crash marked the end of the fourth Argentinian bubble of the 1990s that was identified by Johansen and Sornette (2001).

In the year before October 1997, the value of the Argentinian stock market had increased by approximately $30 \%$. As can be seen in figure 44, the bubble ended in a sharp drop, erasing in just two weeks all the previous year's gains. The same figure shows that the volatility remained at a very low 


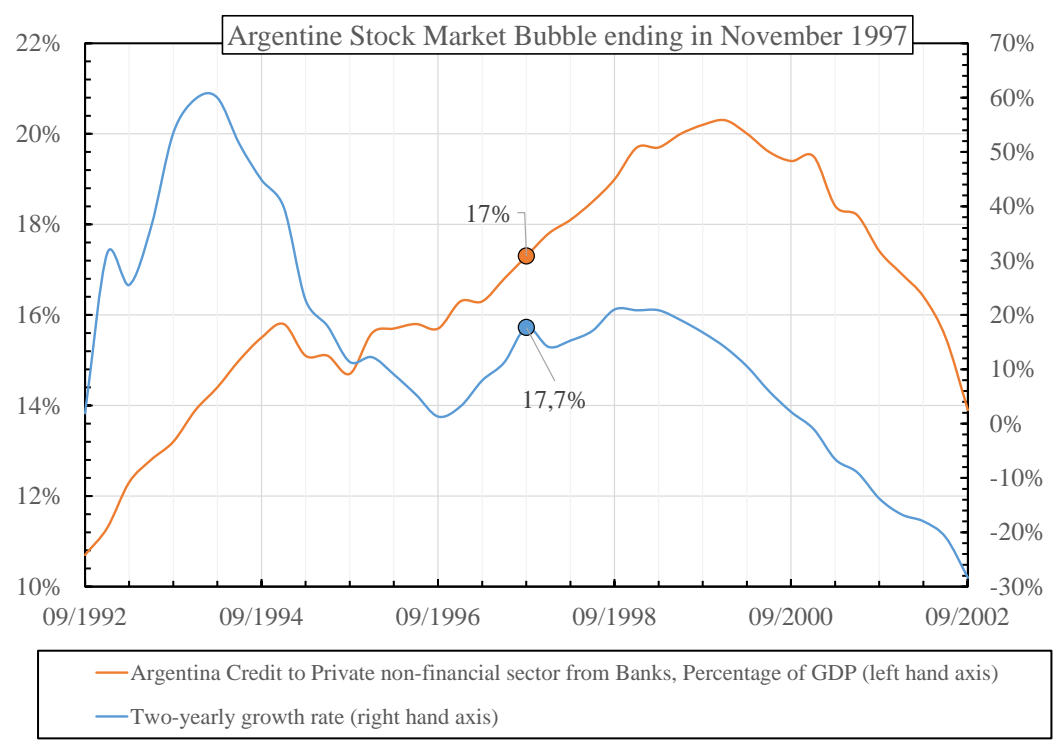

Figure 45. The credit conditions in Argentina between 1992 and 2002, five years before and after October 1997. The two filled circles are the last observations from the data source (BIS, 2017) before the peak and the subsequent crash.

level during the whole bubble build-up phase only to shoot up after the crash. This is particularly well illustrated in the lower panel of the figure 44, where all the green arrows are located in a small area of high return and low volatility, clearly demonstrating, again, the leverage effect at work.

To understand the credit conditions during this bubble and its aftermath, figure 45 shows the credit from banks to the private non-financial sector as a percentage of the GDP of Argentina, together with its two-yearly growth rate. The historical time series are plotted starting five years before and ending five years after the peak of the MERVAL index in October 1997. The data are from the Bank for International Settlements (BIS, 2017). We can see that the credit, as a percentage of GDP, had been growing during the bubble build-up phase with an annual growth rate around $18 \%$.

We will classify this stock market bubble, ending in October 1997, as a fearless, leveraged bubble, the former meaning that the volatility was stable and very low over the development of the bubble, the latter summarising the fact the credit level had been increasing significantly over the period of this bubble.

\subsection{Brazilian stock market bubble ending in July 1997}

The financial crisis in emerging markets in 1997 that was covered in the previous section 6.22, and that was initiated in Thailand in July, affected Brazil in the same month. In the two years before, the Brazilian stock market had seen an impressive bull run, with the BOVESPA index increasing sixfold. This was the result of the so-called Plano Real ("Real Plan"), which was instituted in the spring of 
1994 to fight inflation and which came with the introduction of a new currency, the Brazilian Real, pegged to the US dollar. The plan was successful and inflation was reduced to single digit annual figures. However, the large inflow of foreign investments, which followed, made Brazil vulnerable. As risk aversion inverted due to the Asian crisis in July 1997, capital fled the country and the stock market bubble, which had been fuelled by foreign investments, popped. The result was a crash of $-18 \%$ on July 18, 1997, followed by a very volatile market and a secular downward trend which found a bottom on November 13, 1997, $-41 \%$ below the peak from July. One had to wait until November 1999 to see the BOVESPA index recover this loss.

As we are linking the crash in Brazil to the crisis in Asia, it is important to emphasize that one must not mistake a systematically unstable situation for the specific historical action that triggered the event. So, we are not claiming a direct causality here, just that the Brazilian stock market had entered a fragile period, a "critical regime" (Sornette, 2017; Kaizoji and Sornette, 2010; Sornette and Cauwels, 2015), that made it more vulnerable then usual to external shocks.

Figure 46 shows the bubble in the BOVESPA index, fuelling a 130\% price appreciation in the year before the crash. During that period, the historical volatility stayed quite stable at a low level. Only after the crash, did the volatility increase significantly and become unstable and volatile itself. This behavior is clearly confirmed by the lower panel in the same figure, where we can see the green arrows before the crash confined in the high return and low volatility area. The volatility increased only at the time of the crash and in its sequel. Again, this is an example of the leverage effect. Hence, we identify this as a fearless bubble.

Figure 47 shows the credit from banks to the private non-financial sector as a percentage of the GDP of Brazil together with its two-yearly growth rate. The available data is limited, so the graph is restricted to the period between December 1995 and 1998. The data are from the Bank for International Settlements (BIS, 2017). It can be seen that the credit as a percentage of GDP had been decreasing over the preceding two years as a consequence of the "Plano Real" mentioned above.

We thus classify this stock market bubble, ending in July 1997, as a fearless, non-leveraged bubble, the former meaning that the volatility was stable and very low over the development of the bubble, the latter summarising the fact the credit level had been decreasing and remained low over the period of this bubble.

\subsection{Chilean stock market bubble ending in October 1991}

During the 1980s, Chile saw a progressive democratization from a tight control by the military, in 1980, to an acceptance, by the Pinochet regime, for the creation of political parties and the opening of national registers of voters, in 1987. In July 1989, a constitutional referendum took place, after long negotiations between the government and the opposition, leading to the affirmation of political pluralism, the strengthening of constitutional rights, democratic principles and the participation to political life. In December 1989, the Christian Democrat Patricio Aylwin won a sweeping victory in the first democratic elections. This transition occurred in the atmosphere of the glasnost and the perestroika democratic reforms initiated by Mikhail Gorbachev in the USSR, leading eventually to the fall of the Berlin Wall in 1989 and to the official end of the Cold War in 1990.

In this climate of a progressive transition in governance, tax reforms, government social spending and capital controls, the IPSA index saw a threefold increase in just ten months before October 1991. This was followed by a $22 \%$ drop over the following two months. For the next two years, the Chilean 

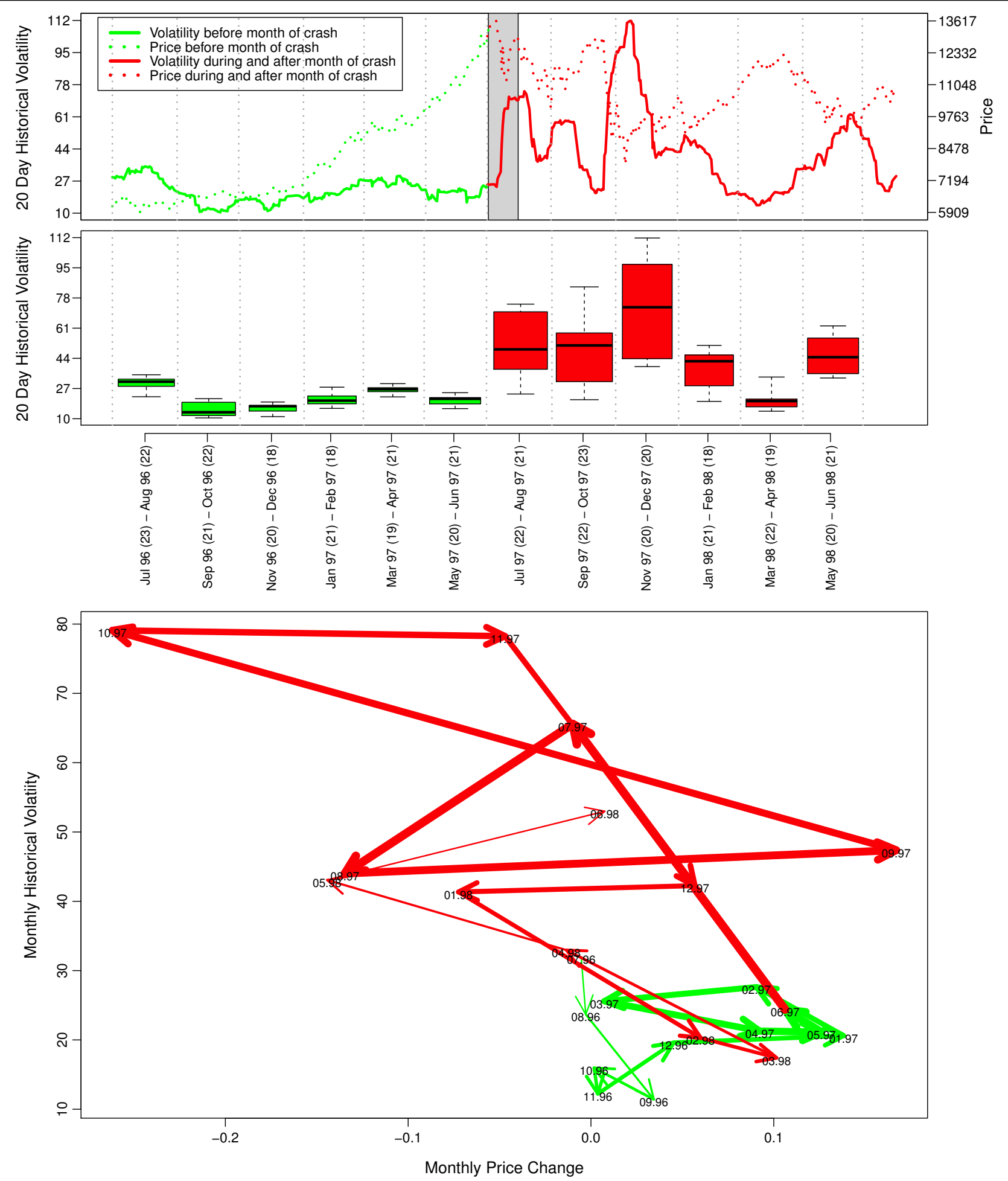

Figure 46. The Brazilian stock market bubble ending in July 1997: price and historical volatility of the BOVESPA index (see section 4 for a detailed methodological explanation).

stock market went sideways, with a series of ups and downs, until the next bubble set off that culminated in February 1994 (this will be covered in the next section 6.25). 


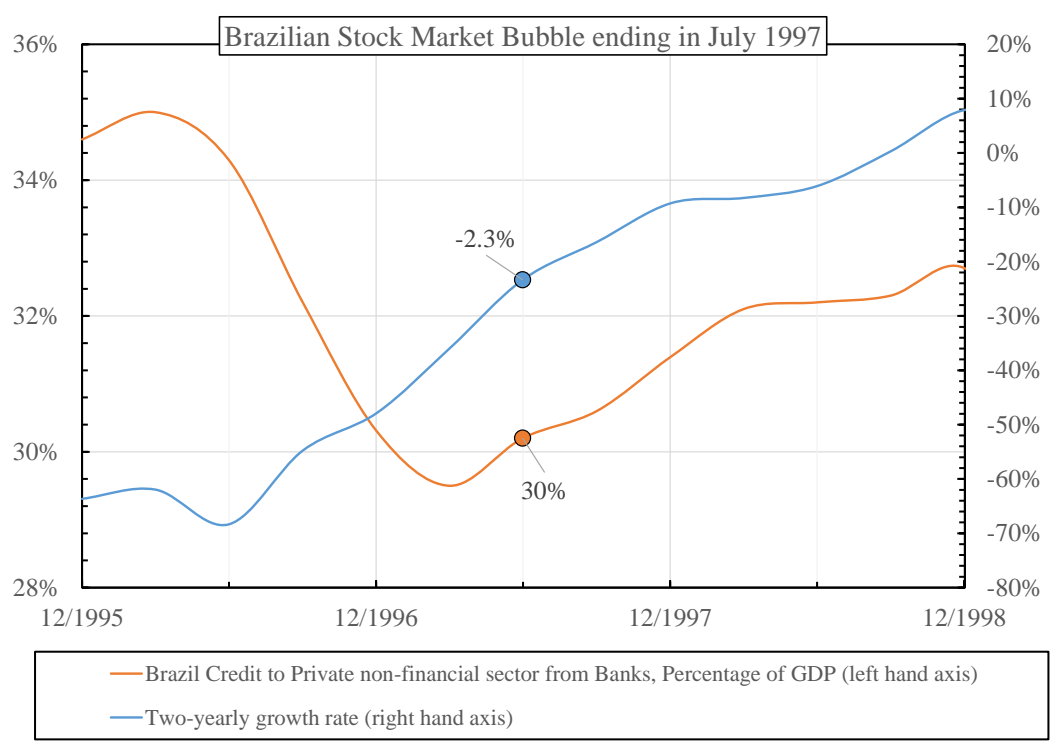

Figure 47. The credit conditions in Brazil between 1995 and 1998. The two filled circles are the last observations from the data source (BIS, 2017) before the peak and the subsequent crash in July 1997.

Figure 48 shows the ascent of the IPSA index in the year before October 1991. Over this period, the volatility was relatively high with four waves of a noisy oscillatory behavior. This is confirmed by the arrow plot in the lower panel. Right before the correction, the volatility had reached a new high. Therefore, we will classify this stock market bubble, ending in October 1991, as a fearful bubble.

The database of the Bank for International Settlements (BIS, 2017) does not contain data on credit from banks to the private non-financial sector in that period for Chile. Therefore we will not evaluate the impact of leverage on this bubble.

\subsection{Chilean stock market bubble ending in February 1994}

After a serious debt crisis in the 1980s, the Chilean government adopted a policy of fiscal discipline and inflation targeting (Caputo and Saravia, 2014). This created a friendly environment for investors. As a consequence, the Chilean stock market doubled in value between May 1993 and February 1994. The correction that followed was part of the "rash of crises spanning January-June 1994" that was identified in 1998 by Lowell et al. (1998) and that we already discussed in our analysis of the Hong Kong stock market correction of January 1994 (see section 6.16) and the Argentinian bubble ending in February 1994 discussed in section 6.21).

Figure 49 shows that the ascent of the IPSA index was undoubtedly associated with a steady increase in the historical volatility during the bubble build-up phase in the six-month period before the crash. Consequently, We will classify this stock market bubble, ending in February 1994, as a fearful bubble. 

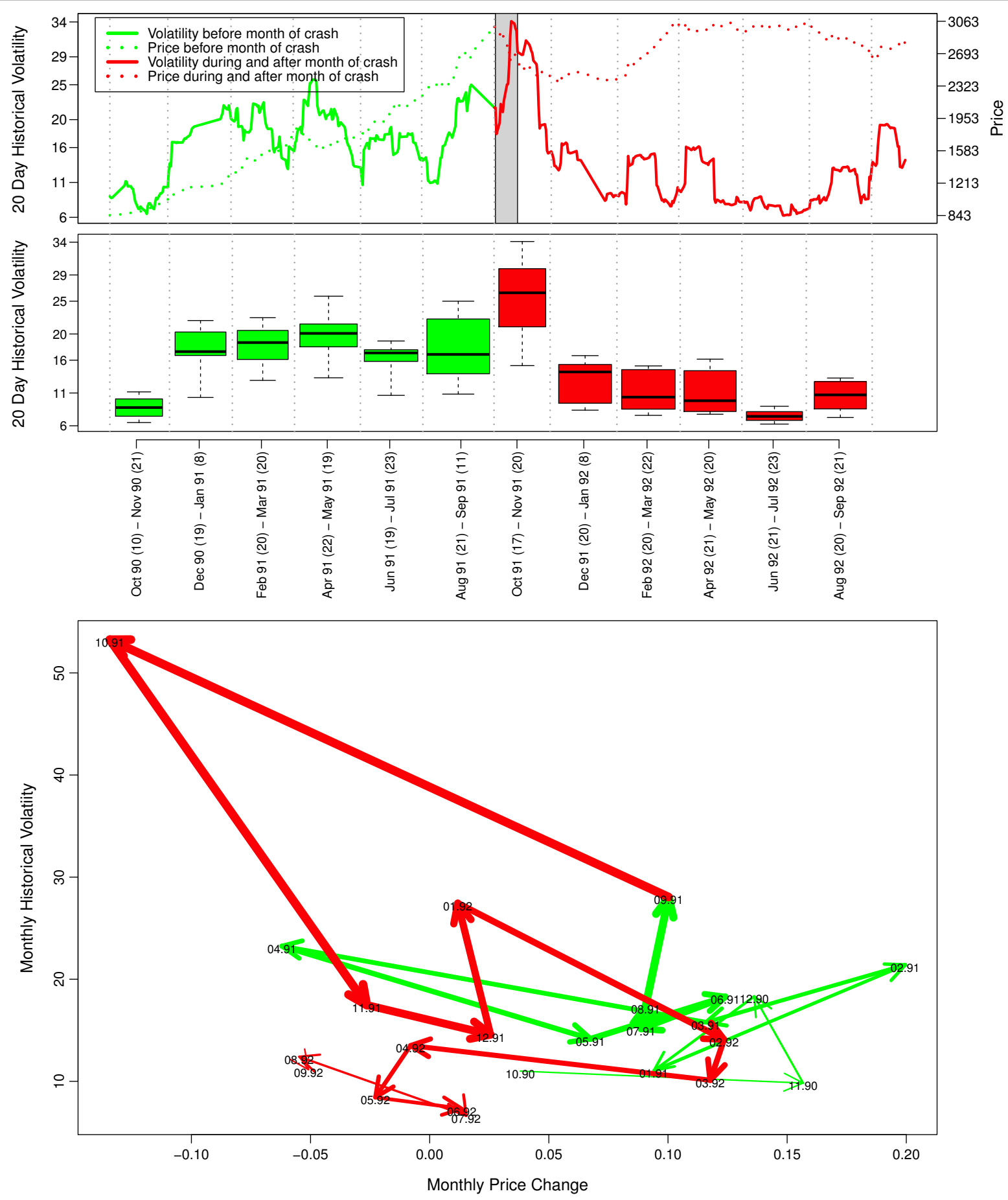

Figure 48. The Chilean stock market bubble ending in October 1991: price and historical volatility of the IPSA index (see section 4 for a detailed methodological explanation).

The database of the Bank for International Settlements (BIS, 2017) does not contain the amount of credit from banks to the private non-financial sector in that period for Chile. Therefore we will not evaluate the impact of leverage on this bubble. 

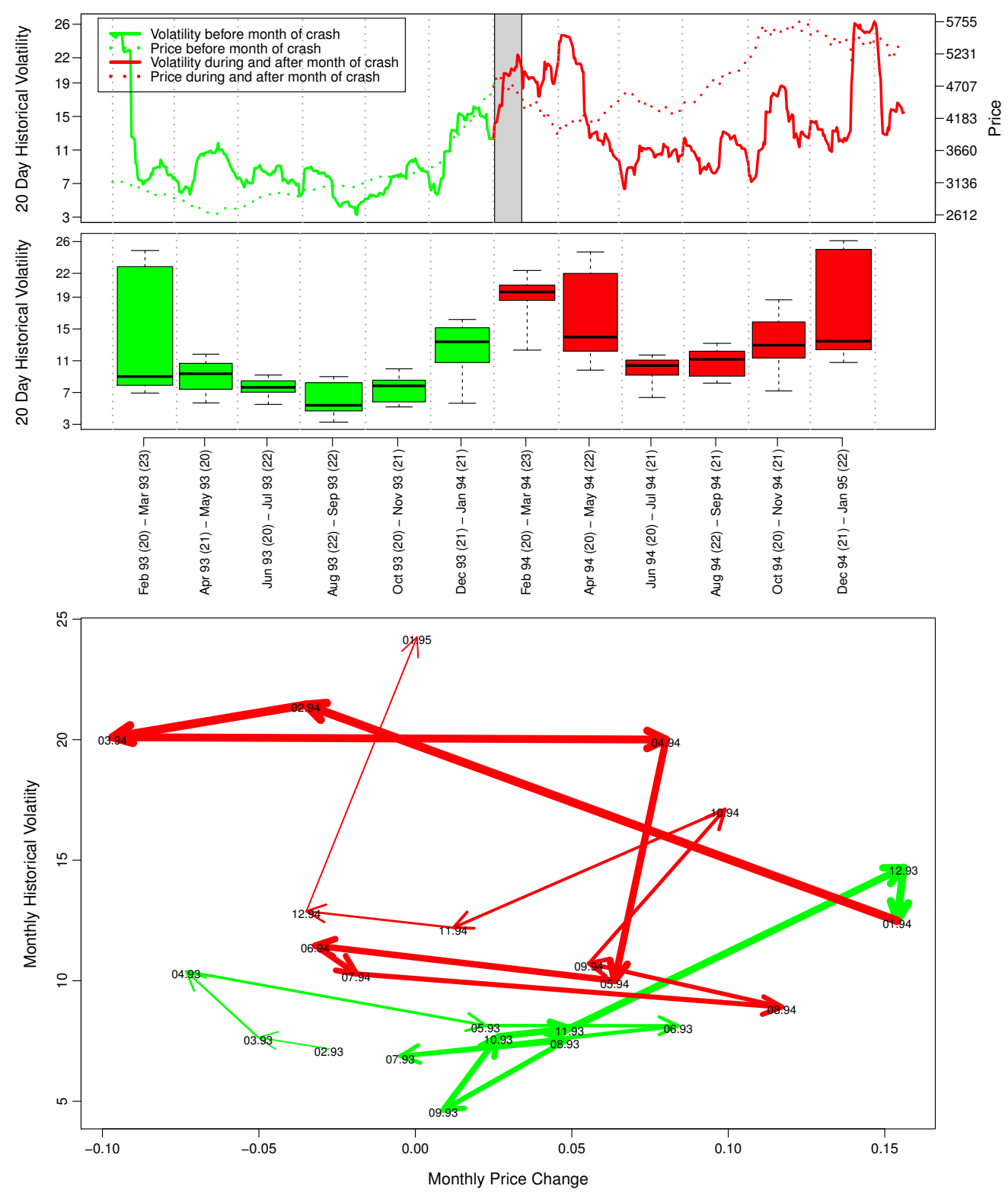

Figure 49. The Chilean stock market bubble ending in February 1994: price and historical volatility of the IPSA index (see section 4 for a detailed methodological explanation).

\subsection{Mexican stock market bubble ending in October 1997}

In the second half of the 1980s, Mexico implemented a large scale reform of its economy (Musacchio, 2012), liberalizing trade and capital flows, reducing import tariffs and deregulating and privatizing its banking system. An important component of the Mexican reform strategy was to fix the value of the Peso to the US Dollar. Reducing the exchange rate risk gave confidence to foreign investors, it boosted import-export business and it facilitated borrowing in international markets for Mexican firms. According to Musacchio (Musacchio, 2012), investor enthusiasm led to a bubble-like dynamic in which the value of Mexican assets and the return to investors went up in line with the amount of foreign capital that entered the country. GDP growth rates of 3\% in 1992 and 2\% in 1993, 
however, did not justify this hype. Investors were betting on Mexico's future and "Any event that triggered expectations to change from positive to negative would spark a massive sale of Mexican assets and capital flight" (Musacchio, 2012). This is exactly what happened. Bad macroeconomic figures, political turmoil and violence brought risk aversion back. The result was a large-scale capital flight, forcing the Mexican government to devalue the Peso against the US dollar in December 1994, which led to a global financial crisis in emerging markets. This is often referred to as the Mexican Peso crisis, or the "Tequila" crisis.

In 1995, Mexico went through the worst recession in its history as capital flight continued and the Peso further depreciated. Rubert Rubin, treasury secretary of the United States, warned that a further collapse of the Mexican economy could bring down economies on a global scale (Musacchio, 2012). Consequently a large scale bailout was orchestrated by the US Treasury, the IMF, the Bank for International Settlements and some private banks to stem further speculative attacks and to stabilize the Peso and the Mexican economy. In the end, as Musacchio (Musacchio, 2012) claims, after the recession of 1995 and the banking crisis of 1995 and 1997, the country ended up with a more stable economy. Trade with the US and other countries expanded rapidly, and the business cycle synchronized with that of the US.

The Mexican BOLSA stock index reached its low around 1450 in the midst of the "Tequila" crisis. After the establishment of the bailout package, stocks started appreciating quickly again, reaching a high around 5300 in October 1997, increasing almost fourfold in two and a half years. At that time the Mexican stock market was in a full bubble expansion mode again, which made it particularly vulnerable to any minor outside trigger. Like a ruler held up vertically on one finger, any small disturbance could trigger its fall. This trigger came from the "mini" crash, which swept through global markets in October 1997 (see sections 6.10 and 6.22).

The upper panel of figure 50 shows the price history and the 20-day historical volatility of the Mexican BOLSA index before (green) and after (red) it peaked around the end of October, 1997. The grey area represents the one month period after the peak. Between October 22 and 27, the index fell from its 5300 peak to a local minimum of 4260, a loss of almost $20 \%$ in just a few days. Before the peak, an increase in the volatility can be clearly observed. This is confirmed by the arrow plot in the lower panel of the figure. From this observation, we can conclude that this is a fearful bubble.

To understand the credit conditions during this bubble and its aftermath, figure 51 shows the credit from banks to the private non-financial sector as a percentage of the GDP of Mexico, together with its two-yearly growth rate. The historical time series are plotted starting five years before and ending five years after the peak of the Mexican BOLSA index in October 1997. The data are from the Bank for International Settlements (BIS, 2017). We can see from the decreasing credit levels that, in the aftermath of the "Tequila" crisis, the economy was still deleveraging.

We will classify the stock market bubble, ending in the October $1997 \mathrm{crash}$, as a fearful, nonleveraged bubble, the former meaning that there was a significant rise in volatility during the bubble period leading up to the crash, the latter meaning that the bubble could not be linked to any rise in credit in the Mexican economy during that same period.

\subsection{Peruvian stock market bubble ending in October 1993}

In his book Irrational Exuberance, Robert Shiller (2006) presents an extensive analysis of the largest global one-year real stock market increases of the second half of the twentieth century. The 

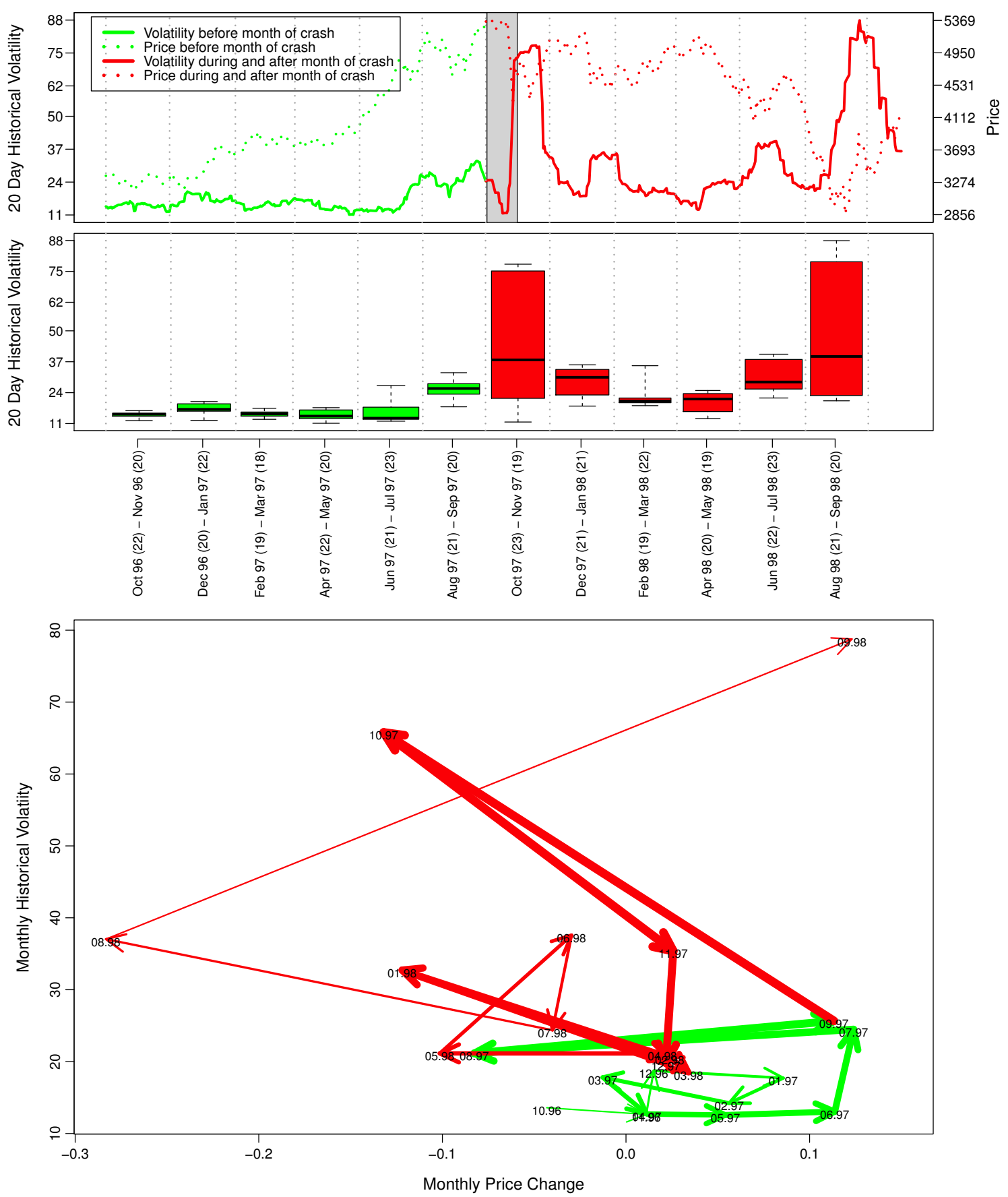

Figure 50. The Mexican stock market bubble ending in October 1997: price and historical volatility of the BOLSA index (see section 4 for a detailed methodological explanation).

Peruvian bubble of 1992-1993 is ranked fourth in this study, with real stock prices appreciating $361 \%$ from August 1992 to 1993. According to Shiller's analysis of the facts (Shiller, 2006), the increase occurred after a market plunge in April 1992, when Alberto Fujimori seized dictatorial powers, dissolved congress and suspended the constitution amid civil war with the Shining Path guerrillas. In September 1992 the Shining Path leadership was captured, and by April 1993 democracy had been 


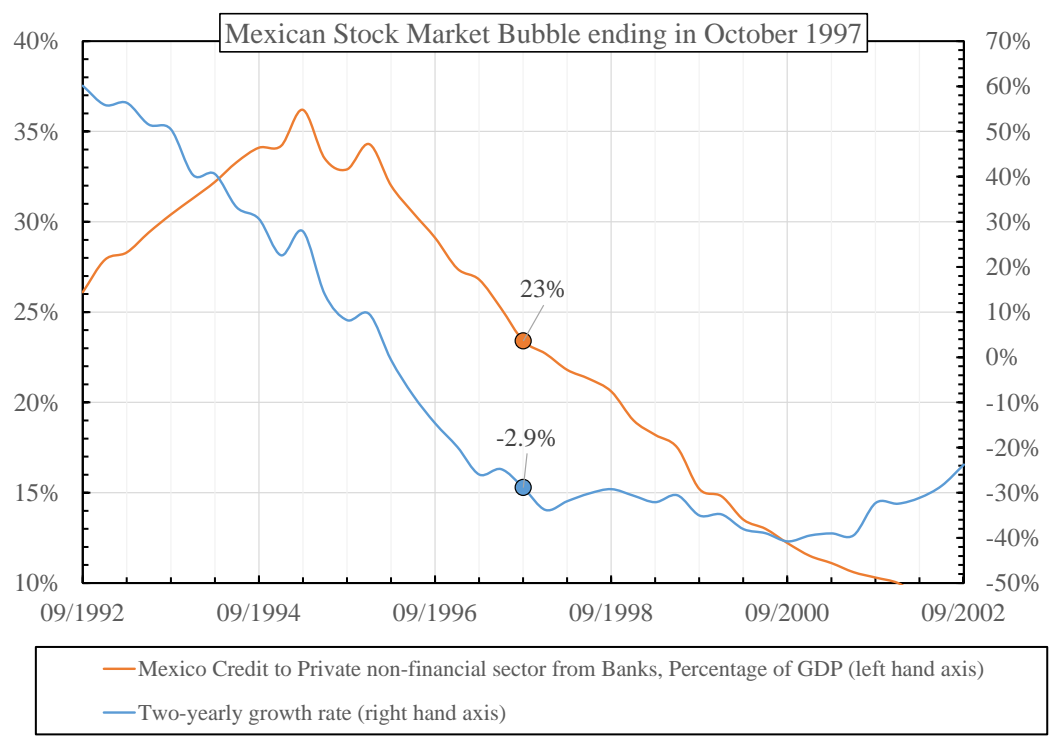

Figure 51. The credit conditions in Mexico between 1992 and 2002. The two filled circles are the last observations from the data source (BIS, 2017) before the peak and the subsequent crash in October 1997.

restored, ending a period of violence that had killed 27,000 people. Additionally, by 1993, inflation was being brought under control after it had reached 7,000\% in 1990, and economic growth was positive. According to Shiller, "A wonderful sense of new era was certainly in evidence - but a quadrupling of stock prices within a year left many wondering if the increase was excessive" (Shiller, 2006).

In November 1993, the Peruvian IGBVL index corrected more than 22\%, dropping from around 1060 to 820 in one month. The correction, however, appeared to be only transient and stock prices soon started rising again, recovering the loss by the end of January 1994. According to Shiller (2006), the Peruvian stock market increase seemed to have been properly motived by genuinely positive fundamentals. Nevertheless, the year before October 1993, with its fourfold increase in price, was a period of clear exuberance, and it was classified as a bubble by Johansen and Sornette (2001) after a super-exponential growth process was identified. As mentioned on different occasions in this paper, this is the hallmark of a non-sustainable regime, due to be followed by a correction (Sornette and Cauwels, 2015). In other words, it is the association of the faster-than-exponential price increase followed by the correction that supported the view that there was a bubble component on top of a possible genuine fundamental growth.

Figure 52 shows the 20-day historical volatility of the IGBVL index before (green) and after (red) October 1993. When looking at the longer trend, between October 1992 and 1993, one can see the volatility going down and the stock market going up. This downward trend in volatility is punctuated, 

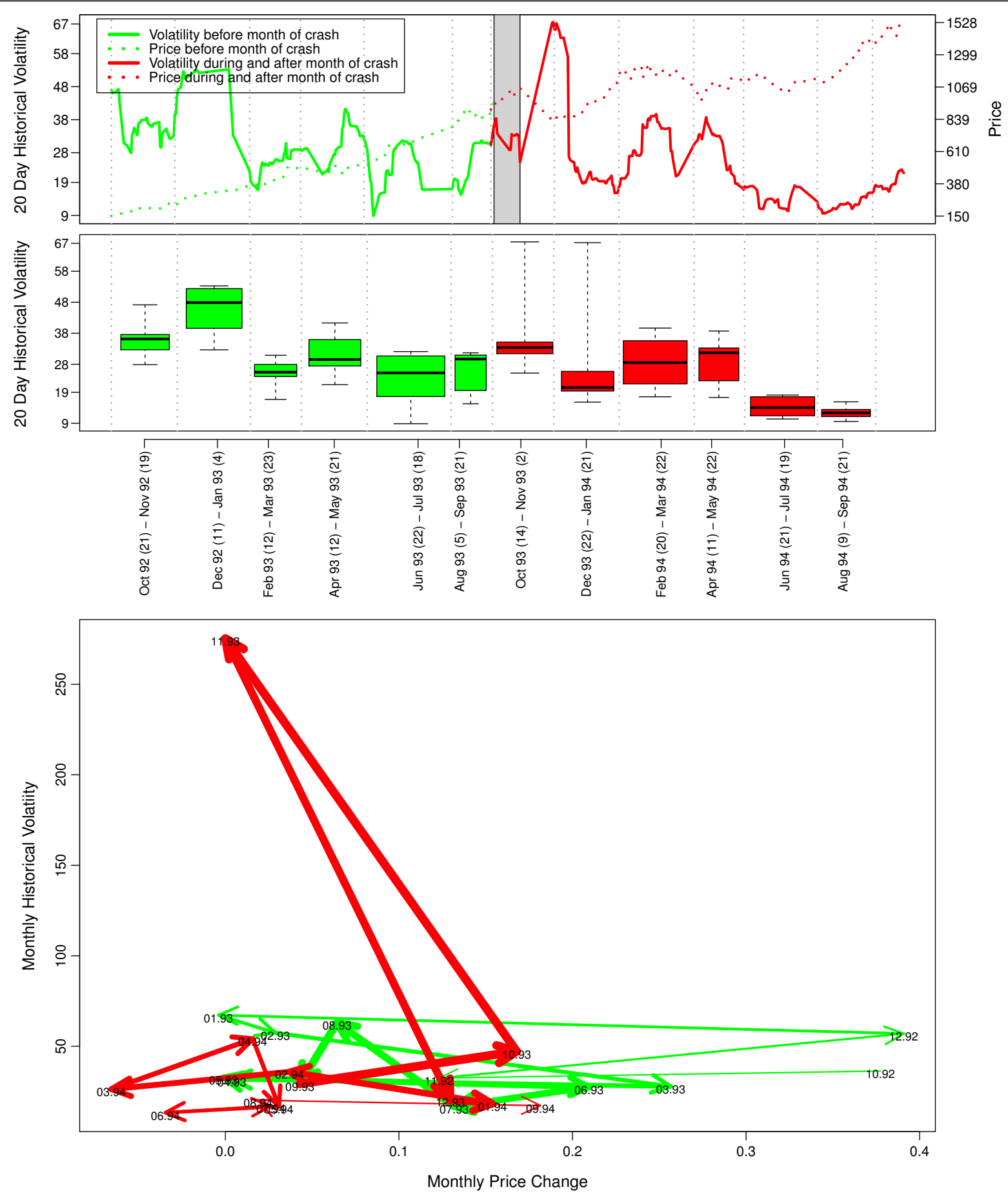

Figure 52. The Peruvian stock market bubble ending in October 1993: price and historical volatility of the IGBVL index (see section 4 for a detailed methodological explanation).

however, with short and sudden bursts, coinciding with minor transient price corrections. The classification of this bubble is not clear-cut. However, one can argue, based on these short and sudden spells in volatility, that market participants were anticipating a correction. So we will conservatively classify this bubble as fearful. 
The database of the Bank for International Settlements (BIS, 2017) does not contain the amount of credit from banks to the private non-financial sector in that period for Peru. Therefore we will not evaluate the impact of leverage on this bubble.

\subsection{Peruvian stock market bubble ending in June 1997}

According to a study of the World Bank from 1998 (Perry and Lederman, 1998), Peru immediately felt the effects of the 1997 Thai crisis (which was discussed before in section 6.22). With 19\% of Peruvian exports going to developing Asia in 1996 (Perry and Lederman, 1998), the country had very strong trade links with the crisis-struck Asian regions. The Asian crisis brought risk aversion back to the global markets, which made foreign capital to flee many emerging market countries, amongst which Peru and Brazil, which we discussed in section 6.23.

In the first five months of 1997, between January 1 and May 30, the IGBVL index gained more than 50\% in value. According to Johansen and Sornette (2001) a numerical analysis of the faster-thanexponential price acceleration could not be done due to an almost vertical rise at the very end of the bubble (between May 6 and June 2 the index gained 27\% in value).

Figure 53 shows the 20-day historical volatility of the IGBVL index before (green) and after (red) June 1997. The grey area represents the one month period after the peak. Interestingly the observation is very similar to the Peruvian stock market bubble of 1993 that we discussed in the previous section (see 6.27). The longer trend does not show a general increase in the volatility during the massive stock appreciation. However, short and sudden spells can be observed in the volatility suggesting that market participant were anticipating a correction. So, we will also classify this bubble as fearful.

The database of the Bank for International Settlements (BIS, 2017) does not contain the amount of credit from banks to the private non-financial sector in that period for Peru. Therefore we will not evaluate the impact of leverage on this bubble.

\subsection{Venezuelan stock market bubble ending in October 1997}

In contrast to Peru, Venezuela's export to the crisis-struck Asian regions in 1997 was less than $1 \%$ (Perry and Lederman, 1998). So, its stock market did not respond to the Thai crisis of mid-1997 in the way that Peru did. To the contrary, the Caracas IBVC index continued its stellar rise and appreciated almost another 50\% in the four months from June to September, 1997.

However, oil prices had been steadily decreasing. From the recent peak of $40 \$$ per barrel (West Texas Intermediate) in December, 1996, they had already come down to $32 \$$ per barrel by September, 1997 , and were destined to fall further to a historical minimum of $17 \$$ per barrel about one year later, in November 1998.

It is interesting to observe that Venezuelan stock prices rose more than $50 \%$ between January 1, 1997 and October 27, 1997 while over that same period oil prices dropped 20\% and an emerging market crisis swept through Asia and Latin America. Only after the "mini" crash infected global markets (which we discussed on several occasions before, see sections 6.10, 6.26 and 6.22) did reality begin to set in. The result was devastating. In the year following the "mini" crash, between October 27, 1997 and October 27, 1998, the IBVC index lost more than $60 \%$ of its value. The "mini" crash was the "straw that broke the camel's back", it was an exogenous perturbation that only acted as a trigger when the system was ripe. The Venezuelan crisis of 1998 constitutes an exemplary illustration of the 

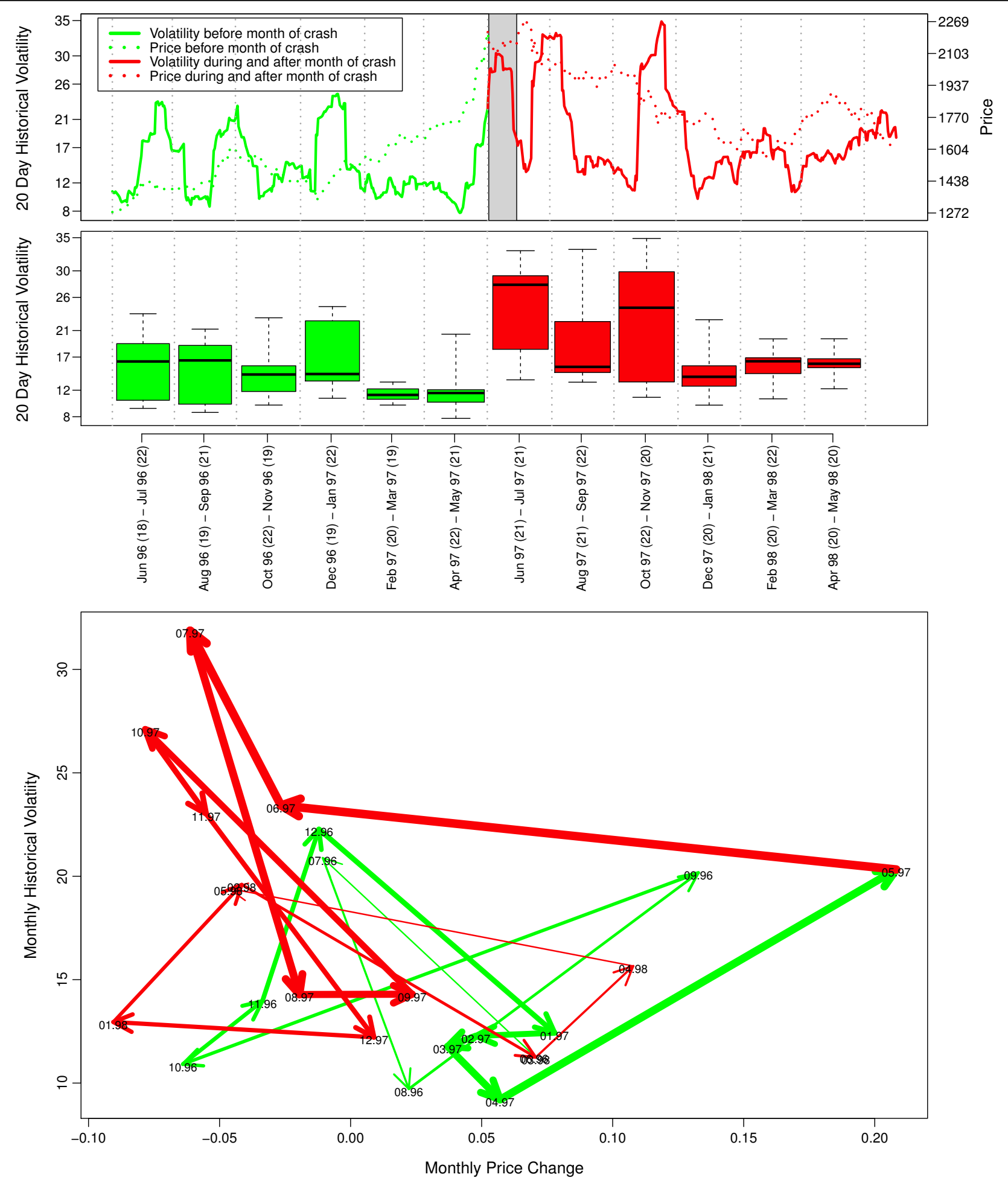

Figure 53. The Peruvian stock market bubble ending in June 1997: price and historical volatility of the IGBVL index (see section 4 for a detailed methodological explanation).

framework based on the mechanics of creep in material sciences that was published by Sornette and Cauwels in 2015 (Sornette and Cauwels, 2015). 

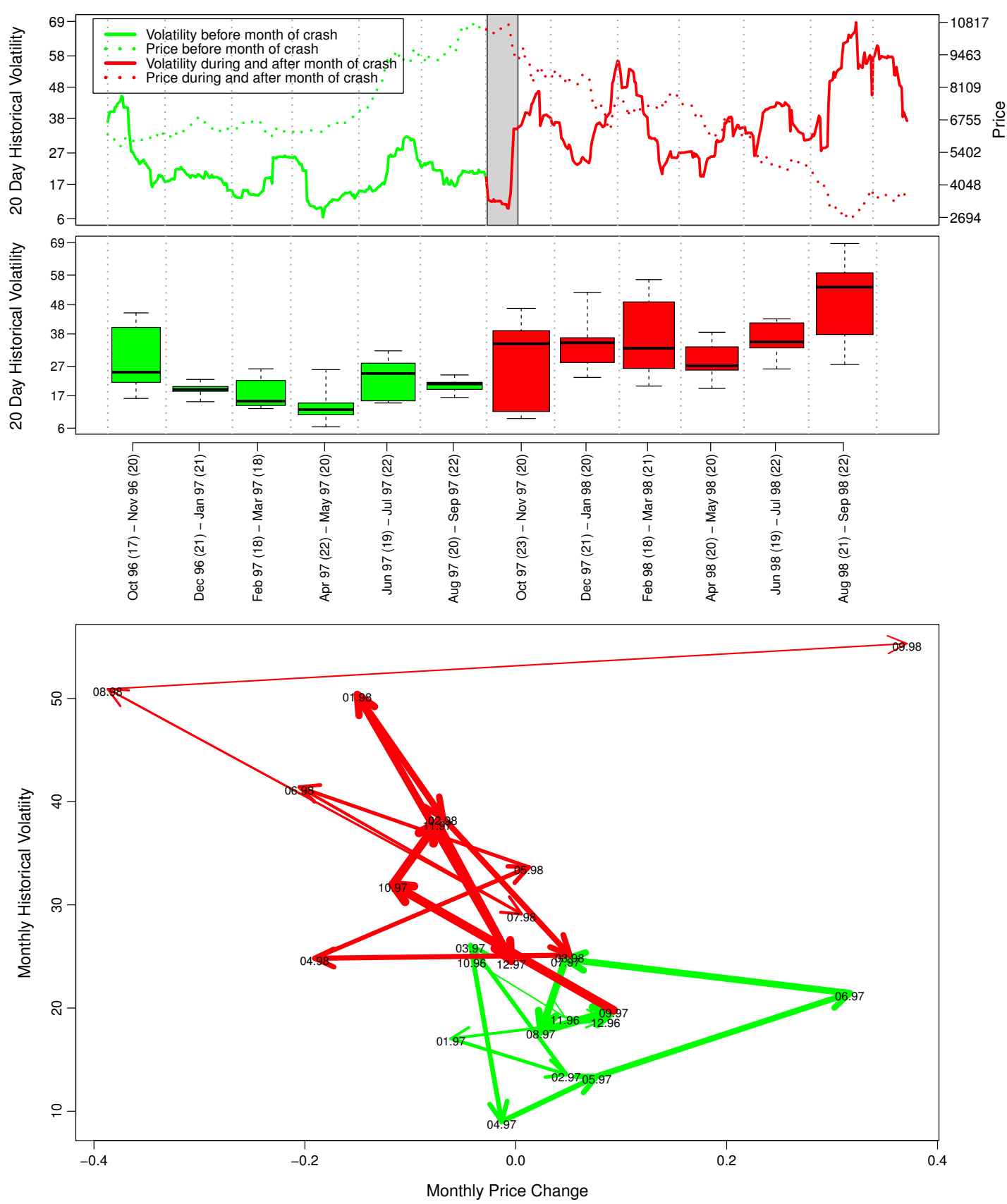

Figure 54. The Venezuelan stock market bubble ending in October 1997: price and historical volatility of the IBVC index (see section 4 for a detailed methodological explanation).

Figure 54 shows the 20-day historical volatility of the Caracas IBVC index before (green) and after (red) October 1997. Besides some fluctuations in the volatility corresponding to minor and transient corrections in the stock price, the general trend for the volatility is downward, with a specific steep drop even in the last two months before the change of regime. This observation is clearly confirmed by the arrow plot where we see the green arrows confined in the low volatility, high return region, and the red arrows in the high volatility, low return region. So, we will also classify this bubble as fearless. 
The database of the Bank for International Settlements (BIS, 2017) does not contain the amount of credit from banks to the private non-financial sector in that period for Venezuela. Therefore we will not evaluate the impact of leverage on this bubble.

\subsection{Indonesian stock market bubble ending in January 1994}

In section 6.16, we discussed the regime-switch that happened in the Hong Kong stock market in January 1994. It was mentioned that this was part of what Lowell et al. (1998) named "a rash of crises", which impacted, between January and June 1994, stock markets in Chile, Hungary, India, Indonesia, Malaysia, Philippines, Poland, South Africa, Turkey, Venezuela, Germany, Hong Kong, Singapore, the UK and the US. The systemic factor of this crisis is generally attributed to sharply rising interest rates in the United States. However, the authors claim that this could not have been the single trigger of this global crisis and that also country specific events must have exacerbated this global financial crisis.

Like the Venezuelan case that was discussed in the previous section 6.29, the framework, proposed by Sornette and Cauwels, based on the mechanics of creep (Sornette and Cauwels, 2015), can also give guidance here and help to better understand the non-linear dynamics behind this "rash of crises". The countries that were severely affected by this crisis had their own specific drivers that slowly increased the tension in their social, economic and financial fabric. Like with creep in materials, for a very long time, the situation looks stable and apparently, everything seems fine. Then all of a sudden, something breaks. The stable phase may hold on for years, but slowly, creep drives the system towards criticality. When the system is close to its critical threshold, any minor exogenous disturbance may trigger a major event or a change in regime. According to Lowell et al. (1998), the idiosyncratic drivers making Indonesia more fragile in the 1990s were labour disputes and ethnic tensions; the exogenous trigger was sharply rising interest rates in the United States.

The Indonesian stock market reached its peak early January 1994. In the year before, the JCI index, Jakarta's benchmark stock index, had increased by 115\%; a massive bubble had been building up, with price levels and growth rates that were not sustainable. This added more idiosyncratic stress in the Indonesian economic system. The peak was reached on January 5, 1994. After that, the index lost more than $25 \%$ in value before reaching a local minimum three months later in April.

The upper panel of figure 55 shows the price history and the 20-day historical volatility of the Indonesian JCI index before (green) and after (red) it peaked in January 1994. It is clear from this plot that the volatility had been increasing firmly before the crash. This observation is confirmed by the arrow plot in the lower panel of the figure.

To understand the credit conditions during this bubble and its aftermath, figure 56 shows the credit from banks to the private non-financial sector as a percentage of the GDP of Indonesia, together with its two-yearly growth rate. The historical time series are plotted starting five years before and ending five years after the peak of the JCI index in January 1994. The data are from the Bank for International Settlements (BIS, 2017). We can see that credit creation had been stable during the build-up period of the stock market bubble.

We will classify this case as a fearful, non-leveraged bubble, the former meaning that there was a significant rise in volatility during the bubble period, the latter meaning that the bubble could not be linked to any rise in credit in the Indonesian economy during that same period. 

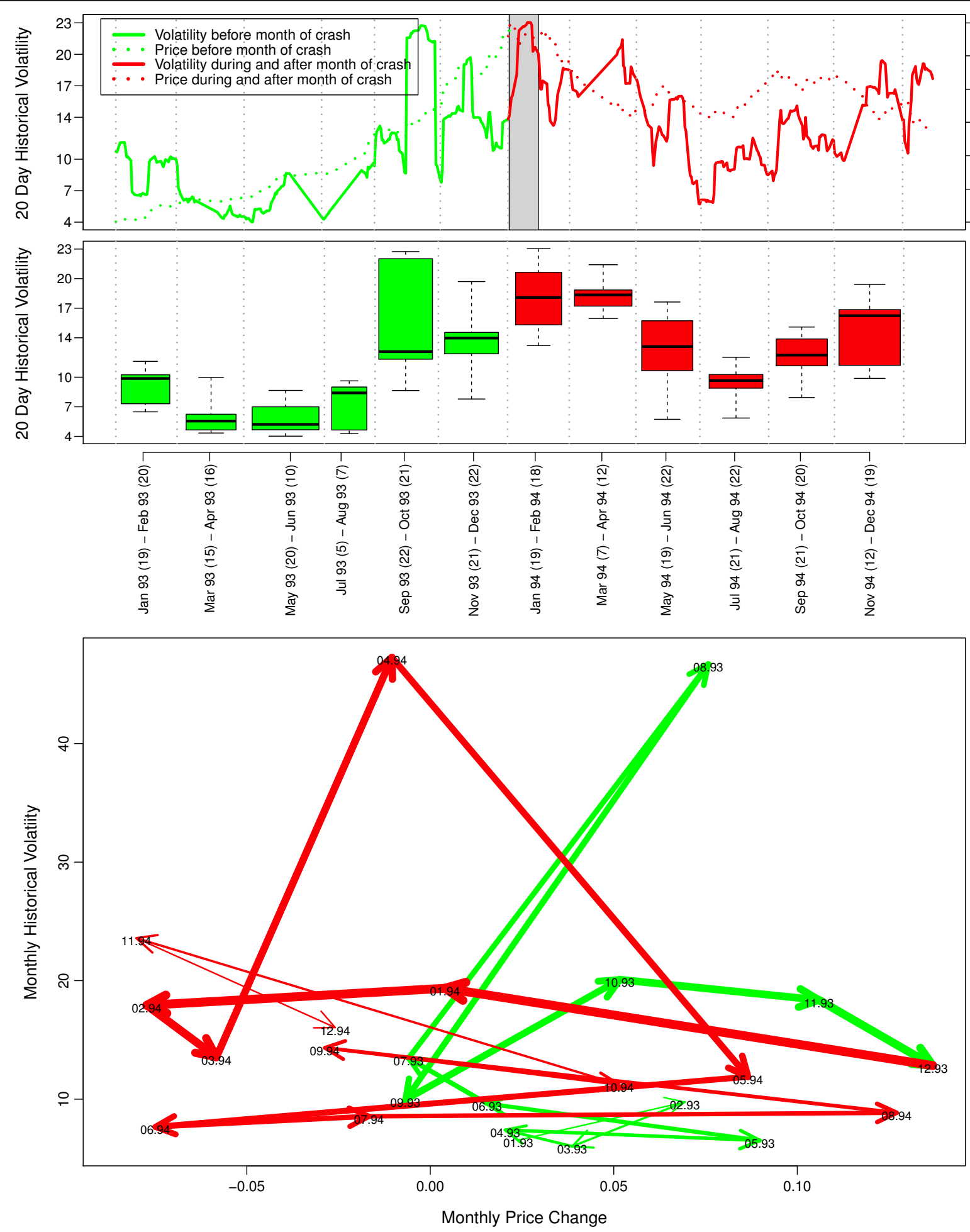

Figure 55. The Indonesian stock market bubble ending in January 1994: price and historical volatility of the JCI index (see section 4 for a detailed methodological explanation). 


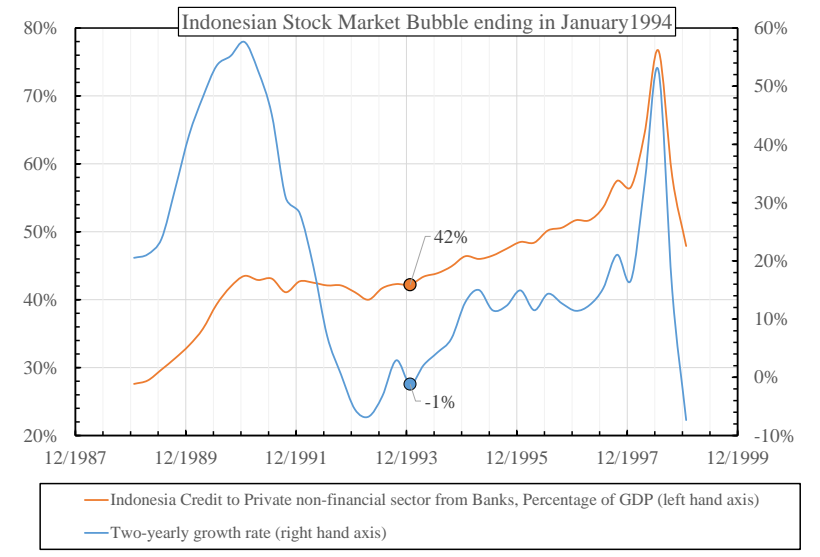

Figure 56. The credit conditions in Indonesia between 1988 and 1998, five years before and after January 1994. The two filled circles are the last observations from the data source (BIS, 2017) before the peak and the subsequent crash.

\subsection{Indonesian stock market bubble ending in July 1997}

The 1997 crisis began in July in Southeast Asia when foreign investors lost confidence in Thailand's ability to service its growing international debt, which had reached 50\% of its GDP (Sornette, 2002). Regional stocks were dumped and foreign lenders stopped rolling over their short-term loans. After depleting its hard currency reserves, the Thai government had little choice but to abandon the currency peg with the US Dollar and let the Baht float. The resulting plunge in the Baht led to a series of forced currency devaluations that soon swept through Indonesia, Malaysia and the Philippines, and then spread to global emerging markets like Brazil and Peru, which were discussed in the previous sections 6.23 and 6.27 .

Indonesia got immediately infected by the crisis in Thailand through speculative pressure on the Rupiah. The Indonesian monetary authorities reacted by widening the currency trading band from $8 \%$ to $12 \%$. Speculative attacks continued and after a series of events the Bank of Indonesia decided to float the currency. This all came as a surprise as the Indonesian economy was characterized in the years before the crisis by strong economic performance with annual real GDP growth rates averaging 8\% from 1989 to 1996 (IMF Independent Evaluation Office, 2003). However, the impact of the short-term foreign debt was underestimated and the weakness of the banking system and the degree of corruption in the country was not adequately recognized (IMF Independent Evaluation Office, 2003).

The Indonesian stock market reached a peak early July 1997. In the year before that, the JCI index, Jakarta's benchmark stock index, had increased by around $30 \%$. The following sell-off was massive and, by the end of the year 1997, losses had accumulated to almost 50\%.

The upper panel of figure 57 shows the price history and the 20-day historical volatility of the Indonesian JCI index before (green) and after (red) it peaked in July 1997. The picture confirms the observation of the IMF that the crisis came as a surprise and that the Indonesian economy was internationally perceived as stable, supported by strong fundamentals (IMF Independent Evaluation 

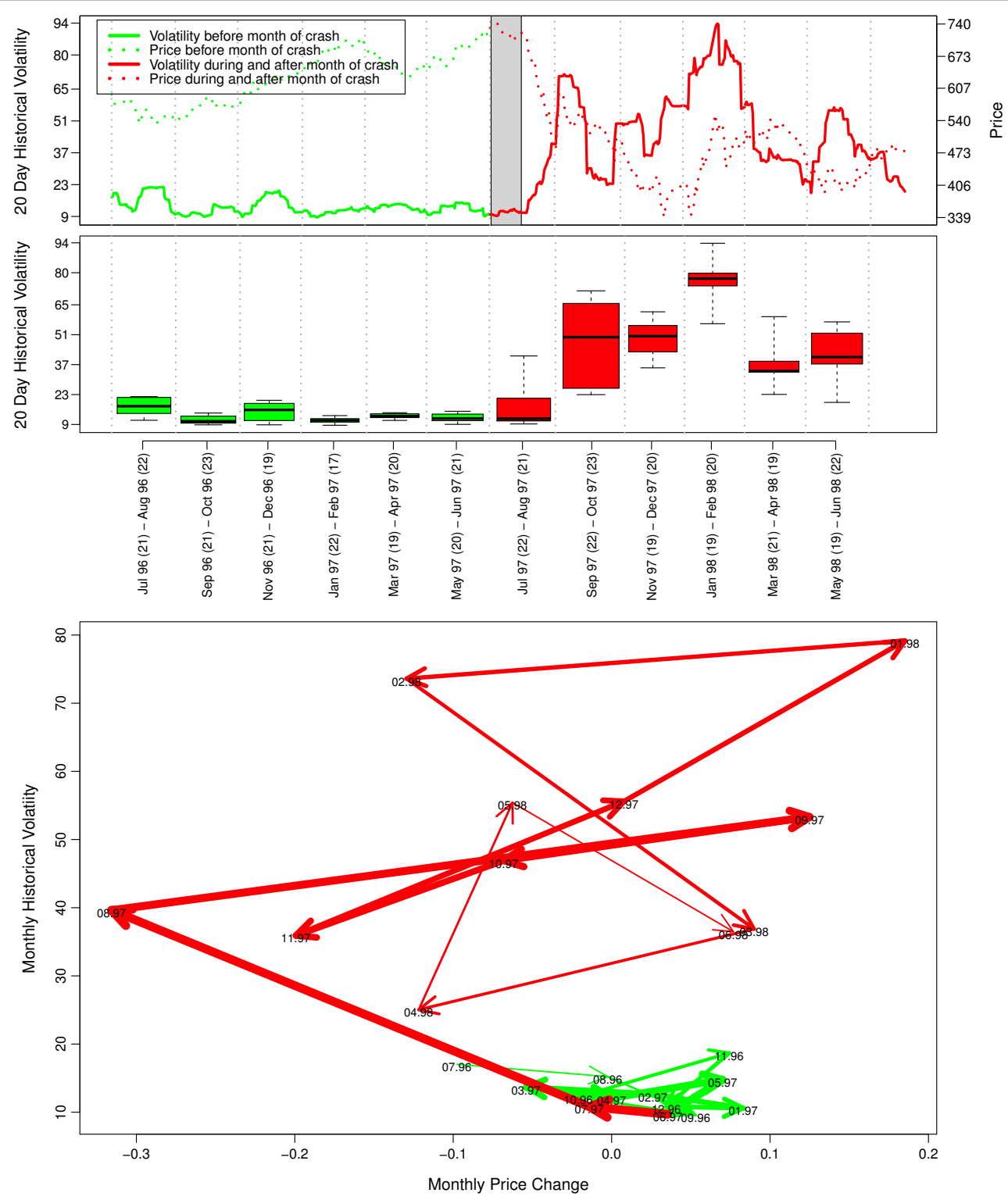

Figure 57. The Indonesian stock market bubble ending in July 1997: price and historical volatility of the JCI index (see section 4 for a detailed methodological explanation).

Office, 2003). The JCI index was clearly blessed with a stable and very low stock market volatility. This is confirmed by the arrow plot in the lower panel of the same figure. The green arrows, representing the period before the crisis, are clearly confined in the high return and low volatility area of the graph.

To understand the credit conditions during this bubble and its aftermath, figure 58 shows the credit from banks to the private non-financial sector as a percentage of the GDP of Indonesia, together with its two-yearly growth rate. The historical time series are plotted starting five years before and ending five years after the peak of the JCI index in July 1997. The data are from the Bank for International Settlements (BIS, 1997). We can see that credit to the private sector had been growing strongly during the build-up period of the stock market bubble.

We will classify this event, as a fearless, leveraged bubble, the former meaning that there was no 


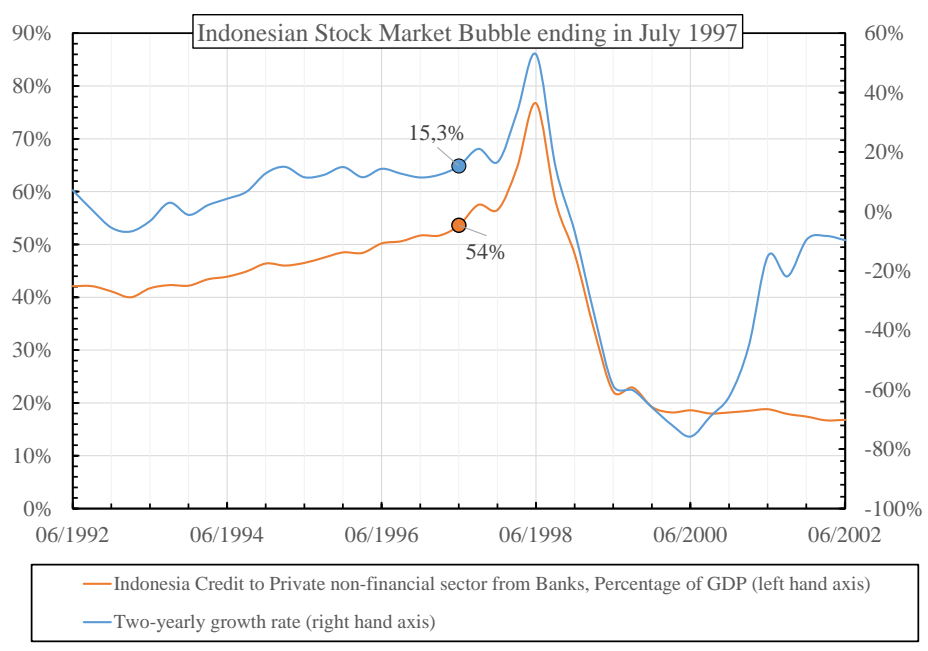

Figure 58. The credit conditions in Indonesia between 1992 and 2002, five years before and after July 1997. The two filled circles are the last observations from the data source (BIS, 1997) before the peak and the subsequent crash.

increase in volatility during the bubble period, the latter meaning that the bubble was clearly linked to a rise in credit in the Indonesian economy during that same period.

\subsection{Malaysian stock market bubble ending in January 1994}

Like Indonesia, which was discussed in the previous section 6.30, Malaysia also felt strongly the impact of the "rash of crises" that infected global markets between January and June 1994 (Lowell and Tong, 1998). Here the exogenous trigger of sharply rising interest rates in the United States amplified the country specific factor of rate hikes by the Malaysian monetary authorities to curb inflation (Lowell and Tong, 1998). On top of that, a massive bubble had been building up in the Malaysian stock market, with price levels and growth rates that were not sustainable, adding more idiosyncratic stress onto the Malaysian economic system.

The Malaysian stock market reached its peak early January 1994. In the year before, the FTSE Bursa Malaysia KLCI index, Kuala Lumpur's benchmark stock index, had increased by almost $110 \%$. The peak was reached on January 5, 1994, at exactly the same date as Indonesia (see section 6.30). The correction was swift and quite aggressive and the index lost almost $20 \%$ in the following week.

The upper panel of figure 59 shows the price history and the 20-day historical volatility of the FTSE Bursa Malaysia KLCI index before (green) and after (red) it peaked in January 1994. The grey area represents the one month period after the peak. To classify this bubble as fearless or fearful, one must focus on the month December 1993. During that month alone stocks went up more than 25\%. The volatility, however, decreased from $27 \%$ to $20 \%$. Therefore we conclude that this bubble was fearless.

To understand the credit conditions during this bubble and its aftermath, figure 60 shows the credit 

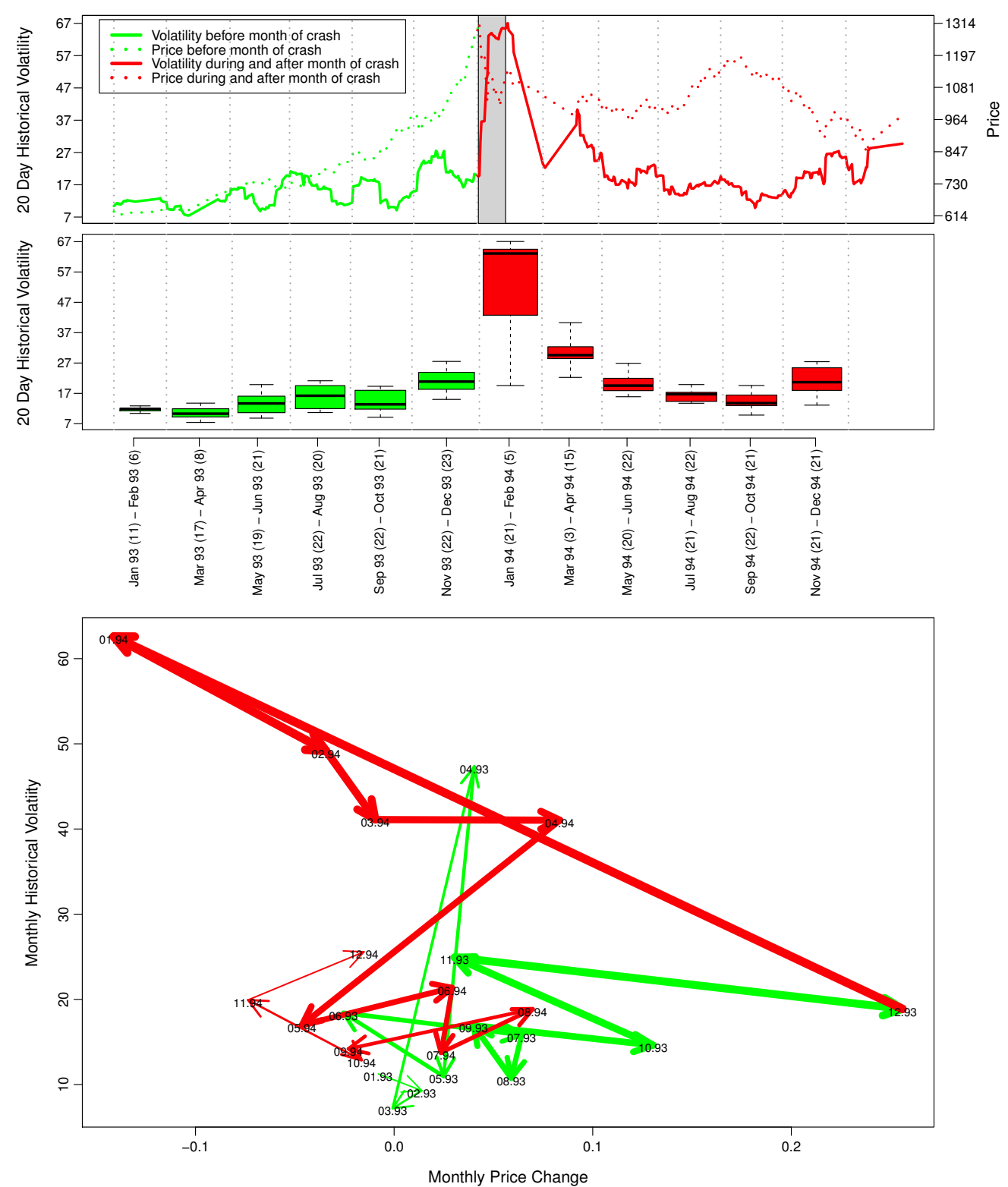

Figure 59. The Malaysian stock market bubble ending in January 1994: price and historical volatility of the FTSE Bursa Malaysia KLCI index (see section 4 for a detailed methodological explanation).

from banks to the private non-financial sector as a percentage of the GDP of Malaysia, together with its two-yearly growth rate. The historical time series are plotted starting five years before and ending five years after the stock market peak in January 1994. The data are from the Bank for International Settlements (BIS, 2017). We can see that credit creation had been stable during the build-up period of the stock market bubble with growth rates close to $0 \%$.

We will classify the stock market bubble, as a fearless, non-leveraged bubble, the former meaning that there was no rise in volatility during the bubble period, the latter meaning that the bubble could not be linked to any rise in credit in the Malaysian economy during that same period. 


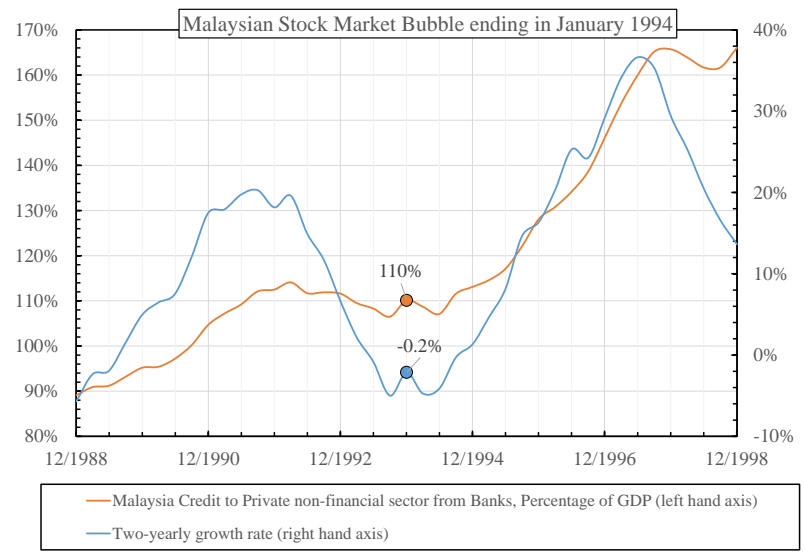

Figure 60. The credit conditions in Malaysia between 1988 and 1998, five years before and after January 1994. The two filled circles are the last observations from the data source [?] before the peak and the subsequent crash.

\subsection{Philippine stock market bubble ending in January 1994}

In 1993, the Philippine Composite, or PCOMP index, had increased more than $150 \%$. A stock market bubble had been building up and its peak was reached on January 6, 1994. There is clearly a communality between the stock market bubbles in Indonesia (rising 115\%, bursting around January 5, 1994), Malaysia (rising 110\%, bursting around January 5, 1994) and the Philippines (rising 150\%, bursting around January 6, 1994). According to Kindleberger and Aliber (2005), these countries were part of what was, at that time, referred to as "The East Asian Miracle". Outsourcing by American, European and Japanese firms that wanted cheaper sources of supply for established domestic markets caused a massive inflow of foreign capital and created a rapid economic growth. It was generally expected that these "dragon economies" would emulate the economic success of the "Asian tigers" of the previous generation (Taiwan, South Korea, Hong Kong and Singapore). As a consequence, stock prices doubled in most of the East Asian countries in 1993 and real estate prices soured (Kindleberger and Aliber, 2005).

The upper panel of figure 61 shows the price history and the 20-day historical volatility of the Philippine Composite index before (green) and after (red) it peaked in January 1994. One can observe a clear increase of the volatility over the six months preceding the price peak and the subsequent change of regime. Moreover, focusing as for the Malaysian stock market bubble (see section 6.32) on the month of December 1993, one can observe that during that month alone Philippine stocks went up by a massive $37 \%$, while the volatility increased from $15 \%$ to $35 \%$. This neatly confirms that this bubble was fearful.

The Malaysian and the Philippine bubbles had common underlying drivers (the belief in the "dragon economies"), developed over the same period (the year 1993), accelerated in the final phase together (December 1993) and burst at exactly the same moment (around January 5, 1994). Yet, in Malaysia the volatility went down right before the crash, whereas in the Philippines, it went up. This observation 

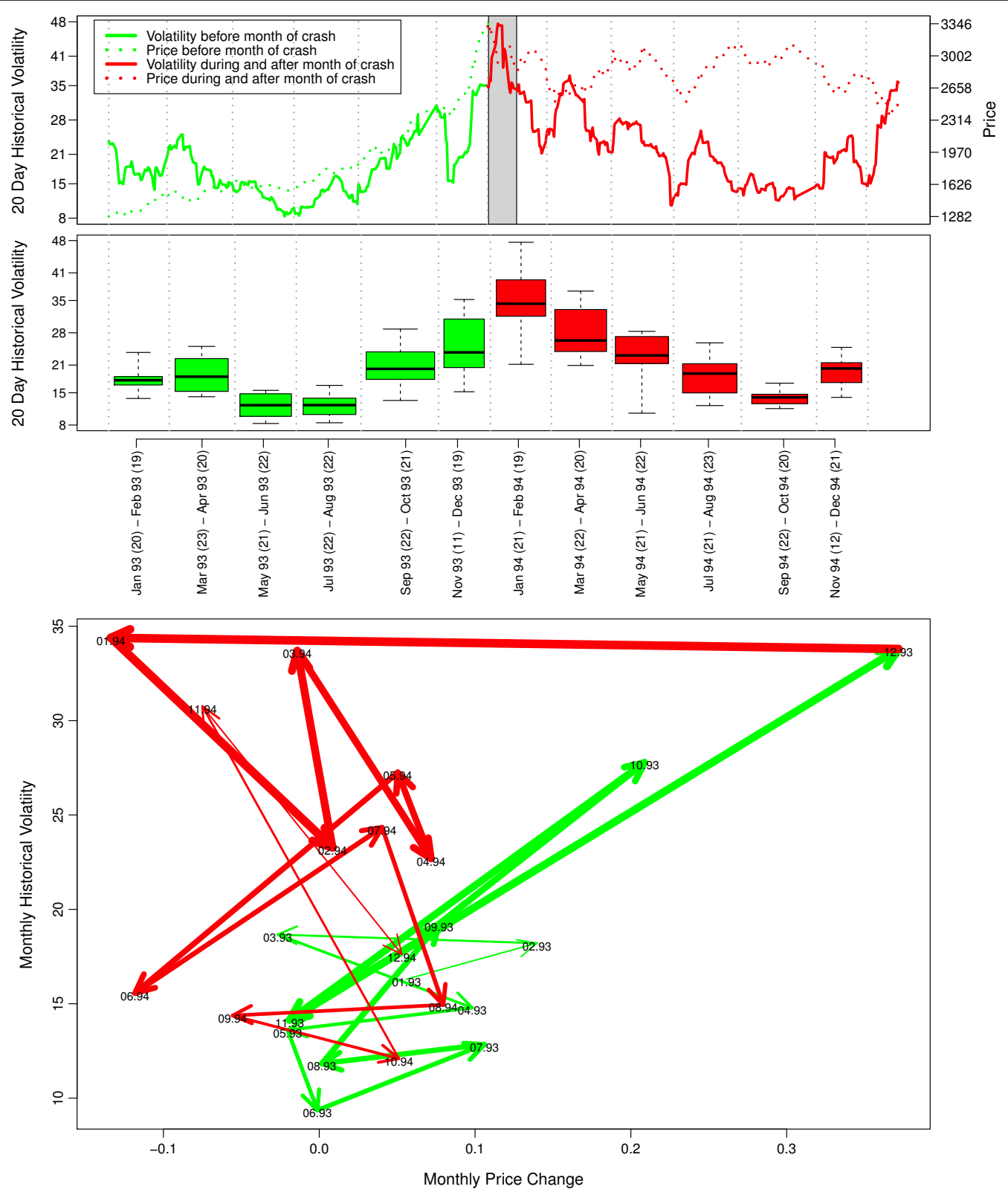

Figure 61. The Philippine stock market bubble ending in January 1994: price and historical volatility of the PCOMP index (see section 4 for a detailed methodological explanation).

strongly counters the assumption that the volatility can be used to diagnose bubbles and forecast their end.

The database of the Bank for International Settlements (BIS, 2017) does not contain the amount of credit from banks to the private non-financial sector in that period for the Philippines. Therefore we will not evaluate the impact of leverage on this bubble. 
6.34. Russian stock market bubble ending in October 1997

Over the year before its peak on October 3, 1997, the Russian stock market (represented by the CSFB Russia index), appreciated by more than $250 \%$. This was caused by a large foreign capital inflow from the US, Germany and Japan that started in 1996 and was attracted by the prospect of a massive reconstruction of the Russian industry in this post cold war era. The bubble was further fuelled by financial liberalization, initiated in January 1997, and a progressive removal of restrictions on foreign capital participation in the lucrative Rouble Treasury bills and notes market (Pinto and Ulatov, 2010). This belief and hope in a new investment haven with large returns led to herding behavior and bubble development. It hid many problems: the corruption in the privatization process, the spread of organized crime, the fundamental weakness of the Russian economy, the proliferation of weapons as a means of generating hard currency and the increasing estrangement of Russia from the United States (Sornette, 2017). Russia's total economic collapse in 1998, following the bubble, inflicted pain, suffering, and disruption on millions of Russians.

From its top in August 1997 to its bottom in October 1997, most of the financial indices tracking the performance of the Russian stock market lost between $17 \%$ and $20 \%$. This crash was the beginning of a secular bearish market with a cumulative drop of 74\% for the CSFB Russia index until mid-1998 (Johansen et al., 1999). This "slow crash" has been identified as a so-called "anti-bubble" by Johansen et al. (1999).

The upper panel of figure 62 shows the 20-day historical volatility of the Russian stock market proxied by the Credit Suisse First Boston Russia index (ROSI) before (green) and after (red) it peaked in October 1997. The correction begins with a first dip in August 1997, followed by a rally and ending in the final crash in October 1997. One can see the volatility increasing somewhat during that interlude. However, it clearly drops again during the final rally in the month before the crash. This is confirmed by the arrow plot in the lower panel of the figure. It can be seen from that figure that the green arrows, representing the volatility before the crash, are clearly confined in the low volatility, high return region of the plot.

To understand the credit conditions during and after this period of boom and bust, figure 63 shows the credit from banks to the private non-financial sector as a percentage of the GDP of Russia together with its two-yearly growth rate. The historical time series are plotted starting five years before and ending five years after the peak in the stock market. The data are from the Bank for International Settlements (BIS, 2017). It is interesting to see that both the credit as a percentage of the GDP and its growth rate peak around the time of the crash.

We will classify this stock market bubble, ending in the October 1997 crash, as a fearless, leveraged bubble, the former meaning that there was no rise in volatility before the crash, the latter indicating that credit was building up in the system during the development of the bubble.

\subsection{Oil bubble ending in July 2008}

In a research paper entitled "1980-2008: The Illusion of the Perpetual Money Machine and What It Bodes for the Future", Sornette and Cauwels (2014) put the Oil bubble ending in July 2008 in a longterm historical perspective. They argue that, since the early 1980s, consumption has been increasingly funded by smaller savings, booming financial profits, wealth extracted from house price appreciation and explosive debt. They describe that this resulted in a transition, in the 1970s, from a productivity- 

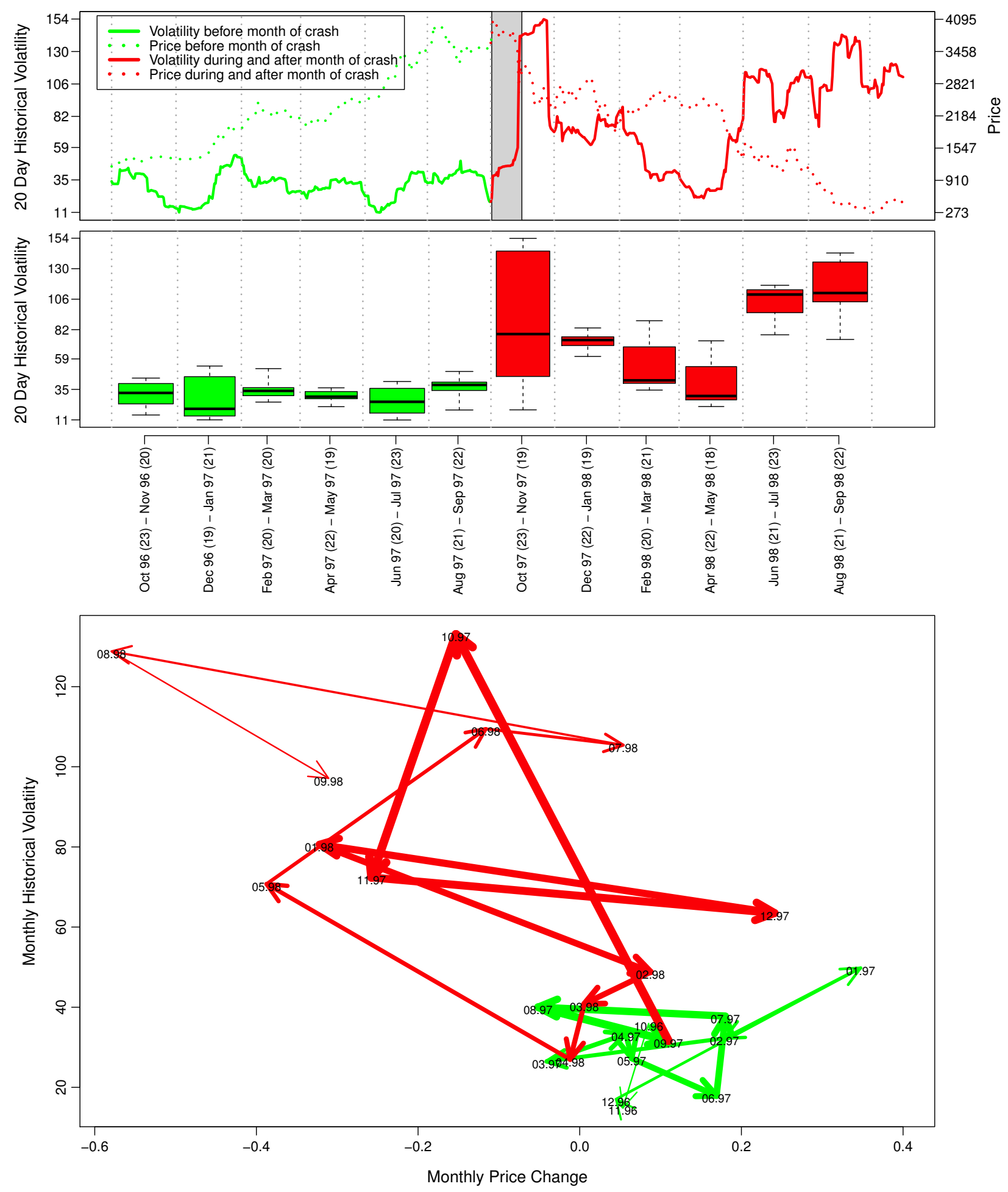

Figure 62. The Russian stock market bubble ending in October 1997: price and historical volatility of the Credit Suisse First Boston Russia (ROSI) index (see section 4 for a detailed methodological explanation). 


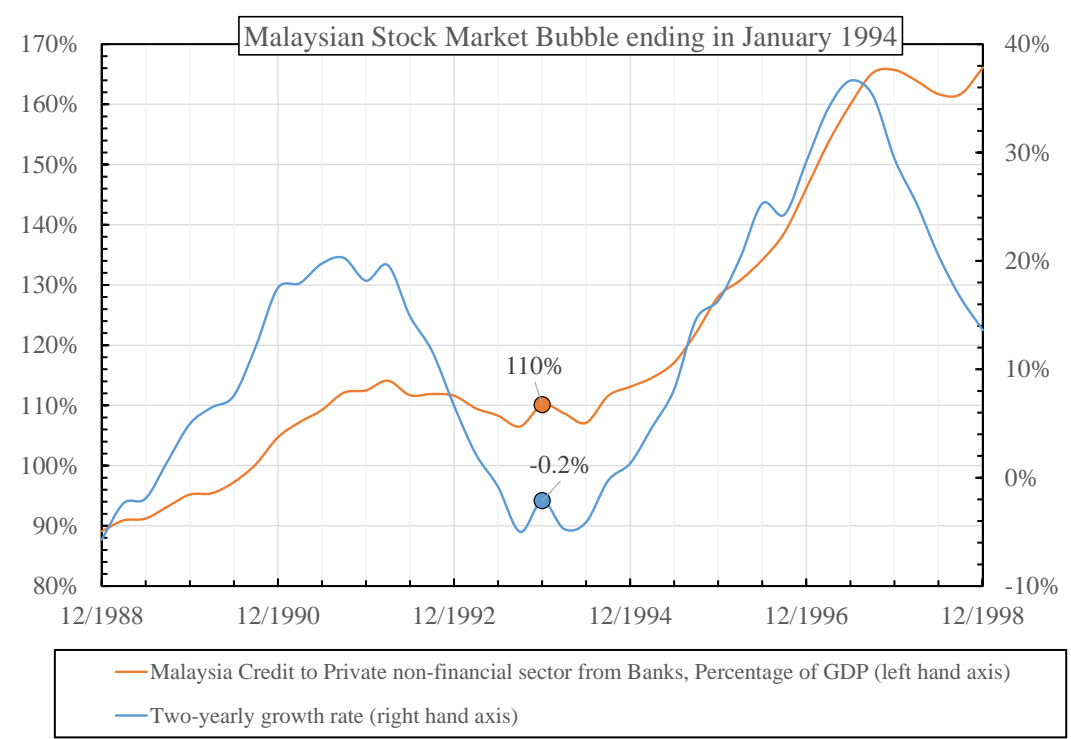

Figure 63. The credit conditions in Malaysia between 1988 and 1998, five years before and after January 1994. The two filled circles are the last observations from the data source (BIS, 2017) before the peak and the subsequent crash.

fuelled growth towards a regime which they call the "illusion of the perpetual money machine". This regime was further supported by a climate of deregulation and a massive growth in financial derivatives designed to spread and diversify the risks globally. The result has been a succession of bubbles and crashes, including the worldwide stock market bubble and great crash of October 1987, the savings and loans crisis of the 1980s, the burst in 1990 of the Japanese real estate and stock market bubbles, the emerging markets bubbles and crashes in 1994 and 1997, the Long-Term Capital Management (LTCM) crisis of 1998, the Dotcom bubble bursting in 2000, the 2008 house price bubbles and subsequent credit, stock market, commodities, oil and debt bubbles and crashes, all developing jointly and feeding on each other until 2008.

On June 6, 2008, Sornette et al. (2009) published a working paper on the Cornell University online Library arxiv.org, diagnosing a faster-than-exponential growth behavior in oil prices caused by speculative behavior. In their paper, they identify the run-up as a bubble, likely to burst in the following months. Brent crude hit a high of $147 \$$ on July 11, 2008, after which a massive correction followed, in which prices dropped below 40\$, in less than six months, before year end.

Figure 64 shows the 20-day historical volatility of the oil price before (green) and after (red) it peaked in July 2008. Oil is represented here by means of the USO ETF. In this way, the implied volatility is easily available and can be compared to the historical volatility. One can clearly observe a long-term gradual increase as well as a short-term peak in the volatility right before the crash. This is confirmed by the implied volatility, which is presented in figure 65. Consequently, we identify this 

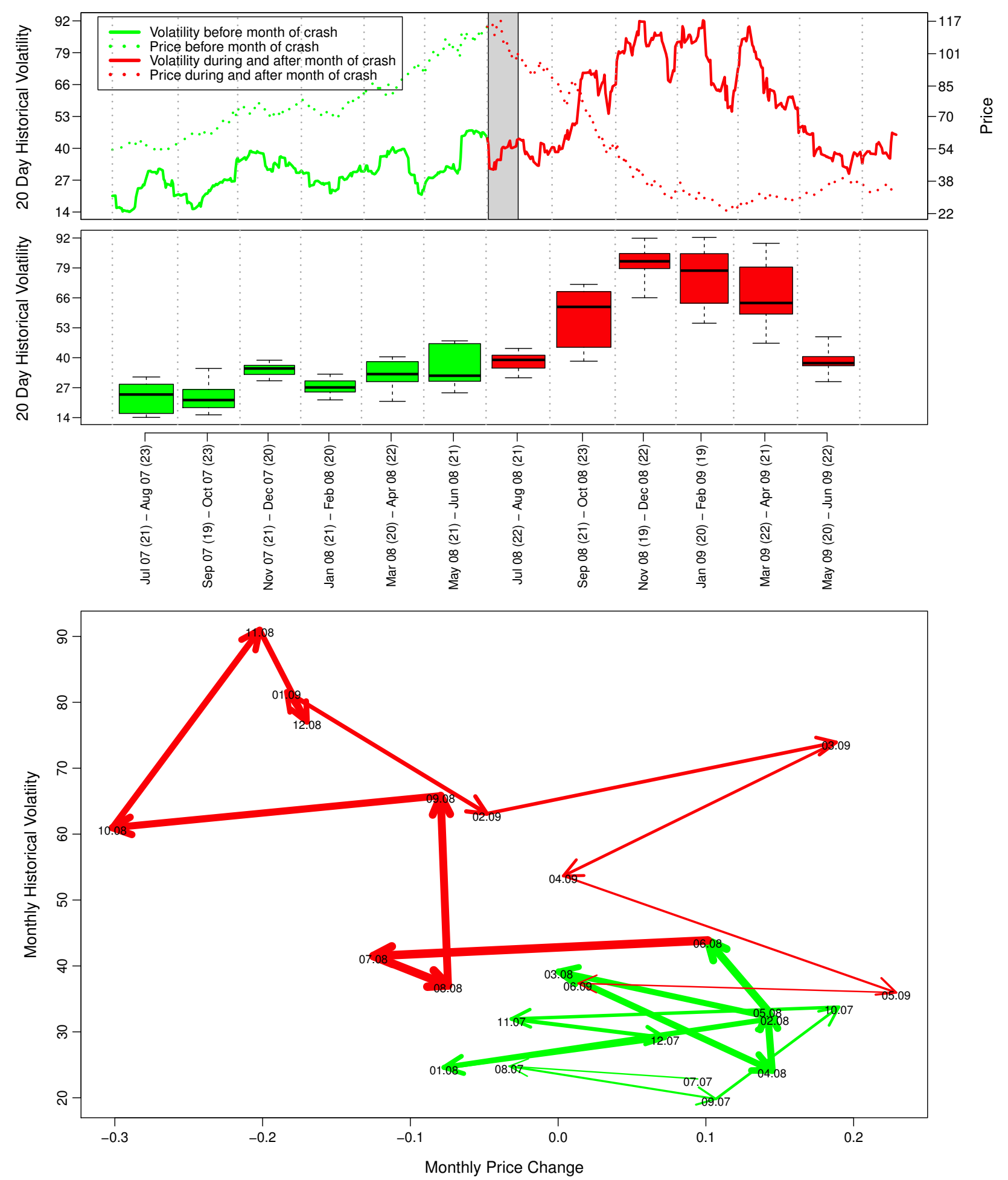

Figure 64. The Oil bubble ending in July 2008: price and historical volatility of the USO ETF (see section 4 for a detailed methodological explanation).

event as a fearful bubble. 


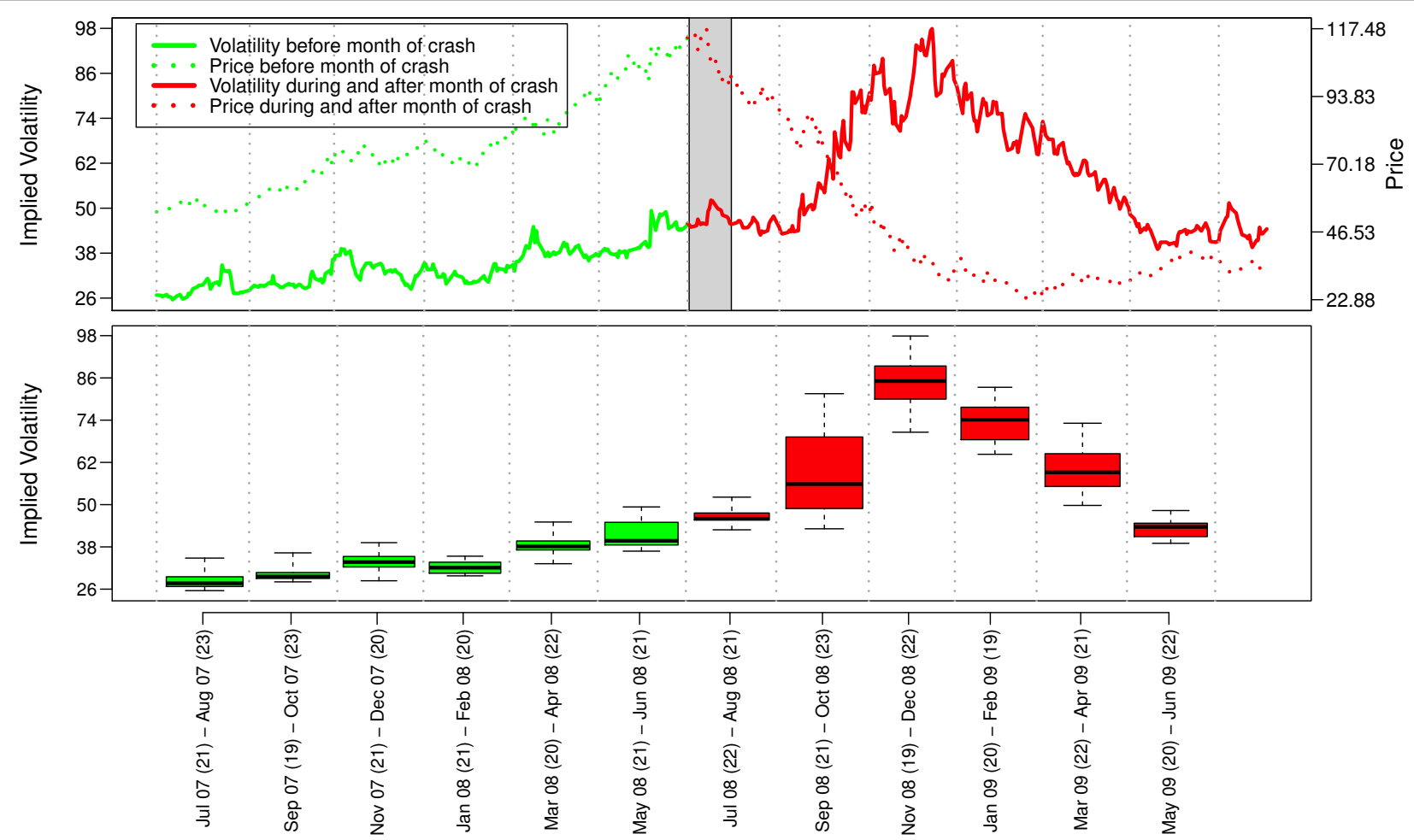

Figure 65. The Oil bubble ending in July 2008: price and implied volatility of the USO ETF (see section 4 for a detailed methodological explanation).

\subsection{Platinum bubble ending in May 2010}

Platinum should be seen as an industrial metal. Its most common application is as a catalyst in chemical reactions e.g. as part of a catalytic converter in cars used for vehicle emissions control. Consequently, it is a cyclical asset that is quite sensitive to industrial growth or slowdowns.

The platinum price crashed, together with all the other commodities like oil (see section 6.35), mid2008, losing almost two-thirds of its value in only a few months time. This was followed by a very strong recovery starting in the beginning of 2009, which turned into a bubble that burst in May 2010. During the boom, in the year between April 30, 2009 and April 30, 2010, the metal gained almost 60\% in value, during the bust, over the month of May 2010, it lost $11 \%$.

The bubble had two underlying drivers. First, there were tentative signs that the automotive industry was recovering after the financial crisis, and second, there was a strong increase in investor demand because the introduction of Exchange Traded Funds (so-called ETFs) made it easier to gain exposure to precious and industrial metals such as gold, silver, platinum and palladium. The bursting of the bubble, on the other hand, was triggered by fears of a sovereign debt crisis in Europe after Standard and Poor's downgraded Greece's debt ratings to junk bond status on April 27, 2010.

At the Financial Crisis Observatory at ETH Zurich (www.er.ethz.ch/financial-crisis-observatory.html), the Platinum bubble was one of the exuberant markets that was diagnosed with a high probability for a crash to occur. Moreover, it was arbitraged successfully by shorting and trading the volatility induced by the crash. While this was not publicly announced at the time, we are now mentioning this fact to support the point that the platinum price 

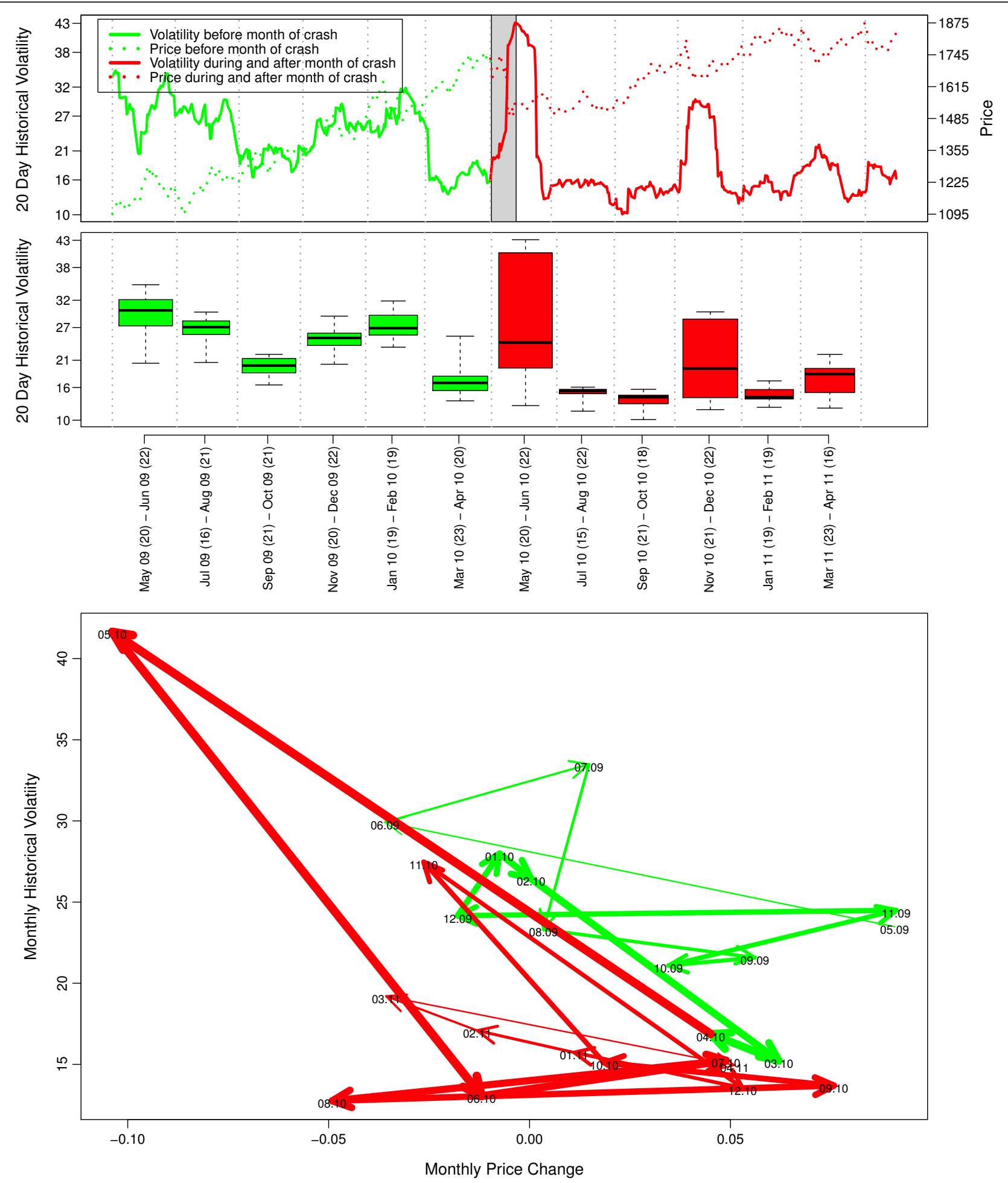

Figure 66. The Platinum bubble ending in May 2010: price and historical volatility of the generic one-month-ahead Platinum future (see section 4 for a detailed methodological explanation). 
pattern exhibited the same reproducible characteristic super-exponential properties as the other bubbles discussed here (Sornette and Cauwels, 2015).

Figure 66 shows the 20-day historical volatility of the platinum price before (green) and after (red) it peaked in May 2010. It is clear that the volatility had dropped quite significantly during the last months of the bubble build-up. Consequently, we identify this event as a fearless bubble.

\subsection{Palladium bubble ending in May 2010}

The Palladium bubble is quite similar to the Platinum bubble, which was discussed in the previous section. This is also an industrial metal, and as such, it is also sensitive to the business cycle. Palladium went through the same boom and bust cycle as Platinum between 2008 and 2010, following the same drivers and responding to the same triggers. Its bull run was even more impressive with a price increase of more than 150\% between April 30, 2009 and April 30, 2010. In the following crash, over the month of May 2010, the metal lost around $17 \%$ in value.

Similarly to Platinum, at the Financial Crisis Observatory at ETH Zurich (www.er.ethz.ch/financialcrisis-observatory.html), the Palladium bubble was one of the exuberant markets that was diagnosed with a high probability for a crash to occur. While this was not publicly announced at the time, we are now mentioning this fact to support the point that the platinum price pattern exhibited the same reproducible characteristic super-exponential properties as the other bubbles discussed here (Sornette and Cauwels, 2015).

Figure 67 shows the 20-day historical volatility of the palladium price before (green) and after (red) it peaked in May 2010. Even though the palladium and platinum bubbles are the result of the same underlying dynamics, they evolved over the same period and they burst at the same moment, their historical volatility shows a different behavior. Whereas the volatility decreased for platinum, here we see it increase for palladium during the final phase of the bubble build-up.

Consequently, we identify this event as a fearful bubble.

\subsection{Sugar bubble ending in November 2010}

In a note in 2010 (De Schutter, 2010), Olivier De Schutter argued that the price spikes in food during the first decade of the twenty-first century were caused by the emergence of speculative bubbles. According to De Schutter, who was at that time UN Special Rapporteur on Food, large and powerful institutional investors, such as hedge funds, pension funds and investment banks, entered the food commodities markets after these were deregulated in the beginning of 2000 (De Schutter, 2010). As a result, the number of futures and options traded globally on commodity exchanges increased by more than five times between 2002 and 2008. In line with the reasoning of Sornette and Cauwels (discussed in the previous section on oil 6.35), De Schutter claims that speculative bubbles feed upon each other: "As each bubble burst, these large institutional investors moved into other markets, each traditionally considered more stable than the last" (De Schutter, 2010). When drought-induced crop failures and the promotion of biofuels sparked off an initial rise in food prices, speculators, fleeing more traditional markets in the wake of the sub-prime crisis jumped on the bandwagon and moved into food commodities. This herding effect created a massive acceleration in food prices leading to the 2007-2008 food crisis, which caused political and economic instability and social unrest in developing countries; it has been suggested to have been the triggering factor of the Arab Spring (Bertrand et al., 

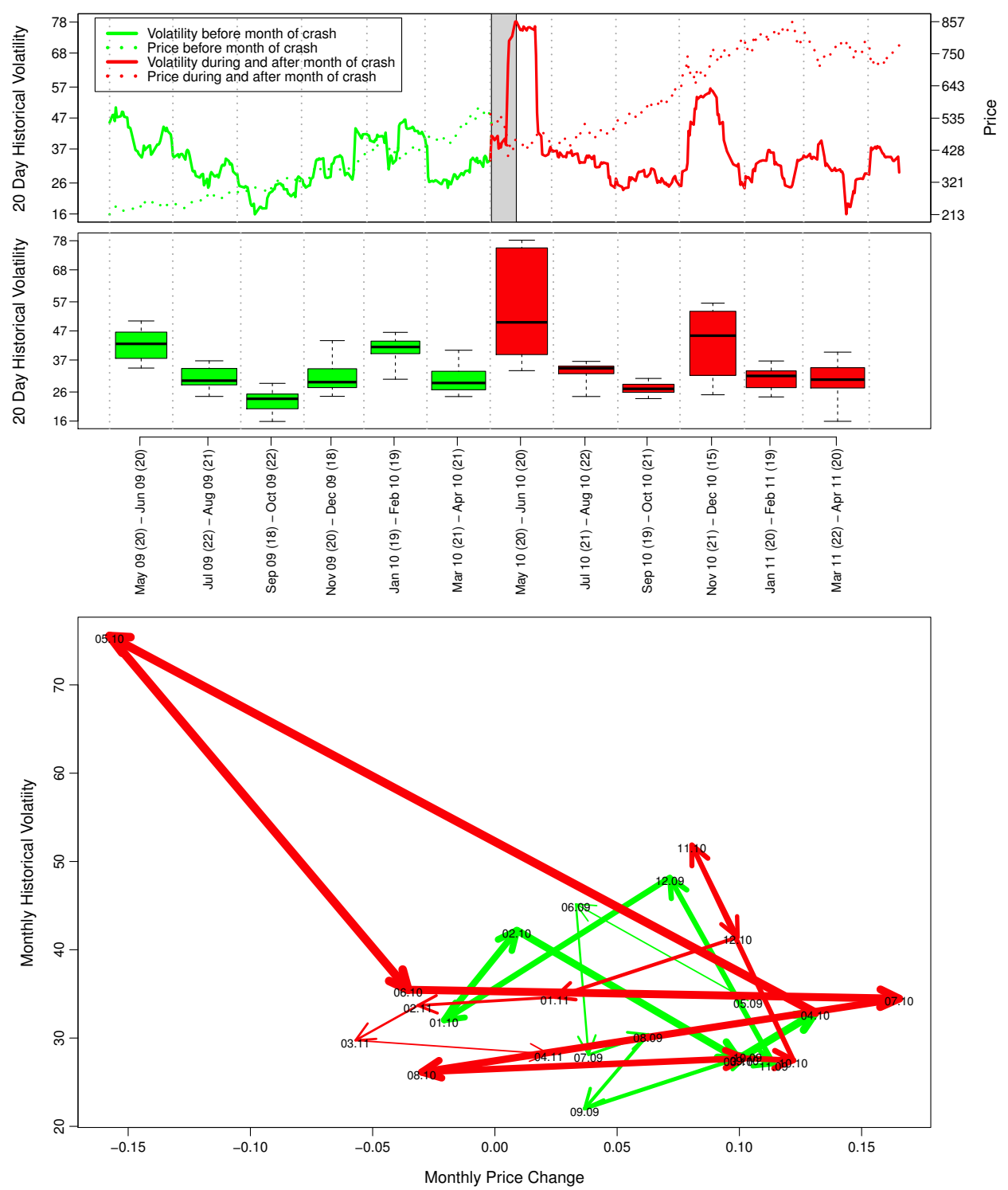

Figure 67. The Palladium bubble ending in May 2010: price and historical volatility of the generic one-month-ahead Palladium future (see section 4 for a detailed methodological explanation).

2011) that commenced in 2010. The bubble in sugar prices, which ended in November 2010, was part of this global systemic event, which was called "the globalization bubble" by Sornette and Cauwels (Sornette and Cauwels, 2014).

In this analysis, we will use the one-month-ahead generic ICE (InterContinental Exchange) future contract. The price of this contract followed some extraordinary spells of boom and bust in the run-up to the November 2010 crash. In the second half of 2009, the price of the futures contract actually doubled from a level of around 15,000 to 30,000 , only to drop again to 15,000 during the three months between mid-January and mid-April 2010. This bust was immediately followed by a new boom, even more fierce than the previous one, with a price increase of more than $140 \%$ in the six months before 


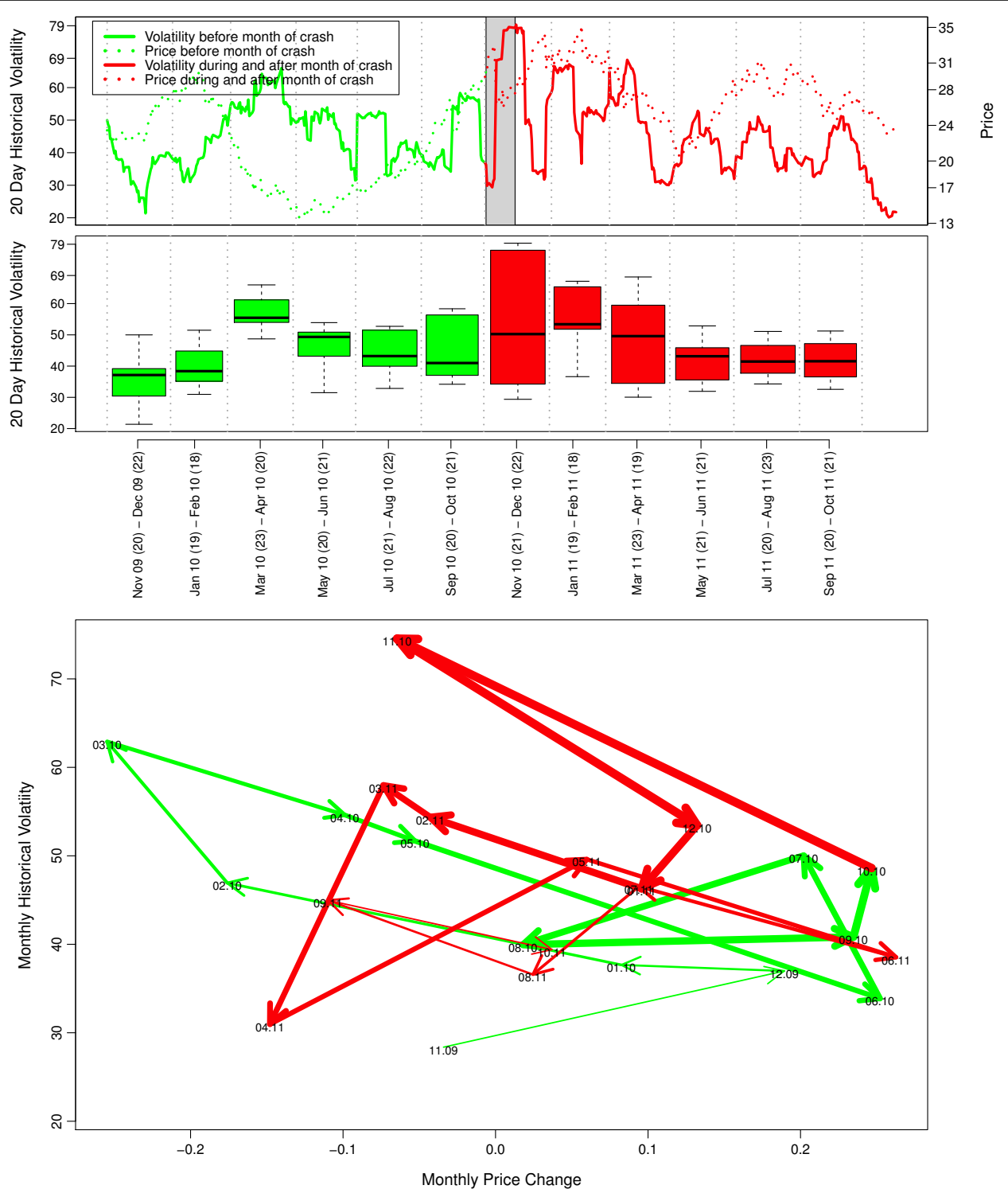

Figure 68. The Sugar bubble ending in November 2010: price and historical volatility of the generic one-month-ahead Sugar future (see section 4 for a detailed methodological explanation).

November 9, 2010. A crash followed, with a correction of more than $20 \%$ in only three days (from 10 to 12 November). It would be a difficult case to argue that this type of price behavior was driven by fundamental drivers of supply and demand.

Figure 68 shows the 20-day historical volatility of the sugar price before (green) and after (red) it peaked in November 2010. We see some strong spikes in the volatility, coinciding with transient periods when a minor correction in the price is observed. Looking at the broad picture, however, there is no specific increase in the volatility that could be interpreted as the increased risk of an imminent crash. This observation is confirmed by the implied volatility in figure 69. Consequently, we identify this event as a fearless bubble. 


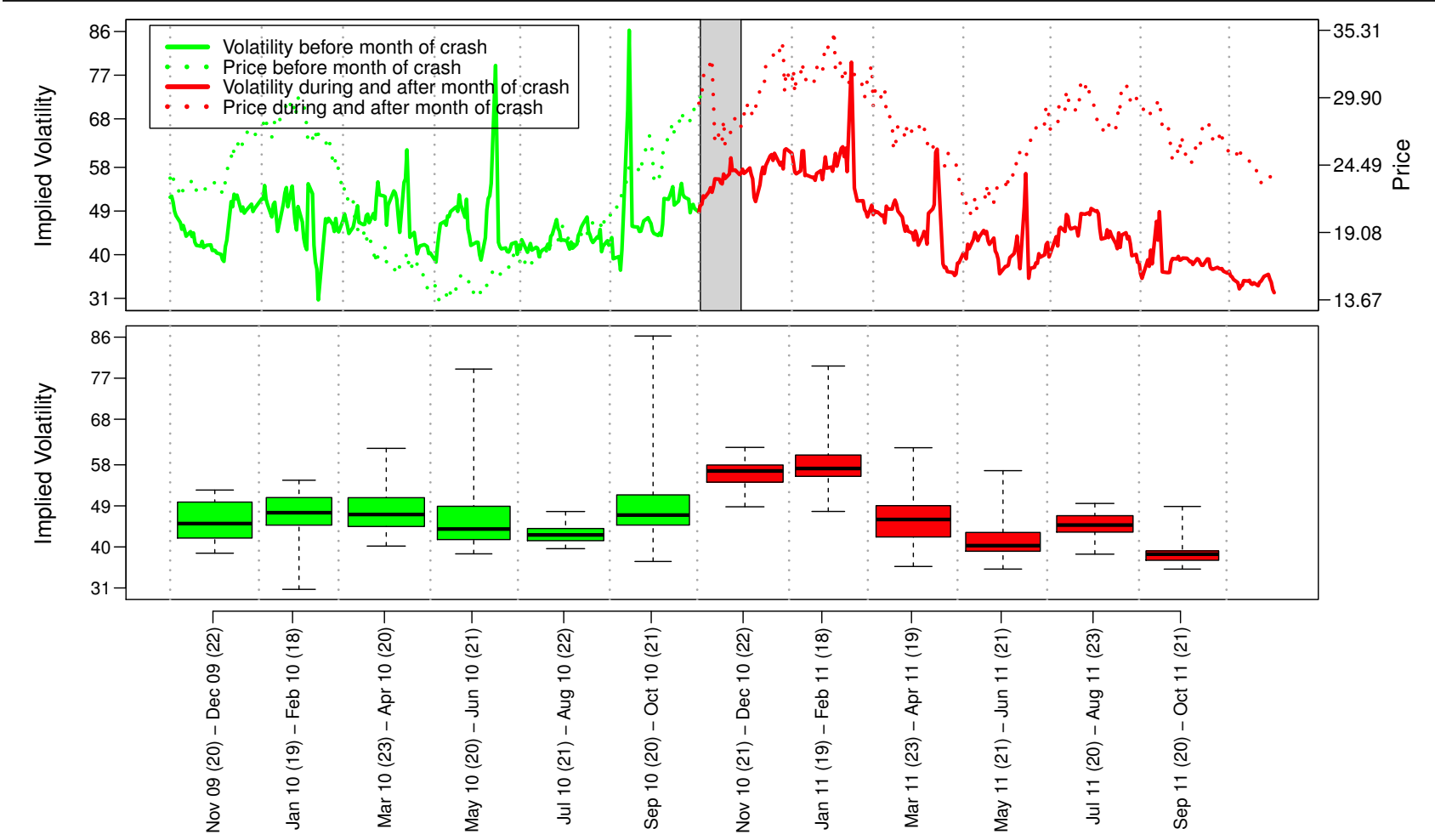

Figure 69. Sugar, November 2010: price and 20-day moving average of the historical daily volatility. See section 4 on methods for the meaning of the presentation of the arrows and end dates.

\subsection{Gold bubble ending in September 2011}

In the ten years between August 2001 and 2011, the market price for gold increased 600\%, corresponding to an average annualized return of $20 \%$, for ten years in a row. This was quite a trend reversal after two decades of steady decline caused by the selling of gold inventories by many central banks. Actually, in the twenty years between the crash of the gold bubble in 1980, which was the result of inflation and the geopolitical concerns of that era, and the start of the bull run in 2000, the gold price had halved.

A whole series of events evolved during the first decade of the twenty first century, which sequentially pushed the gold price higher until it gave birth to the speculative bubble that ended in September 2011.

First, in the spring of 2000, the Dotcom bubble burst (see section 6.5). After this crash, investor confidence was further put to the test by the accounting scandals of Enron in 2001, and Tyco and Worldcom in 2002. The result was a three-year bear market in global stocks with the Eurostoxx 50 losing more than $60 \%$ and the S\&P 500 over 40\%. On top of that, the September 11 attacks in 2001 brought geopolitical risks back into the spotlights. The events led to the invasion of Afghanistan that same year and the war in Iraq in 2003. As a consequence, risk-averse investors, beaten by the stock market and seeking a safe-haven, started accumulating gold.

At about the same time, the dollar started weakening, losing half of its value between 2000 and 2008; in 2000, one Euro would buy 0.85\$, in 2008 that would be around 1.60\$. The reason for this 

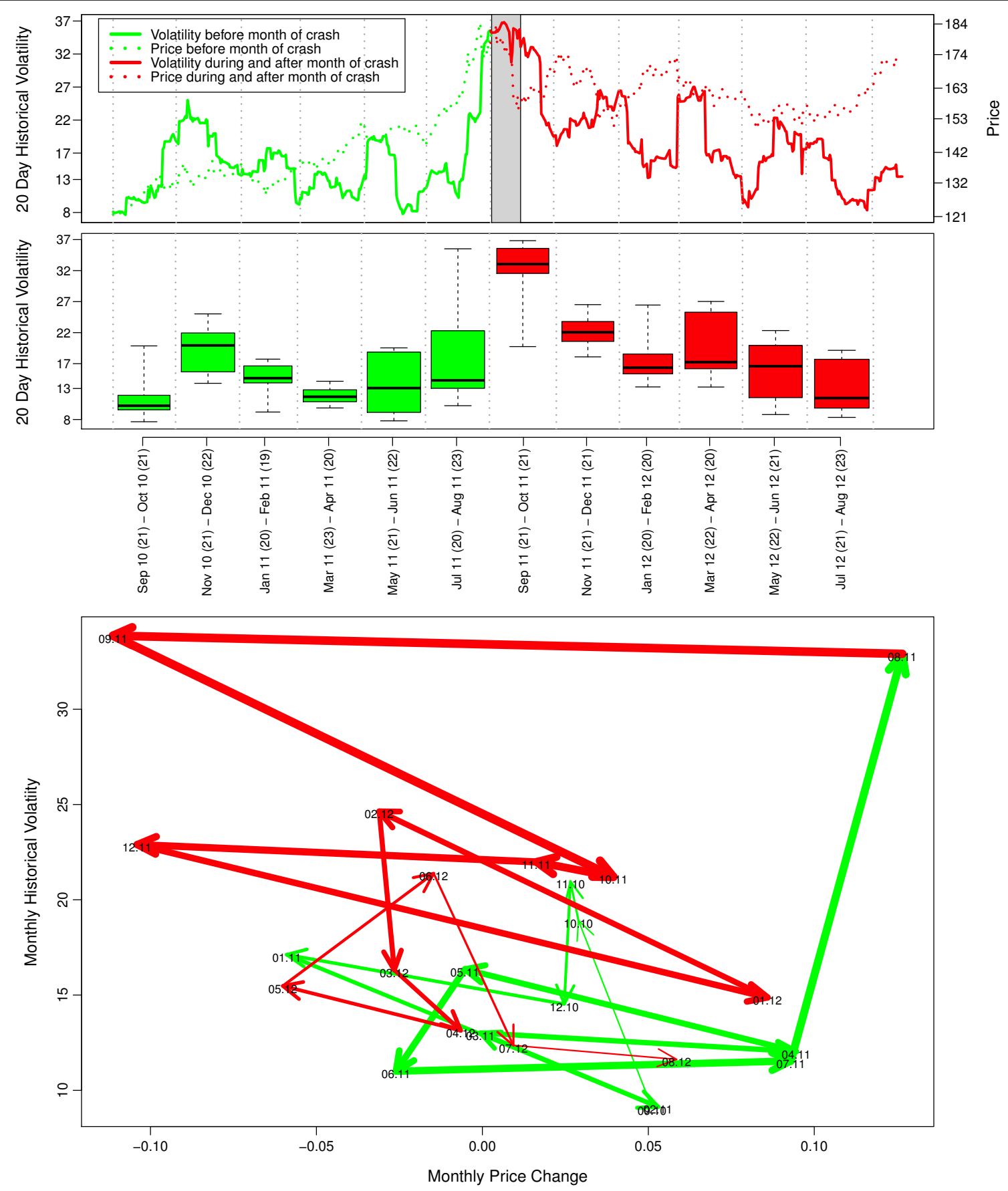

Figure 70. The Gold bubble ending in September 2011: price and historical volatility of the SPDR Gold Trust (see section 4 for a detailed methodological explanation).

decline was the soaring deficit in US trade, further aggravated by the strong increase of debt in the US economic and financial system. There is a well-documented inverse relationship between the tradeweighted US Dollar and the price of gold. Thus, the fall in the US Dollar further fuelled rising gold prices.

Then, in 2007, a crisis in the subprime mortgage market in the US developed into an international 
banking crisis and led to the collapse of the Lehman Brothers investment bank in September 2008 (see section 6.6). This was immediately followed by the European debt crisis in which several Eurozone member states were unable to refinance their government debt or to bail out their over-indebted banks. Many central banks worldwide responded with extraordinary measures such as quantitative easing, which massively inflated their balance sheets. The fear of a global collapse of the financial system, of insolvency of some European countries and of inflation due to central banks' extraordinary measures made gold prices soar.

The last and final acceleration of the bubble came mid-2011 when Standard and Poor's downgraded the United States federal government credit rating from AAA to AA+ based on concerns about the debt ceiling crisis. This resulted in an excessive acceleration of the gold price until investors realised that the hyperbolic price trajectory was not sustainable and the bubble collapsed. A trend reversal started in which gold prices dropped from the high of over 1900\$ per ounce in September 2011 to less than $1100 \$$ per ounce four years later.

This whole sequence of events was further impacted by the fundamental change in the structure of the commodities markets caused by the introduction of Exchange Traded Funds (or ETFs). This resulted in what could be called a financialization of commodities markets, and gave speculators easy access without the need for buying any physical assets. In November 2004, the SPDR Gold Trust (ticker: GLD) was created. The total net asset value of this ETF grew from \$115 million at initiation to over $\$ 77$ billion at the crest of the bubble in August 2011.

As for the Platinum and Palladium bubbles, at the Financial Crisis Observatory at ETH Zurich (www.er.ethz.ch/financial-crisis-observatory.html), the gold bubble was one of the exuberant markets that were diagnosed with a high probability for a crash to occur. Moreover, it was arbitraged successfully by shorting and trading the volatility induced by the crash. While this was not publicly announced at the time, we are now mentioning this fact to support the point that the gold price pattern exhibited the same reproducible characteristic super-exponential properties as the other bubbles discussed here (Sornette and Cauwels, 2015).

Figure 70 shows the 20-day historical volatility of the price of the GLD ETF before (green) and after (red) it peaked in September 2011. It can be seen from this graph that the volatility was strongly increasing, together with the price, during the final phase of the bubble. This conclusion is confirmed by the arrow graph in the lower panel of figure 70 and by the implied volatility, which can be seen in figure 71. Consequently, we identify this event as a fearful bubble.

\subsection{Swiss Franc bubble ending in July 2011}

As discussed in the previous section 6.39, there was a very strong demand for gold during the banking and sovereign debt crisis that swept through Europe between 2008 and 2011. Investors were desperately seeking for safe-haven assets. In this context, the Swiss Franc had a long reputation as a safe haven currency, meaning a relatively stable currency in a politically and economically welldeveloped, secure state.

When the euro was introduced in 1999, its value was set to 1.58 Swiss francs. In the subsequent years, the exchange rate experienced mild fluctuations with a low of 1.44 on September 2001 and a peak of 1.67 on October 2007, as determined by the free market and guided by a stable European economy and the belief that the creation of the Eurozone would lead to prosperity for the entire region. This changed when the European debt crisis made investors lose faith in the European currency union and 


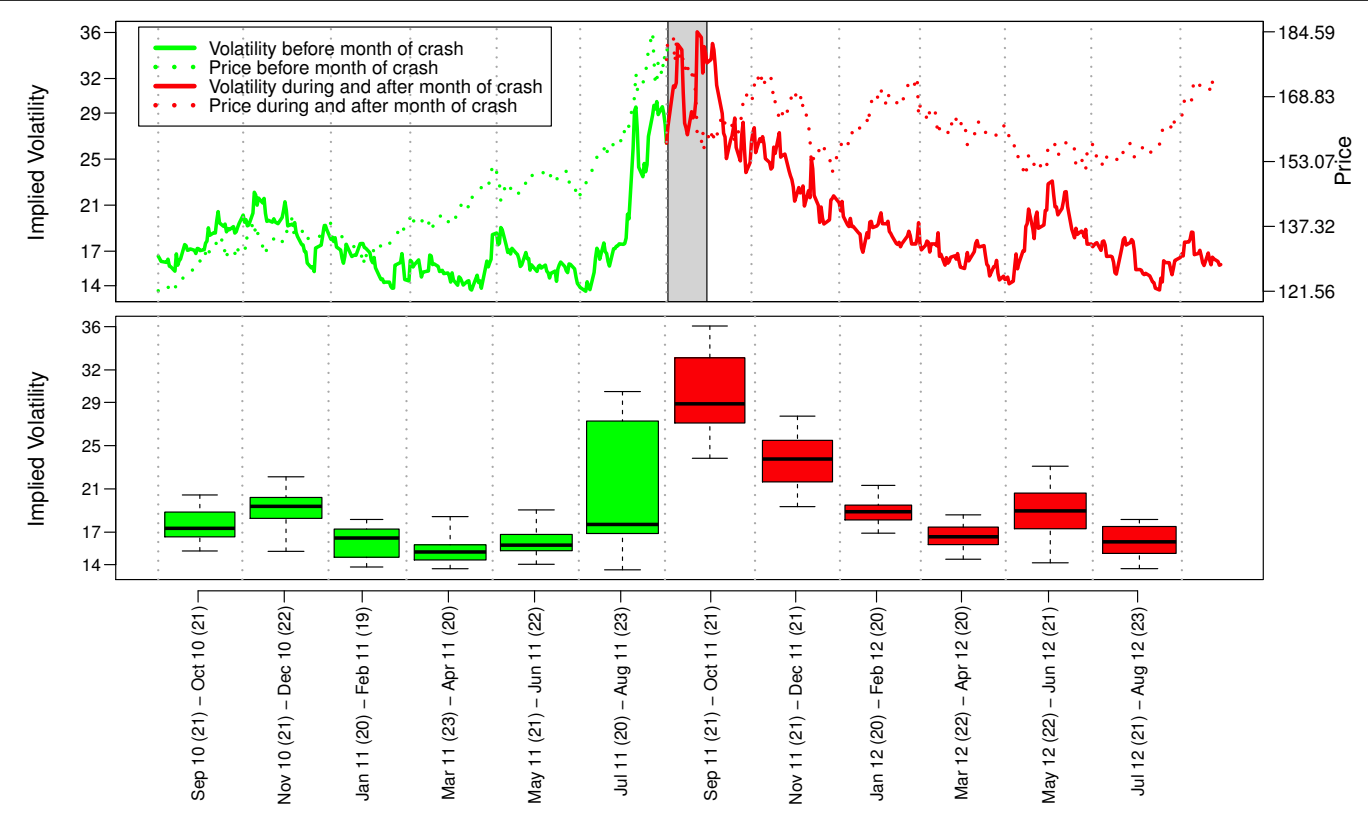

Figure 71. The Gold bubble ending in September 2011: price and implied volatility of the SPDR Gold Trust (see section 4 for a detailed methodological explanation).

seek investments in more stable currencies, like the Swiss Franc. As a consequence of this increased demand, the Swiss Franc appreciated very strongly; in the beginning of 2011, one could buy 1.3 Swiss Francs for one Euro, half a year later, this amount would have dropped to 1.1. This appreciation developed the characteristic pattern of a bubble, in the sense of a super-exponential growth that cannot go on forever and is likely to end in a rupture. Sure enough, the CHF/EUR exchange rate concluded its hyperbolic ascent at the record high of 1.0070 Swiss Franc per Euro on August 9, 2011. As a result of pressures to mitigate the negative consequences to the export-based Swiss economy, the Swiss National Bank intervened massively on that day leading to a fast rebound of the Euro, i.e., to the crash of the Swiss Franc bubble. Moreover, on September 6, 2011, when parity was approaching again, an incredibly low exchange rate of one Swiss franc per Euro, passive monetary policies (e.g. interest rates) were no longer effective and the Swiss National Bank (SNB) decided to intervene actively in the market. Because of the Swiss economy's strong dependency on exports and to combat the risk of deflation, the Swiss National Bank announced its decision to enforce a minimum exchange rate of 1.20 Swiss Francs (CHF) per Euro (EUR). Under severe market pressure, this peg was abandoned three and a half years later and the exchange rate briefly touched parity again early 2015 (Lera and Sornett, 2016).

As for the Platinum, Palladium and gold bubbles, at the Financial Crisis Observatory at ETH Zurich (www.er.ethz.ch/financial-crisis-observatory.html), the Swiss Franc bubble was one of the exuberant markets that was diagnosed with a high probability for a crash to occur. Moreover, it was arbitraged successfully by shorting and trading the volatility induced by the crash. While this was not publicly announced at the time, we are now mentioning this fact to support the point that the Swiss Franc exhibited the same reproducible characteristic super-exponential properties as the other bubbles discussed here (Sornette and Cauwels, 2015).

The upper panel of figure 72 shows the 20-day historical volatility of the price of the FXF Currency 

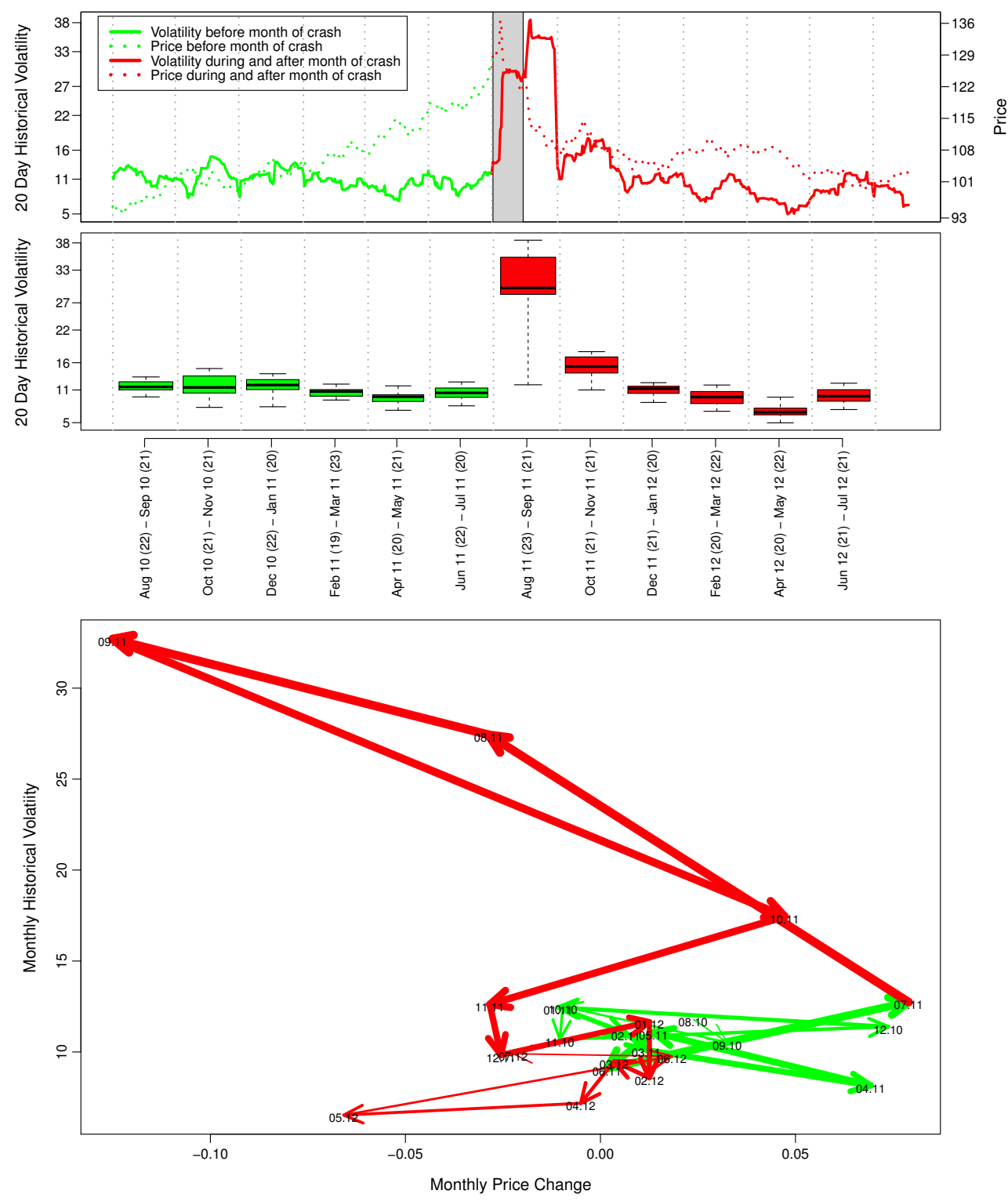

Figure 72. The Swiss Franc bubble ending in July 2011: price and historical volatility of the FXF Currency Swiss Franc ETF (see section 4 for a detailed methodological explanation).

Swiss Franc ETF before (green) and after (red) it peaked in July 2011. It can be seen that the volatility remains remarkably stable during the build up phase of the bubble. This is even more clear from the arrow plot in the lower panel of that same figure. Here we can see that the green arrows are confined to the low-volatility high-return part of the plot. This observation is further confirmed by the implied volatility, which can be seen in figure 73 . Consequently, we identify this event as a fearless bubble.

\section{Conclusions}

Forty different bubble cases were analysed in detail to look for the possible existence of a relationship between volatility and bubble expansion. The research questions were articulated as 


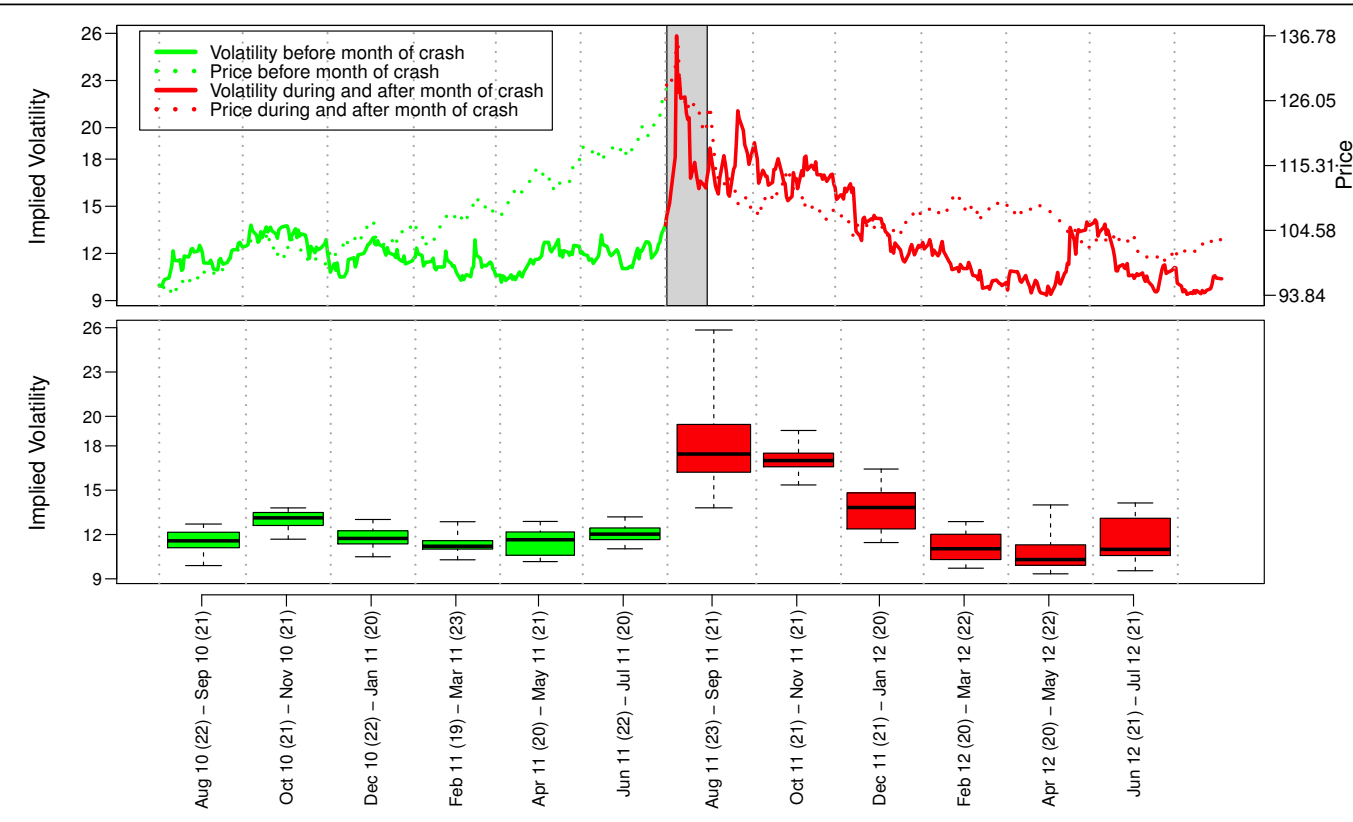

Figure 73. The Swiss Franc bubble ending in July 2011: price and implied volatility of the FXF Currency Swiss Franc ETF (see section 4 for a detailed methodological explanation).

follows:

Research questions: Does volatility, historical and/or implied, exhibit a tendency to increase during the maturation of a bubble? Is volatility surging towards the end of a bubble? Could volatility be used to diagnose bubbles and forecast their end?

Borrowing the semantics from Sornette and Andersen (2004), each of the bubble cases was classified as being either "Fearful" or "Fearless", the former meaning that a significant rise in volatility could be observed during the bubble period leading up to the crash, the latter meaning that no such behavior could be seen. The classification was done by visual inspection with informative graphical tools, for each of the forty cases, of a set of plots, with different representations of the volatility (implied or historical) with respect to the price acceleration during the bubble. Because of the qualitative approach of this type of analysis, the full reasoning behind the classification was explained in all transparency.

When the data from the Bank for International Settlements (BIS, 2017) are available, the credit conditions before and after the crash were also estimated. Bubbles were identified as leveraged or nonleveraged depending on whether the credit level and growth rate were increasing significantly during the bubble build-up. For 29 bubbles, the data are available to do this type of analysis, 16 of these were identified as leveraged, 13 as non-leveraged. This result suggests that the formation and development of a majority of the bubbles can be linked to a period of credit expansion.

Our main finding is that volatility is neither a reliable indicator of the maturation of a bubble nor of its impeding ending in a crash. In contradiction with some claims that the volatility increases before a crash (Jarrow et al., 2011a, b; Protter, 2013), we report, based on extensive empirical observations, that it does not consistently show such a behavior. If any conclusion can be drawn, it is the opposite. For the majority of the cases that were analysed, the volatility was relatively low at the crest of the bubble; 
from the forty bubbles that were analysed, only 14 (35\%) were identified as "Fearful" and 26 (65\%) as "Fearless". A quite informative case study is provided by the Malaysian and the Philippine bubbles. Both had common underlying drivers (the great expectations of the "dragon economies"), developed over the same period (the year 1993), accelerated in the final phase together (December 1993) and burst at exactly the same moment (around January 5, 1994). Yet, in Malaysia, the volatility went down right before the crash, whereas in the Philippines, it went up.

Additionally, a systematic review of the arrow plots that were made for each of the forty cases, revealed a distinct class of "Fearless" bubbles. A subset of bubbles shared the same specific characteristic that all the green arrows, representing the dynamics before the crash, were narrowly clustered, confined to the bottom right corner of the plot corresponding to a state of high positive returns and low volatility whereas the red arrows, representing the dynamics after the crash were more dispersed with extremes in the top left corner, corresponding to a state of high negative returns and high volatility. This could be clearly observed for the following eleven cases: the US in March 1962 (see figure2) and October 1987 (see figure 4), Procter \& Gamble in January 2000 (see figure 16), the UK in October 1987 (see figure 18), Japan in January 1990 (see figure 26), Hong Kong in October 1987 (see figure 30), Argentina in October 1997 (see figure 44), Brazil in July 1997 (see figure 46), Indonesia in July 1997 (see figure 57), Russia in October 1997 (see figure 62) and the Swiss Franc in July 2011 (see figure 72). So, more than one quarter of the cases that were studied here, many of which were notorious and well-documented bubbles, clearly bear the fingerprint of very low volatility, right at the crest of the bubble. Those should not merely be identified as "Fearless", they are cases of investors, being deaf, dumb and blind for the risk of the impeding crash, investors that are only focussed on riding the bubble to score a short-term profit during the strong price acceleration.

In contrast to the generally accepted paradigm of fundamental valuation, based on the expected return and the expected risk (as formalised in the Capital Asset Pricing Model), the "Fearless" bubbles are situations where a low volatility corresponds to a high imminent risk (Cauwels, 2017). This paradoxical behavior, from the lenses of traditional asset pricing models, casts further doubts on the supposed general relationship between risk and return.

Of course, such seemingly paradoxical behaviour between risk and return is immediately resolved if one uses a single jump process with the possibility of a crash with crash hazard rate $h$ and crash amplitude $\kappa$. Then, the correct risk-adjusted return decreases from $\mu$ to $\mu-\kappa h$, while the correct measure of risk increases from $\sigma^{2}$ to $\sigma^{2}+h \kappa^{2}$ (ignoring possible correlations between $\sigma, \kappa$ and $h$ ). If the probability of the crash increases as the bubble develops, such model yields a measure of risk that increases together with the price, a "fearful" bubble representation. The problem is that, empirically, the crash hazard rate $h$ is not directly observable. Models are required to infer it, as in the so-called Log-Periodic Power Law Singularities (LPPLS) models (Johansen et al., 1999, 2000; Sornette, 2017; Hüsler et al., 2013; Leiss et al., 2015; Sornette and Cauwels, 2015).

In summary, overall, these considerations strengthen the necessity to provide a general framework for the development of bubble models that can account for empirical observations during exuberant financial regimes and can be operationally implemented.

\section{Acknowledgments}

We are grateful to Michael Schatz for constructive remarks on the manuscript. 


\section{Conflict of Interest}

All authors declare no conflicts of interest in this paper.

\section{References}

Abreu D, Brunnermeier MK (2003) Bubbles and crashes. Econome 71: 173-204.

Ahmed E, Rosser BJ, Uppal JY (2010) Emerging Markets and Stock Market Bubbles: Nonlinear Speculation? Emerg Mark Financ Tr 46: 23-40.

Allen F, Gale D (2000) Bubbles and crises. Econ J 110:236-255.

Allen F, Gale D (2007) Understanding Financial Crises. Oxford University Press, New York.

Allen F, Morris S, Postlewaite A (1993) Finite bubbles with short sale constraints and asymmetric information. J Econ Theory 61: 206-229.

Andersen JV, Sornette D (2004) Fearless versus fearful speculative financial bubbles. Physica A 337: $565-585$.

Anderson K, Brooks C, Katsaris A (2013) Testing for speculative bubbles in asset prices. In A. R. Bell, C. Brooks and M. Prokopczuk, eds, Handb Research Methods Applica Empiri Financ.

Barro RJ, Fama EF, Fischel DR, et al. (1989) Black monday and the future of financial markets. Dow Jones- Irwin.

Barsky R (2009) The Japanese Bubble: A 'Heterogeneous' Approach. Technical Report 15052, NBER Working Paper.

Bastiaensen K, Cauwels P, Sornette D, et al. (2009) The Chinese Equity Bubble: Ready to Burst. Available from: http://arxiv.org/abs/0907.1827.

Bates DS (1991) The crash of '87: was it expected? the evidence from options markets. J Financ 46: 1009-1044.

Bates DS (2000) Post-'87 crash fears in the s\&p 500 futures option market. J Econometrics 94: $181-238$.

Baur DG, Glover K (2012) A Gold Bubble? Technical Report No 175, UTC Business School Working Paper.

Bear Markets since 1929, as defined by the S\&P 500. Available from: http://www.feesonly.com/Client_Letter_Archive/Bear_Markets_Since_1929.pdf.

Bloomberg News, Palladium Crashes With Car Sales as Ratio Signals Bear Trade. URL http://www.bloomberg.com/news/2010-05-09/ palladium-crashes-with-china-car-sales-as-platinum-trades-give-bear-signal. html. 


Bloomberg News, Soros Sees Gold Prices on Brink of Bear
Market. URL http://www.bloomberg.com/news/2011-12-29/ $\backslash$ gold-bubble-seen-by-soros-ends-bull-year-on-bear-market-brink-commodities . html.

Bortolotti B, Beltratti A, Caccavaio M (2011) The Stock Market Reaction to the 2005 non-Tradable Share Reform in China. Working Paper 3: 583-590.

Beran J (1994) Statistics for Long-Memory Processes. Chapman $\mathcal{E}$ Hall/CRC, 1 edition.

Bergsten CF (1997). The Asian Monetary Crisis: Proposed Remedies. Statement before the Committee on Banking and Financial Services, US House of Representatives, November 13, Washington DC.

Bertrand KZ, Lagi M, Bar-Yam Y (2011) The Food Crises and Political Instability in North Africa and the Middle East. Soc Science Electron Publ. Available from: https://arxiv.org/pdf/1108.2455.pdf.

Bhattacharya U, Yu XY (2008) The causes and consequences of recent financial bubbles: an introduction. Rev Financ Stud 21: 3-10.

Blanchard O, Watson M (1982) Bubbles, rational expectations, and financial markets. In P. Wachter (ed.), Cris Econ Financ Structure, Lexington, MA: Lexington Books: 295-315.

BIS. Total credit to the non-financial sector, 2017. Available from: https://www.bis.org/statistics/totcredit.htm.

Blustein P (2005) And the Money Kept Rolling In (And Out). Public Affairs.

Bohl MT, Siklos PL, Werner T (2007) Do Central Banks React to the Stock Market? The Case of the Bundesbank. J Bank Financ 31: 719-733.

Bouchaud J-P, Matacz A, Potters M (2001) Leverage effect in financial markets: The retarded volatility model. Phys Rev Lett 87: 228701.

Business Insider. Sugar Crash, 2010. Available from: http://www.businessinsider.com/sugar-crash2010-11.

Brunnermeier MK, Oehmke M (2013) Bubbles, Financial Crises, and Systemic Risk. Handb Econ Financ 2: 1221-1288.

Calvet LE, Fisher AJ (2004) How to forecast long-run volatility: Regime switching and the estimation of multifractal processes. J Fin Econom 2: 49-83.

Camerer C (1989) Bubbles and fads in asset prices. J Econ Surv 3: 3-14.

Caputo R, Saravia D (2014) The Fiscal and Monetary History of Chile 1960-2010. Central Bank Chile.

Carlson M (2006) A Brief History of the 1987 Stock Market Crash with a Discussion of the Federal Reserve Response. Soc Science Electron Publ 2007-13.

Cauwels P (2017) Economic Ideas You Should Forget, chapter Chapter: Volatility Is Risk 33-34.

Colombo J (2012) Japan's bubble economy of the 1980s. Forbes column. 
Corsi F, Sornette D (2014) Follow the money: The monetary roots of bubbles and crashes. Int Rev Financ Anal 32: 47-59.

Craig BR, Glatzer E, Keller J, et al. (2003) The Forecasting Performance of German Stock Option Densities. Technical Report 03-12, FRB of Cleveland Working Paper.

De Long JB, Shleifer A, Summers LH, et al. (1990) Noise trader risk in financial markets. J polit Econ 98: 703-738.

De Schutter Olivier (2010) Food Commodities Speculation and Food Price Crises. Technical report, United Nations Special Rapporteur on the Right to Food.

Diba B, Grossman H (1988) Explosive rational bubbles in stock prices? Am Econ Rev 78: 520-530.

Eckaus RS (2008) The Oil Price Really Is A Speculative Bubble. Technical report, MIT Center for Energy and Environmental Policy Research Working Paper.

ETF Database, SGG Tumbles: Historic Day For Sugar ETF, 2010. Available from: http://etfdb.com/2010/sgg-tumbles-historic-day-for-sugar-etf/.

Evanoff DD, Kaufman G, Malliaris AG (2012) New perspectives on asset price bubbles. Oxford University Press.

Evans G (1991) Pitfalls in testing for explosive bubbles in asset prices. Am Econ Rev 31: 922-930.

Figlewski S, Wang XZ (2000) Is the 'leverage effect' a leverage effect? Available at SSRN: http://ssrn.com/abstract=256109.

Filimonov VA, Sornette D (2011) Self-excited multifractal dynamics. Europhys Lett 94: 46003.

Financial Times. Swiss franc soars in hunt for haven, 2011. Available from: http://www.ft.com/cms/s/0/17df8456-c2ca-11e0-8cc7-00144feabdc0.html\#axzz2N41WtKTy.

Flood R, Hodrick R, Kaplan P (1994) An evaluation of recent evidence on stock price bubbles. In R. Flood and P. Garber (eds.), Speculative Bubbles, Speculative Attacks, and Policy Switching, Cambridge, MA: MIT Press:105-133.

Flowerdew J (1998) The Final Years of British Hong Kong: The Discourse of Colonial Withdrawal. St. Martin's Press.

Forró Z, Woodard R, Sornette D (2015) Using trading strategies to detect phase transitions in financial markets. Phys Rev E 91: 042803.

Froot K, Obstfeld M (1991) Intrinsic bubbles: the case of stock prices. Am Econ Rev 81: 1189-1214.

Galbraith JK (2009) The Great Crash, 1929. Houghton Mifflin Haircourt.

Greenspan A, Kennedy J (2005) Estimates of home mortgage originations, repayments, and debt on one-to-four-family residences. Finance and Economic Discussion Series, Washington Board of Governors of the Federal Reserve System, 2005-41. 
Greenspan A, Kennedy K (2007) Sources and uses of equity extracted from homes. Finance and Economics Discussion Series Divisions of Research E Statistics and Monetary Affairs, Federal Reserve Board, Washington, D.C., 2007-20, 2007.

Gürkaynak R (2008) Econometric tests of asset price bubbles: taking stock. J Econ Surv 22: 166-186.

Hamao Y, Mei J, Xu Y (2003) Idiosyncratic Risk and the Creative Destruction in Japan. Technical Report 9642, NBER Working Paper.

Hardouvelis GA (1988) Evidence on stock market speculative bubbles: Japan, the united states, and great britain. Federal Reserve Bank of New York Quarterly Review 13: 4-16.

Harrison M, Kreps DM (1978) Speculative investor behavior in a stock-market with heterogeneous expectations. Q J Econ 92: 323-336.

Homm , Breitung J (2012) Testing for speculative bubbles in stock markets: A comparison of alternative methods. J Financ Economet 10: 198-231.

Hong H, Stein JC (2003) Differences of opinion, short?sales constraints, and market crashes. Rev Financ Stud 16: 487-525.

Hong Kong Monetary Authority, Asset Pricing and Central Bank Policies: The Case of Hong Kong, 1997. Available from: http://www.hkma.gov.hk/eng/publications-and-research/quarterlybulletin/1998/may/qbfa03e.shtml.

Hüsler A, Sornette D, Hommes CH (2013) Super-exponential bubbles in lab experiments: evidence for anchoring over-optimistic expectations on price. J Econ Behav Organ 92: 304-316.

IMF Independent Evaluation Office, The IMF and Recent Capital Account Crises: Indonesia, Korea, Brazil, 2003. Technical report, IMF Evaluation Report.

Jao YC (2001) The Asian financial crisis and the ordeal of Hong Kong. Quorum Books, Westport, Connecticut, London.

Jarrow R, Kchia Y, Protter P (2011a) How to detect an asset bubble. SIAM J Financ Math 2: 839-865.

Jarrow R, Kchia Y, Protter P (2011b) Is There a Bubble in LinkedIn's Stock Price? J Portfolio Manage 38: $125-130$.

Jarrow R, Protter P, Shimbo K (2006) Asset price bubbles in a complete market. Adv Math Financ 105-130.

Jarrow R, Protter P, Shimbo K (2010) Asset price bubbles in incomplete markets. Math Financ 20: $145-185$.

Jiang ZQ, Zhou W-X, Sornette D, et al. (2010) Bubble Diagnosis and Prediction of the 2005-2007 and 2008-2009 Chinese stock market bubbles. J Econ Behav Organ 74: 149-162.

Johansen A, Ledoit O, Sornette D (2000) Crashes as critical points. Int J Theor Appl Financ 3: 219-255. 
Johansen A, Sornette D (1999) Financial "anti-bubbles": log-periodicity in gold and nikkei collapses. Int J Mod Phys C 10: 563-575.

Johansen A, Sornette D (2000a) Evaluation of the quantitative prediction of a trend reversal on the japanese stock market in 1999. Int J Mod Phys C 11: 359-364.

Johansen A, Sornette D (2000b) The Nasdaq crash of April 2000: Yet another example of logperiodicity in a speculative bubble ending in a crash. Eur Phys $J$ B 17: 319-328.

Johansen A, Sornette D (2001) Bubbles and anti-bubbles in Latin-American, Asian and Western stock markets: An empirical study. Int J Theor Appl Financ 4: 853-920.

Johansen A, Sornette D (2010) Shocks, Crashes and Bubbles in Financial Markets. Bruss Econ Rev 53: 201-253.

Johansen A, Sornette D, Ledoit O (1999) Predicting financial crashes using discrete scale invariance. J Risk 1: 5-32.

Jord O, Chularick M, Taylor AM (2015) Leveraged Bubbles. Technical report, Federal Reserve Bank of San Francisco Working Paper Series. URL http://www.frbsf.org/economic-research/ files/wp2015-10.pdf.

Kaizoji T, Leiss M, Saichev A, et al. (2015) Super-exponential endogenous bubbles in an equilibrium model of rational and noise traders. J Econ Behav Organ 112: 289-310.

Kaizoji T, Sornette D (2010) Market Bubbles and Crashes. Encyclopedia Quant Financ (Wiley). Available from: http://arXiv.org/abs/0812.2449.

Kaufman GG, Hunter WC, Pomerleano M (2002) Asset Price Bubbles: The Implications for Monetary, Regulatory, and International Policies, chapter Chapter 3: Tropical Bubbles: Asset Price Bubbles in Latin America 1980-2001.

Khan MS (2009)The 2008 Oil Price "Bubble". Technical report, Peterson Institute for International Economics. Available from: http://www.iie.com/publications/pb/pb09-19.pdf.

Kindleberger C (1978) Manias, Panics, and Crashes: A History of Financial Crises. John Wiley \& Sons, New York.

Kindleberger CP, Aliber RZ (2005) Manias, Panics, and Crashes: A History of Financial Crises. John Wiley \& Sons, New York.

Koning JP (2004) Explaining the 1987 Stock Market Crash and Potential Implications. Available from:http://www. lope.ca/markets/1987crash/1987crash.pdf.

Kotz DM (1999) Russia's Financial Crisis: The Failure of Neoliberalism? Z Magazine 28-32.

Krugman P (1998) What happened to asia? http://web.mit.edu/krugman/www/disinter.html.

Lammerding M, Stephan P, Trede M, et al. (2013) Speculative bubbles in recent oil price dynamics: Evidence from a Bayesian Markov-switching state-space approach. Energy Econ 36: 491-502. 
Leiss M, Nax HH, Sornette D (2015) Super-Exponential Growth Expectations and the Global Financial Crisis. J Econ Dyn Control 55: 1-13.

Lera S, Sornette D (2016) Quantitative modelling of the EUR/CHF exchange rate during the target zone regime of September 2011 to January 2015. J Int Money Financ 63: 28-47.

LeRoy S, Porter R (1981) The present-value relation: tests based on implied variance bounds. Econome 49: 555-574.

Lleo B, Ziemba WT (2012) Stock market crashes in 2007-2009: were we able to predict them? Quant Financ 12: 1161-1187.

Ma Y, Kanas A (2004) Intrinsic bubbles revisited: evidence from nonlinear cointegration and forecasting. J Forecasting 23: 237-250.

Magazine T (2009) Why China's Stock Market Bubble Is Fizzling. URL http://www.time.com/ time/world/article/0, 8599, 1919777,00.html.

Malkiel AG, Urrutia JL (1992) The international crash of october 1987: Causality tests. J Financ Quant Anal 27: 353-364.

Malkiel BG (2007) A Random Walk Down Wall Street. W. W. Norton \& Company.

Manoel D, Martin L (2004) Identification of Rational Speculative Bubbles in IBOVESPA (after the Real Plan) using Markov Switching Regimes. EconomiA, Selecta, Brasilia 5.

Minsky HP (1993) The Financial Stability Hypothesis. InHandb Radic Political Econ, P. Arestis and M. C. Saw-yer. Edward Elgar: Aldershot.

Musacchio A (2012) Mexico's Financial Crisis of 1994-1995. Technical Report 12-101, Harvard Business School Working Paper.

Nagel S, Brunnermeier MK (2004) Hedge funds and the technology bubble. J Financ 59: 2013-2040.

Nam CW (2008) What happened to Korea ten years ago? CESifo Forum 4: 69-73.

Neu CR, Lowell J, Tong D (1998) Financial Crises and Contagion in Emerging Market Countries. Technical report, RAND National Security Research Division.

Nochteff H (1996) The Argentine experience: development or a succession of bubbles. CEPRL Rev 59: 111-126.

Orléan A (1995) Bayesian interactions and collective dynamics of opinion - herd behavior and mimetic contagion. J Econ Behav Organ 28: 257-274.

Perry GE, Lederman D (1998) Financial Vulnerability, Spillover Effects, and Contagion: Lessons from the Asian Crises for Latin America. Technical report, World Bank Latin American and Caribbean Studies Viewpoints.

Phillips P, Wu Y, Yu J (2011) Explosive behavior in the 1990s Nasdaq: When did exuberance escalate asset values? Int Econ Rev 201: 201-226. 
Phillips PCB, Shi SP, Yu J (2013) Testing for multiple bubbles: Historical Episodes of Exuberance and Collapse in the S\&P 500. Int Econ Rev 56: 1043-1078.

Pinto B, Ulatov S (2010) Financial globalization and the russian crisis of 1998. The World Bank, Europe and Central Asia Region \& The Managing Director? Office, Policy Research Working Paper 5312: 1-39.

Darst DM (2013) Portfolio Investment Opportunities in Precious Metals. Jpn J Pediatr Dent 40: 32-45.

Protter P (2013) A mathematical theory of financial bubbles. Lect Notes Math 2081: 1-108.

Rangel GJ, Pillay SS (2007) Evidence of bubbles in the Malaysian stock market. In Asia-Pac Financ Mark: Integr, Innov Chall.

Sang WK, Rogers JH (1995) International stock price spillovers and market liberalization: evidence from korea, japan and the united states. Int Financ Discuss Papers 2: 117-133.

Sato K (1995) Bubbles in Japan's Stock Market: A Macroeconomic Analysis. Jpn Econ 23: 32-58.

Scheffer M, Carpenter SR, Lenton TM, et al. (2012) Anticipating critical transitions. Science 338: 344-348.

Scheinkman JA, Xiong W (2003) Overconfidence and speculative bubbles. J Polit Econ 111: 11831219.

Scherbina A, Schlusche B (2014) Asset price bubbles: a survey. Quant Financ 14: 589-604.

Shiller R (1979) The volatility of long term interest rates and expectations models of the term structure. J Polit Econ 87: 1190-1209.

Shiller R (1981) Do stock prices move too much to be justified by subsequent changes in dividends? Am Econ Rev 71: 421-436.

Shiller RJ (2006) Irrational exuberance. Crown Business, 2nd edition.

Shiller RJ (2014) Speculative Asset Prices. Am Econ Rev 104: 1486-1517.

Shu-jie Y, Dan L (2008) Chinese Stock Market Bubble: Inevitable or Accidental? J Xi'an Jiaotong University(Soc Sci) 6.

Sornette D (2000) Stock Market Speculation: Spontaneous Symmetry Breaking of Economic Valuation. Phys A 284: 355-375.

Sornette D (2004) Critical Phenomena in Natural Sciences (Chaos, Fractals, Self-organization and Disorder: Concepts and Tools). Springer 37: 9604-9605.

Sornette D (2007) Keynote address on why stock markets crash?. Thurday 18 October 2007 at the Drobny global conference, Stockholm, Sweden, October 18-20.

Sornette D (2017) Why Stock Markets Crash: Critical Events in Complex Financial Systems. Princeton University Press (new print with new preface). 
Sornette D, Andersen JV (2002) A nonlinear super-exponential rational model of speculative financial bubbles. Int J Mod Phys C 13: 171-188.

Sornette D, Cauwels P (2014) 1980-2008: The Illusion of the Perpetual Money Machine and what it bodes for the future. Risks 2: 103-131.

Sornette D, Cauwels P (2015a) Managing risk in a creepy world. J Risk Manage Financ Inst 83-108.

Sornette D, Cauwels P (2015b) Financial bubbles: mechanisms and diagnostics. Rev Behav Econ 2: 279-305.

Sornette D, Demos G, Zhang Q, et al. (2015) Real-time prediction and post-mortem analysis of the shanghai 2015 stock market bubble and crash. J Invest Strateg 4: 77-95.

Sornette D, Johansen A (2001) Significance of log-periodic precursors to financial crashes. Quant Financ 1: 452-471.

Sornette D, Johansen A, Bouchaud JP (1996) Stock market crashes, precursors and replicas. J Phys I France 6: 167-175.

Sornette D, von der Becke S. Crashes and high frequency trading (an evaluation of risks posed by high-speed algorithmic trading). report for the UK Government project entitled "The Future of Computer Trading in Financial Markets", Foresight Driver Review - DR7, Government Office for Science, 2nd Floor, 1 Victoria Street, London SW1H OET, United Kingdom, 2011 (http://ssrn.com/abstract=1976249).

Sornette D, Woodard R, Fedorovsky M (2011) The Financial Bubble Experiment: Advanced Diagnostics and Forecasts of Bubble Terminations Volume III-Master Document. Available from: http://arxiv.org/abs/1011.2882.

Sornette D, Woodard R, Fedorovsky M, et al.(2009) The Financial Bubble Experiment: Advanced Diagnostics and Forecasts of Bubble Terminations Volume II - Assets Document. URL http: //arxiv.org/abs/0911.0454.

Sornette D, Zhou W-X (2002) The us 2000-2002 market descent: How much longer and deeper? Quant Financ 2: 468-481.

Sornette D, Zhou W-X (2004a) Evidence of fueling of the 2000 new economy bubble by foreign capital inflow: Implications for the future of the US economy and its stock market,. Phys A 332: 412-440.

Sornette D, Zhou W-X (2004b) Causal Slaving of the U.S. Treasury Bond Yield Antibubble by the Stock Market Antibubble of August 2000. Phys A 337: 586-608.

Sornette D, Woodard R, Zhou W-X (2009b) The 2006-2008 Oil Bubble and Beyond. Physica A 388: 1571-1576.

Stiglitz JE (1990) Symposium on bubbles. J Econ Perspect 4: 13-18.

Taipalus K (2012) Detecting asset price bubbles with time-series methods. Scientific monograph E 47, Helsinski. 
The Closure and Subsequent Events. a. Available from: http://www.fstb.gov.hk/fsb/ppr/ report/doc/DAVISON_E_APPENDIX.PDF.

The Gold Bubble. Available from: https://www. wealthmanagementinsights.com/userdocs/ pubs/QMU_The_Gold_Bubble__IMT_FINAL_8.15.11_TAGGED.pdf.

The observer, consumers go sour on the market's sugar rush, 2010. Available from: http://www.guardian.co.uk/business/2010/jan/31/sugar-prices-commodities.

Topol R (1991) Bubbles and volatility of stock prices: Effect of mimetic contagion. Econ J 101: 786-800.

Norden SV (1996) Regime switching as a test for exchange rate bubbles. J Appl Economet 11: 219251.

Norden SV, Vigfusson R (1998) Avoiding the pitfalls: can regime-switching tests reliably detect bubbles? Stud Nonlinear Dyn E 2: 1-22.

Vogel HL, Werner RA (2015) An analytical review of volatility metrics for bubbles and crashes. Int Rev Financ Anal 38: 15-28.

Werner R (2005) The New Paradigm in Macroeconomics: Solving the Riddle of Japanese Macroeconomic Performance. Palgrave McMillan.

West K (1987) A specification test for speculative bubbles. Q J Econ 102: 553-580.

West K (1998) Bubbles, fads and stock price volatility tests: a partial evaluation. J Financ 43: 639-656.

Wu Y (1997) Rational bubbles in the stock market: accounting for the U.S. stock price volatility. Econ Inq 35: 309-319.

Xiong W(2013) Bubbles, Crises, and Heterogeneous Beliefs Handbook on Systemic Risk, Cambridge University Press 663-713.

Yang J, Bessler DA (2008) Contagion around the October 1987 stock market crash. Eur J Oper Res 184: 291-310.

Yao S, Luo D (2009) The Economic Psychology of Stock Market Bubbles in China. World Econ 32.

Zhang Q, Sornette D, Balcilar M, et al. (2016) LPPLS Bubble Indicators over Two Centuries of the S\&P 500 Index. Physica A 458: 126-139.

Zhou WX, Sornette D (2003) The US 2000-2003 market descent: Clarifications. Quantitative Financ 3: C39-C41.

Zweig J (2010) Back to the future: lessons from the forgoten 'flash crash' of 1962. Intell Invest.

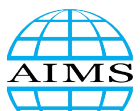

AIMS Press (c) 2018 the Author(s), licensee AIMS Press. This is an open access article distributed under the terms of the Creative Commons Attribution License (http://creativecommons.org/licenses/by/4.0) 